FACULDADE DE MEDICINA DE RIBEIRÃO PRETO DEPARTAMENTO DE GENÉTICA

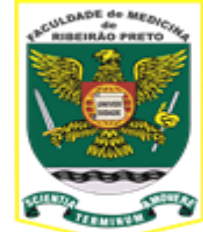

PROGRAMA DE PÓS-GRADUAÇÃO EM GENÉTICA

MODELOS DE NORMA DE REAÇÃO PARA ESTUDO DA INTERAÇÃ̃ GENOTIPO × AMBIENTE EM REBANHOS DA RAÇA NELORE

ANIELLY DE PAULA FREITAS

Ribeirão Preto - SP

Agosto de 2020 


\section{MODELOS DE NORMA DE REAÇÃO PARA ESTUDO DA INTERAÇÃO GENOTIPO $\times$ AMBIENTE EM REBANHOS DA RAÇA NELORE}

Tese de doutorado apresentada ao Programa de Pós-Graduação Ciências Biológicas (Genética) da Faculdade de Medicina de Ribeirão Preto da Universidade de São Paulo, como parte dos pré-requisitos para obtenção do título de Doutor em Ciências.

Área de concentração: Genética

Orientadora: Dr ${ }^{\mathrm{a}}$. Claudia Cristina Paro de Paz Co-orientadora: Dr ${ }^{\mathrm{a}}$. Maria Eugênia Zerlotti Mercadante

Ribeirão Preto, SP 
AUTORIZO A DIVULGAÇÃO TOTAL OU PARCIAL DESTE TRABALHO, POR QUALQUER MEIO CONVENCIONAL OU ELETRÔNICO, PARA FINS DE ESTUDO E PESQUISA, DESDE QUE CITADA A FONTE.

“Versão corrigida. A versão original encontra-se disponível tanto na Biblioteca da Unidade que aloja o Programa, quanto na Biblioteca Digital de Teses e Dissertações da USP (BDTD)"

\section{FICHA CATALOGRÁFICA}

Freitas, Anielly de Paula

Modelos de norma de reação para estudo da interação genótipo $\times$ ambiente em rebanhos da raça Nelore. Ribeirão Preto, 2020.

114 p.: il.; $30 \mathrm{~cm}$

Tese de Doutorado, apresentada à Faculdade de Medicina de Ribeirão Preto / Universidade de São Paulo. Área de concentração: Genética

Orientadora: Paz, Claudia Cristina Paro.

1. Inferência bayesiana. 2. Regressão aleatória. 3. Sensibilidade ambiental. 


\section{APOIO INSTITUCIONAL E SUPORTE FINANCEIRO}

Este trabalho foi realizado com apoio e suporte financeiro das seguintes instituições:

1) Programa de Excelência Acadêmica (Proex) da Coordenação de Aperfeiçoamento de Pessoal de Nível Superior - Brasil (CAPES) - Código de Financiamento 001.

2) Fundação de Amparo à Pesquisa do Estado de São Paulo (FAPESP) processo número: 2016/17517-4. Linha de fomento: Programas Regulares / Bolsas / No País / Doutorado - Fluxo Contínuo.

3) Fundação de Amparo à Pesquisa do Estado de São Paulo (FAPESP) processo número: 2019/01814-8. Linha de fomento: Programas Regulares / Bolsas / No Exterior / Bolsa Estágio de Pesquisa no Exterior (BEPE) - Doutorado - Fluxo Contínuo.

4) Departamento de Genética da Faculdade de Medicina de Ribeirão Preto da Universidade de São Paulo.

5) Centro Avançado de Pesquisa em Bovinos de Corte, do Instituto de Zootecnia/APTA/SAA. 


\section{DADOS CURRICULARES DA AUTORA}

Anielly de Paula Freitas - filha de José Olavo de Freitas e Shirley de Paula Freitas, nasceu no dia 12 de novembro de 1987 na cidade de Ituverava, interior de São Paulo. Em fevereiro de 2008 ingressou na Universidade Estadual Paulista - Campus de Jaboticabal, no curso de Zootecnia pela Faculdade de Ciências Agrárias e Veterinárias, em 2012/2013 fez intercâmbio e estágio de docência na Universidad de Santiago de Compostela em Lugo, na Espanha. Iniciou o curso de Mestrado em Produção Animal Sustentável pela Instituição de Zootecnia no ano de 2014. No ano de 2016, ingressou na Universidade de São Paulo, na Faculdade de Medicina de Ribeirão Preto no programa de Genética sob orientação da Dra. Claudia Cristina Paro de Paz e sob co-orientação da Dra. Maria Eugênia Zerlotti Mercadante e em 2019 iniciou o doutorado sanduiche na University of Guelph sob supervisão do Dr. Flavio Schramm Schenkel. 


\section{DEDICATÓRIA}

Primeiramente a Deus, aos meus pais que tanto amo José Olavo e Shirley, ao meu irmão Wellington, à minha "parça e maninha” Eliana e à minha princesinha Larissa. 


\section{AGRADECIMENTOS}

Acima de tudo à Deus, pela minha vida, por ter me presenteado com uma família e pessoas maravilhosas ao meu lado e por todas as oportunidades que me presenteou, de conhecer pessoas maravilhosas e lugares inesquecíveis.

Aos meus amorosos pais, Shirley de Paula Freitas e José Olavo de Freitas, por sempre me incentivarem a lutar pelos meus objetivos e por todo amor e carinho, ao meu irmão Wellington de Paula Freitas, meu grande amigo, a minha "maninha e parça" Eliana Aparecida dos Santos Freitas, por todo carinho e incentivo e a minha princesinha Larissa, luz da minha vida. Vocês são minha referência e minha vida.

À minha orientadora Profa. Dra. Claudia Cristina Paro de Paz, pela orientação, dedicação, paciência, pelos ensinamentos e por me conceder a oportunidade de realizar este trabalho. Serei sempre grata pelo seu incentivo em um passo muito importante na minha profissão. Além de ser compreensiva e humana quando precisamos. Eu e minha família nunca iremos esquecer do que a senhora fez por nós.

Ao Dr. Mário Luiz Santana Júnior que foi de vital importância para o desenvolvimento deste trabalho, agradeço sua atenção, pela paciência e todos os ensinamentos e à minha coorientadora Dra. Maria Eugênia Zerlotti Mercadante, pela valiosa contribuição na execução deste trabalho.

Ao Dr. Flavio Schramm Schenkel, pela grande oportunidade de aprender a questionar, a me perguntar o porquê de tudo. Também agradeço a Giovana, Tatiane, Malane, Samla, Mariana, Riani, Hinayah, Ivan, Gerson, Lucas Alcantara, Diercles, Pablo, Aroa, Zahra, Hakimeh, amigos que fiz na University of Guelph e a todo carinho, atenção e principalmente aos ensinamentos e paciência de todos.

"For my Canadin Family Rob and Karen Kamphuis, Mayuka, David and Lucas, I thank you all for your friendship, companionship and for all the great times we spent together, I learned a lot from you all. For my lovely friends Cathy and John Fairchild, Elvira and Elmer Warkentins and for my dear teachers Linda Buchner, Karen Ting and Jennifer Brodie who taught and supported me with great care and attention".

Às Profas. Dras. Lenira El Faro Zadra, Maria Lúcia Pereira Lima e Flávia Fernanda Simili, pela paciência, pela orientação, pelos ensinamentos, incentivos e principalmente pelo 
carinho e a todos os professores, pesquisadores e funcionários do Centro Avançado de Pesquisas de Bovinos de Corte de Sertãozinho e aos funcionários e professores do Departamento de Genética da Faculdade de Medicina de Ribeirão Preto pelos ensinamentos, carinho e atenção pelo qual fui tratada, e por fornecer suporte e infraestrutura para a realização deste trabalho e a todos que de alguma forma ajudaram direta ou indiretamente no desenvolvimento deste trabalho.

Aos membros da banca Dr. José Bento Sterman Ferraz, Dr. Ricardo Vieira Ventura e Dr. Mário Luiz Santana Júnior pela disposição, pelos ensinamentos, pela paciência e por toda contribuição.

Aos meus amigos Alex, Cherlynn, Dayane, Genevieve e Guilherme pelo apoio muitas vezes fundamental para que eu conseguisse concluir a jornada. Muito obrigada pelo carinho e pela atenção de vocês.

À Fundação de Amparo à Pesquisa do Estado de São Paulo, pela bolsa de estudos nacional (processo n ${ }^{\circ}$ 2016/17571-4) e pela Bolsa Estágio de Pesquisa no Exterior (processo n ${ }^{\circ}$ 2019/01814-8). E também à Coordenação de Aperfeiçoamento de Pessoal de Nível Superior, pela bolsa de estudos. 


\section{RESUMO}

Freitas, A.P. Modelos de norma de reação para estudo da interação genótipo $\times$ ambiente em rebanhos da raça Nelore. 2020. 118f. Tese (Doutorado). Faculdade de Medicina de Ribeirão Preto, Universidade de São Paulo, Ribeirão Preto, agosto de 2020.

O objetivo deste estudo será avaliar a importância da interação genótipo x ambiente (IGA) e o efeito de diferentes práticas de seleção sobre a sensibilidade ambiental de características de crescimento e reprodutivas em machos e fêmeas de bovinos da raça Nelore provenientes de três linhas de seleção $(\mathrm{NeC}=$ Nelore Controle, $\mathrm{NeS}=$ Nelore Seleção, e NeT=Nelore Tradicional), bem como estimar tendências genéticas para cada linha, tanto para o MA, quanto para a capacidade geral de produção (intercepto da norma de reação) e para a capacidade específica de responder às variações ambientais (inclinação da norma de reação). Um total de 9.065 informações de peso a desmama padronizado (P210), 8.757 informações do peso à seleção (PS), 7.799 informações sobre a altura da garupa (ALT) de machos e fêmeas, 3.331 informações sobre a perímetro escrotal (PE) coletadas aos 378 dias de idade em machos e 2.311 dias para o primeiro parto (DPP) em fêmeas da raça Nelore, nascidos entre 1981 e 2017 no Centro Bovinos de Corte, do Instituto de Zootecnia de Sertãozinho, SP. Os componentes da (co) variância e os parâmetros genéticos para as todas as características nas três linhas foram estimados usando um modelo animal padrão (MA) e um modelo de norma de reação (MNR) utilizando amostrador de Gibbs. O descritor ambiental adotado foram as soluções dos grupos de contemporâneos. O MNR homocedástico apresentou, em geral, o melhor ajuste para todas as características estudadas. Os coeficientes de herdabilidade para todas as características foram maiores quando estimadas pelo MNR. As médias de herdabilidade das características estudadas variaram de 0,08 a 0,36 para $\mathrm{P} 210$ direto e 0,18 a 0,40 para P210 materno, 0,39 a 0,75 para PS de machos e fêmeas; 0,52 a 0,79 para ALT de machos e fêmeas; 0,46 a 0,68 para PE, e 0,06 a 0,57 para DPP, para as três linhas de seleção, ao longo do descritor ambiental. As correlações genéticas entre intercepto e inclinação variaram de -0,62 a 0,32 para P210 direta, $-0,29$ a 0,10 para P210 materna; 0,03 a 0,81 para PS, - $-0,19$ a 0,63 para ALT; $-0,14$ a 0,39 para PE; e -0,87 a -0,42 para DPP, para as três linhas de seleção. As tendências genéticas estimadas tanto pelo MA quanto para o intercepto (do MNR) demostraram incremento para as linhas selecionadas para maior diferencial de peso pós-desmama e uma tendência nula para a linha $\mathrm{NeC}$, exceto 
para DPP. As tendências genéticas para inclinação das normas de reação e a porcentagem de animais plásticos evidenciam que os animais das linhas $\mathrm{NeC}$ e $\mathrm{NeT}$ tenderam responder de forma mais modesta as mudanças ambientais, enquanto a linha NeS foi mais responsiva às mudanças ambientais. Foi possível observar que houve reclassificação dos touros para todas características devido à baixa correlação entre ambientes desfavoráveis e favoráveis, principalmente para as linhas $\mathrm{NeC}$ e NeT. Para a linha $\mathrm{NeS}$ somente houve reclassificação de touros para as características ALT e DPP. Os resultados indicaram que os efeitos da IGA são importantes e devem ser considerados nas avaliações genéticas de bovinos Nelore e que as diferentes práticas de seleção podem interferir na sensibilidade ambiental dos animais.

Palavras chave: inferência bayesiana, regressão aleatória, sensibilidade ambiental. 


\begin{abstract}
Freitas, A.P. Reaction norm models for study genotype $\times$ environment interaction in Nellore cattle. Thesis (Ph.D. Degree). Medical School of Ribeirão Preto, University of São Paulo, Ribeirão Preto, 2020.
\end{abstract}

The aim of this study was to evaluate the importance of genotype-environment interaction $(\mathrm{G} \times \mathrm{E})$ and the effects of different selection practices on the environmental sensitivity of reproductive and growth traits in males and females of three Nellore cattle lines [control $(\mathrm{NeC})$, selection $(\mathrm{NeS})$, and traditional (NeT) lines] with different selection goals. Moreover, genetic trends for the intercept and slope were estimated for each line, and the possible reclassification of sires was examined. A total of 9,065 records of weaning weight adjusted over 210 days (W210); 8,208 records of selection weight (SW); 7,799 records of hip height $(\mathrm{HH}) ; 3,331$ records of scrotal circumference (SC), and 2,311 records of days to first calving (DFC) from Nellore cattle born between 1981 and 2017 at the Advanced Beef Cattle Research Center of the Animal Science Institute /APTA/SAA, Sertãozinho, SP, Brazil, were utilized in the study. (Co)variance components and genetic parameters for all traits were estimated using a standard animal model (AM) and a reaction norm model (RNM) using a reaction norm model using Gibbs sampler. The environmental descriptor adopted were the solutions of contemporary groups (CG). The RNM showed, in general, the best fit for all traits studied. Mean heritability of the studied traits ranged from 0.08 to 0.36 for direct W210 and 0.18 to 0.40 for maternal W210, 0.39 to 0.75 for males and females $\mathrm{SW} ; 0.52$ to 0.79 for $\mathrm{HH}$ of males and females; 0.46 to 0.68 for SC, and 0.06 to 0.57 for DFC, along the environmental descriptor. The genetic correlations coefficients between intercept and slope ranged from -0.62 to 0.32 for direct W210, -0.29 to 0.10 for maternal W210; 0.03 to 0.81 for $\mathrm{SW},-0.19$ to 0.63 for $\mathrm{HH}$; -0.14 to 0.39 for SC; and -0.87 to -0.42 for DFC, in all cattle lines. Genetic trends estimated by both AM and intercept of the reaction norm showed gains for the direct effects for the for selected lines for greater postweaning weight differential and a null trend for the $\mathrm{NeC}$ line, except for DFC. Genetic trends for the slope and proportion of plastic genotypes indicated that the $\mathrm{NeS}$ line was more responsive to environmental changes, whereas the $\mathrm{NeC}$ and $\mathrm{NeT}$ lines tended to respond more modestly to environmental changes and to be more robust. Reclassification of sires was observed for all traits, specifically in the $\mathrm{NeC}$ and $\mathrm{NeT}$ lines, 
because of the weak correlation between the opposite extreme environments. In the NeS line, reclassification of sires was observed for $\mathrm{HH}$ and DFC traits. Our results indicate that the effects of genotype by environment interaction are important and should be considered in genetic evaluations of Nellore cattle. Moreover, different selection practices affected the environmental sensitivity of Nellore selection lines tested in this study

Keywords: Bayesian inference, random regression, environmental sensitivity 


\section{LISTA DE FIGURAS}

Figura 1. Coeficientes de herdabilidade diretos e maternos ao longo do descritor ambiental determinado pelas amplitudes das soluções dos GC para peso a desmama padronizado (P210, kg), diretos para peso a seleção (PS, kg) de machos e fêmeas, altura da garupa $(\mathrm{ALT}, \mathrm{cm})$ de machos e fêmeas, perímetro escrotal $(\mathrm{PE}, \mathrm{cm})$ e dias para o primeiro parto (DPP, dias) para as três linhas de seleção (NeC, linha controle; NeS, linha seleção; NeT, linha tradicional) de bovinos Nelore.

Figura 2. Correlações genéticas diretas e maternas para peso a desmama padronizado (P210); diretas para peso a seleção (PS, kg) de machos e fêmeas; altura da garupa (ALT, cm) de machos e fêmeas; perímetro escrotal (PE, cm); e dias para o primeiro parto (DPP, dias) ao longo do descritor ambiental determinado pelas amplitudes das soluções dos GC para as três linhas de seleção $(\mathrm{NeC}$, linha controle; NeS, linha seleção; e NeT, linha tradicional) de bovinos Nelore.

Figura 3. Tendências genéticas dos efeitos diretos e maternos observadas para os coeficientes de regressão relacionados ao intercepto da norma de reação para peso a desmama padronizado (P210, kg), e diretos para peso a seleção (PS, kg) de machos e fêmeas, altura da garupa (ALT, $\mathrm{cm})$ de machos e fêmeas, perímetro escrotal (PE, cm) e dias para o primeiro parto (DPP, dias) para as três linhas de seleção estudadas $(\mathrm{NeC}$, linha controle; NeS, linha seleção; e NeT linha tradicional)

Figura 4. Tendências genéticas dos efeitos direto e materno observadas para os coeficientes de regressão relacionados a inclinação da norma de reação para peso a desmama padronizado (P210, kg), e diretos para peso a seleção (PS, kg) de machos e fêmeas, altura da garupa (ALT, $\mathrm{cm})$ de machos e fêmeas, perímetro escrotal $(\mathrm{PE}, \mathrm{cm})$ e dias para o primeiro parto (DPP, dias) para as três linhas de seleção estudadas $(\mathrm{NeC}$, linha controle; NeS, linha seleção; e NeT linha tradicional)

Figura 5. Frequências observadas de genótipos robustos, plásticos e extremamente plásticos para peso a desmama padronizado (P210, kg), peso a seleção (PS, kg), altura da garupa $(\mathrm{ALT}, \mathrm{cm})$, perímetro escrotal (PE, cm) e dias para o primeiro parto (DPP, dias) para as três linhas estudadas para as três linhas de seleção estudadas; $\mathrm{NeC}$, linha controle; $\mathrm{NeS}$, linha seleção; e NeT linha tradicional;_M, machos;_F, fêmeas;_DIR, efeito genético aditivo direto; _MAT, efeito genético aditivo materno .522 


\section{LISTA DE TABELAS}

Tabela 1. Descrição do conjunto de dados de bovinos Nelore das três linhas de seleção: Controle (NeC), Seleção (NeS), e Tradicional (NeT).

Tabela 2. Comparação da qualidade do ajuste entre modelo animal (MA) e o modelo de norma de reação homocedástico $\left(\mathrm{MNR}_{\mathrm{HO}}\right)$ para peso a desmama padronizado $(\mathrm{P} 210, \mathrm{~kg})$, peso a seleção (PS, kg), altura da garupa (ALT, cm), perímetro escrotal (PE, cm) e dias para o primeiro parto (DPP, dias) para as três linhas de seleção (NeC, linha controle; $\mathrm{NeS}$, linha seleção; NeT, linha tradicional) de bovinos da raça Nelore

Tabela 3. nálise descritiva dos parâmetros genéticos para peso a desmama padronizado (P210, $\mathrm{kg}$ ), peso a seleção (PS, kg), altura da garupa (ALT, $\mathrm{cm})$, perímetro escrotal (PE, cm) e dias para o primeiro parto (DPP, dias) de cada linha de seleção pelo modelo animal padrão (MA)

Tabela 4. Correlações de Spearman entre $25 \%$ melhores touros por valores genéticos para peso ao desmame padronizado (P210, kg), peso a seleção (PS, kg), altura da garupa (ALT, $\mathrm{cm})$, perímetro escrotal $(\mathrm{PE}, \mathrm{cm})$ e dias para o primeiro parto (DPP, dias) para as três linhas estudadas ( $\mathrm{NeC}$, linha controle; $\mathrm{NeS}$, linha seleção; NeT, linha tradicional), obtidos pelo modelo animal padrão (MA) e pelo modelo de norma de reação (MNR) em diferentes ambientes (favorável com maiores valores das soluções dos GC; médio, com as soluções intermediárias dos GC; e desfavorável, com os valores mais baixos das soluções dos GC) 


\section{LISTA DE EQUAÇÕES}

(1) Peso padronizado aos 210 dias de idade $-\mathrm{P} 210=\frac{\text { Peso inicial-Peso ao nascer }}{\text { Idade ao peso inicial }} \times 210+$ Peso ao nascer 28

(2) Ganho médio diário foi obtido no período de 112 dias - G112 = Peso final na PGP - Peso após 56 dias de adaptação 28

(3) Peso final padronizado aos 378 dias de idade $-\mathrm{P} 378=\mathrm{P} 210+(\mathrm{G} 112 \times 168)$ 28

(4) Ganho de peso no pasto - GDP $=\frac{\text { Peso da última pesagem }- \text { P210 }}{\text { DPT }}$ 28

(5) Peso final padronizado aos 550 dias de idade P550 = P210 + (GDP x 340) 29

(6) Modelo animal padrão - $\mathrm{y}=\mathrm{X} \beta+\mathrm{Z}_{1} a+\mathrm{Z}_{2} m+\mathrm{Z}_{3} p m+e$

(7) Modelo de norma de reação $-\mathrm{y}_{i j}=$ fixo $_{i}+\varphi_{f} \phi_{f}\left(\mathrm{GC}_{j}\right)+a_{j} \phi_{f}\left(\mathrm{GC}_{j}\right)+m_{j} \phi_{f}\left(\mathrm{GC}_{j}\right)+p m_{j} \phi_{f}$ $\left(\mathrm{GC}_{j}\right)+e_{i j}$

(8) Variâncias genéticas aditivas diretas $-\sigma_{a}^{2} \mid \mathrm{X}=\sigma_{a}^{2}+\mathrm{X}^{2} \sigma_{b}^{2}+2 \mathrm{X} \sigma_{a, b}$ 33

(9) Variâncias genéticas aditivas diretas $-\sigma_{m}^{2} \mid \mathrm{X}=\sigma_{m}^{2}+\mathrm{X}^{2} \sigma_{b m}^{2}+2 \mathrm{X} \sigma_{a m, b m}$ 33

(10) Critério de informação de deviance $-D I C=2 \bar{D}_{i}-D\left(\bar{\theta}_{M}\right)=\bar{D}+P_{D(i)}$ .34 


\section{SUMÁRIO}

RESUMO .88

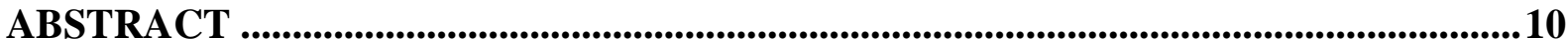

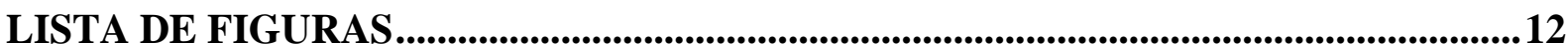

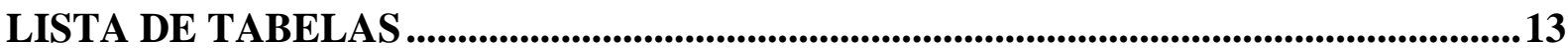

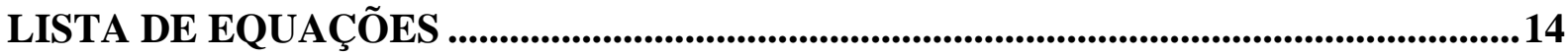

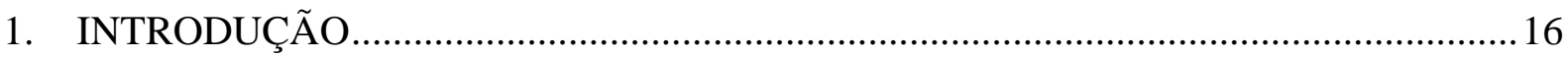

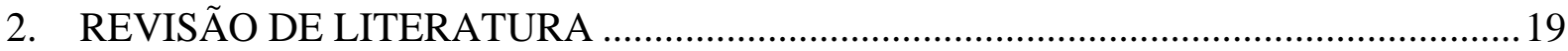

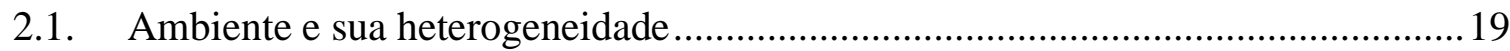

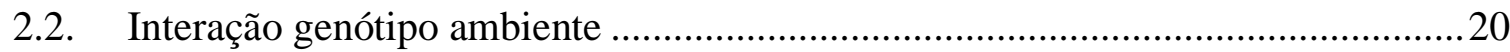

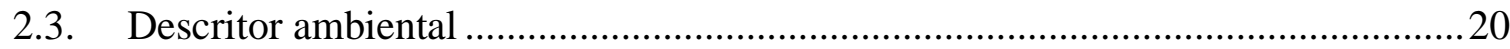

2.4. Métodos de predição da IGA ….........................................................................21

2.5. Importância da IGA no melhoramento genético animal .......................................23

2.6. O grande problema dos programas de melhoramento genético brasileiros em não

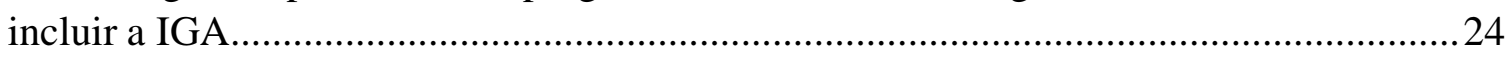

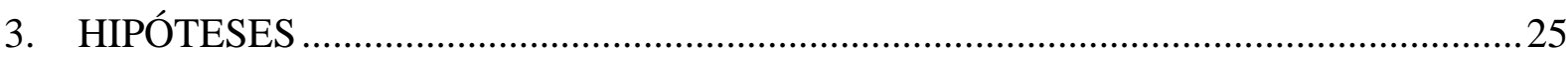

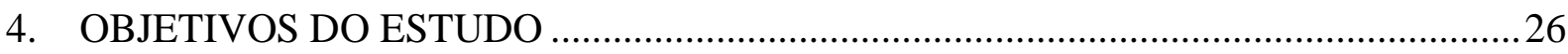

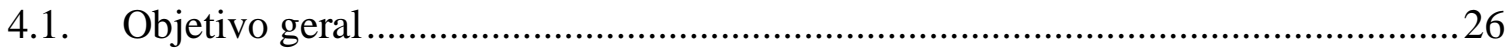

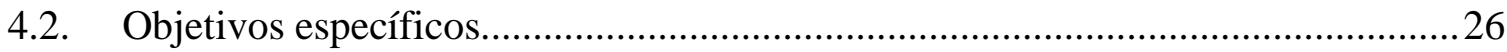

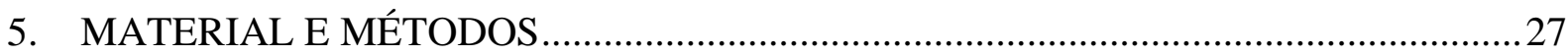

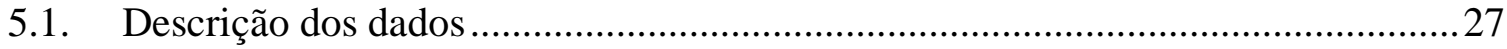

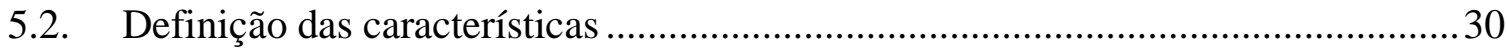

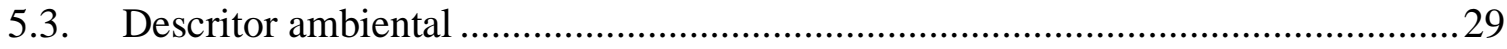

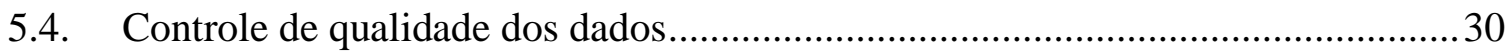

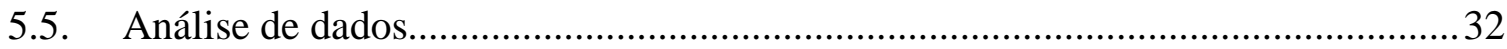

5.6. Tendência genética e sensibilidade ambiental ...................................................... 34

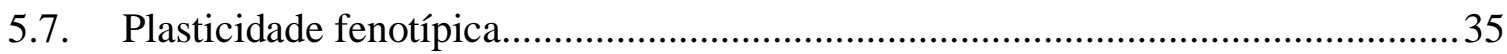

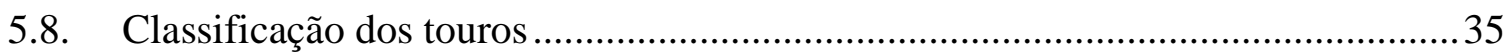

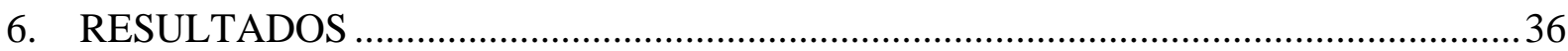

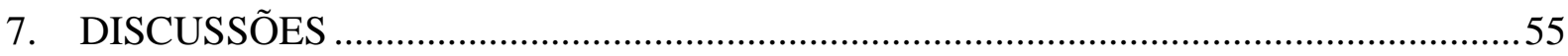

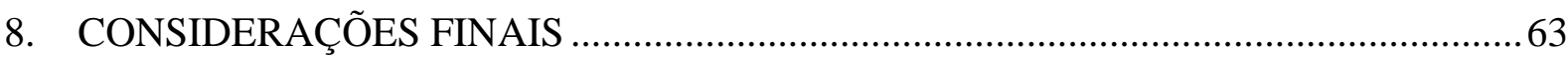

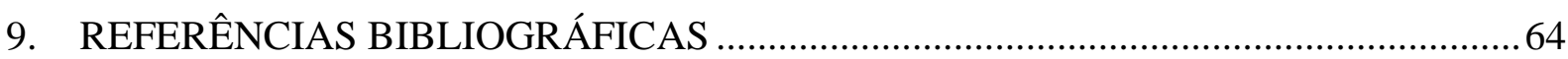

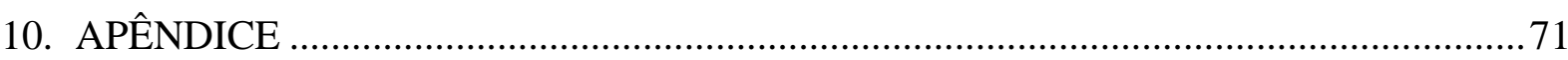

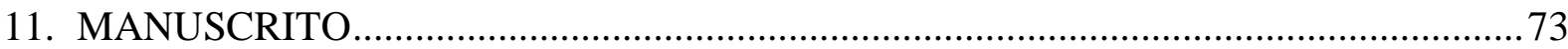




\section{INTRODUÇÃO}

A pecuária brasileira está entre as mais eficientes, sustentáveis e competitivas do mundo, com um efetivo de bovinos com aproximadamente 214,8 milhões de cabeças em 2019 (IBGE, 2020). No entanto, por ser um país de grande extensão e heterogeneidade ambiental, a pecuária é fortemente influenciada por diversos fatores como climáticos, econômicos e culturais. Por essa razão, a interação entre genótipo e ambiente (IGA) é um aspecto importante a ser considerado em programas de melhoramento animal (CORRÊA et al., 2009; MOTA et al., 2016), uma vez que as progênies do mesmo criador podem não expressar todo o desempenho esperado, se criado em ambientes distintos em que os pais foram avaliados, devido a existência da IGA (MULDER; BIJMA, 2005).

A modificação ambiental do fenótipo é comum em caracteres quantitativos ou poligênicos, principalmente em organismos que habitam ambientes heterogêneos (VIA; LANDE, 1985; SANTANA et al., 2018). A ação destes genes pode estar condicionada pelo conjunto de efeitos ambientais, podendo provocar alterações nas variações genéticas e fenotípicas, como modificações no desempenho dos animais em relação ao ambiente, o que resulta em mudanças nas estimativas dos parâmetros genéticos e na classificação dos animais (CORRÊA et al., 2009; CARDOSO; TEMPELMAN, 2012; MOTA et al., 2016). Portanto, a identificação e consideração dos efeitos da IGA em avaliações genéticas pode contribuir para aumentar a eficiência dos programas de melhoramento genético de bovinos de corte, oferecendo maior segurança na escolha do material genético mais apropriado para cada ambiente de produção (MULDER et al, 2006).

Quando um organismo qualquer produz uma resposta fenotípica que varia como uma função contínua em relação ao seu ambiente, esta relação é chamada de norma de reação (WOLTERECK, 1909). O modelo de norma de reação (MNR) pode ser empregado para um número infinito de ambientes, além de permitir a atribuição de vários valores genéticos para um mesmo animal e permitir verificar a expressão fenotípica de um genótipo continuamente em um gradiente ambiental (DE JONG, 1995; SANTANA et al., 2015).

Para autores como Kolmodin e Bijma (2004), Cardoso et al., (2011), Santana et al., (2015) e Ambrosini et al. (2016a) a aplicação dos MNR é eficiente para estudos de IGA, uma vez que se houver uma boa distribuição dos dados nos diferentes ambientes, a previsão de 
resposta à seleção pode se tornar mais acurada, pois os componentes de variância podem ser estimados com maior confiabilidade e pelas respostas diretas e correlacionadas de todos os pontos ao longo de uma trajetória, sendo muito útil quando os genótipos mudam gradualmente ao longo do gradiente ambiental.

Com o intuito de investigar o efeito da IGA sobre características de crescimento e reprodutivas de bovinos Nelore, Araújo Neto et al., (2018) observaram diferenças nas estimativas de correlação entre as mesmas características em diferentes ambientes e concluíram que é importante projetar um programa de melhoramento que inclua o efeito da IGA e que leve em consideração covariâncias entre ambientes e entre características. Souza et al. (2018) ao avaliarem a IGA e estimar parâmetros e tendências genéticas para características de crescimento de Nelore em três regiões do Brasil, relataram a existência da IGA para as características avaliadas e que touros selecionados com base em um mérito genético elevado para uma região podem não ser os melhores para outras.

Ambrosini et al. (2016a), relataram a existência da variação genética quanto à sensibilidade dos animais em diferentes ambientes, inferindo sobre a importância selecionar animais com genótipos mais adequados para a produção em determinado ambiente. Santana et al. (2015), ao analisarem ganho de peso pós-desmama, perímetro escrotal e produtividade média anual de vacas concluíram que a resposta à seleção varia de acordo com o ambiente, principalmente para ganho de peso pós-desmama e produtividade média anual de vacas. Segundo os autores, o perímetro escrotal não exibiu importante IGA.

Embora vários estudos evidenciem o efeito da IGA nas características de crescimento e reprodutivas, para os programas de melhoramento genético de bovinos de corte, a pressuposição que geralmente é assumida nas avaliações genéticas é que existe a ausência da interação genótipo e ambiente e que as variâncias residuais e genéticas são consideradas constantes. Entretanto sabe-se que existe o efeito dessa interação, e quando a mesma não é devidamente detectada pode implicar em uma predição tendenciosa dos valores genéticos e consequentemente uma redução no progresso genético (RIBEIRO et al., 2009; LIMA SILVA et al., 2019), resultando em perda econômica para o produtor.

Existem poucos relatos na literatura sobre como a seleção pode afetar a resposta dos animais ao ambiente, como o de Aguilar et al. (2010) que contrastaram os 100 touros mais e menos tolerantes ao calor e concluíram que os touros mais tolerantes ao calor transmitem a suas filhas menor produtividade leiteira e menor rendimento de produtos lácteos, porém maior 
fertilidade. De acordo com Carabaño et al. (2019), o estresse térmico é um fenômeno complexo que desencadeia vários mecanismos de resposta em bovinos leiteiros que afetam negativamente a lucratividade da fazenda, pois segundo os autores existe antagonismo entre a produtividade e a tolerância ao calor. Entretanto, estudos de como a seleção pode afetar a resposta de bovinos de corte ao ambiente são escassos na literatura e deste modo, o objetivo deste estudo foi avaliar o efeito de diferentes práticas de seleção na sensibilidade ambiental das características reprodutivas e de crescimento em bovinos machos e fêmeas de um rebanho Nelore com três linhas de seleção com diferentes objetivos, utilizando modelo de norma de reação, bem como estimar tendências genéticas para cada linha, tanto para a capacidade geral de produção (intercepto da norma de reação) quanto para a capacidade específica de responder às variações ambientais (inclinação da norma de reação). 


\section{REVISÃO DE LITERATURA}

\subsection{Ambiente e sua heterogeneidade}

O início da domesticação foi baseado no conhecimento das necessidades dos animais em seu ambiente natural, entretanto o ambiente de criação pode ser diferente do habitat natural, desde que o ambiente em questão supra as necessidades fisiológicas, morfológicas e comportamentais dos animais. Devido a variabilidade genética entre os indivíduos de um grupo, alguns indivíduos tendem a se reproduzir e a prosperar melhor em diferentes circunstancias ambientais e um maior número desses genes serão passados à geração seguinte, ou seja, a IGA é umas das bases da teoria da evolução proposta por Charles Darwin em 1859, em que animais mais adaptados a um determinado ambiente levam vantagem e tendem a deixar mais descendentes. A seleção genética artificial de animais domésticos visa selecionar os melhores genótipos que irão contribuir para as futuras gerações, para isso os animais são selecionados no ambiente de interesse.

O ambiente é um conjunto de fatores físicos, químicos e biológicos permitido que um organismo exista (KING et al., 2006). Para Cardoso (2009), o ambiente é definido como um conjunto de elementos, não genéticos, que exerce alguma influência sobre a expressão dos genótipos dos animais. No melhoramento genético animal toda e qualquer variação não genética é considerada de causa ambiental e as principais causas da variação não genética são as condições climáticas, nutricionais, manejo e até o efeito materno, que por sua vez são dentre todos os mais difíceis de controle (GIANNONI; GIANNONI, 1987).

Considerando que o Brasil é um país de grande extensão e heterogeneidade ambiental, que a grande maioria dos bovinos de corte brasileiros são criados em pastagem e que a exploração pecuária é influenciada por diversos fatores como: diferenças de fatores climáticos com presença ou ausência de estresse térmico (hídrico), econômicos e culturais, que influenciam no manejo nutricional e sanitário, além da disponibilidade de recursos de uma dada região, um aspecto importante a ser considerado em programas de melhoramento genético animal é a presença da IGA em que os animais e sua progênie são criados (CORRÊA et al., 2009; MOTA et al., 2016; LIMA SILVA et al., 2019). 


\subsection{Interação genótipo ambiente}

Por definição o termo interação genótipo ambiente serve para descrever o fenômeno que ocorre quando um conjunto de genótipos muda sua performance em ambientes diferentes, deste modo, quando existe a presença dessa interação a resposta diferenciada dos genótipos frente as variações ambientais pode sofrer alterações quanto ao seu mérito relativo, ou seja, quanto o mérito relativo de dois ou mais genótipos é dependente do ambiente no qual são comparados (FALCONER; MACKAY, 1996).

Sabe-se que essa interação pode provocar alterações nas variações genéticas e fenotípicas, como modificações no mérito genético dos animais, o que resulta em mudanças nas estimativas dos parâmetros genéticos dos mesmos, com alteração no ranking dos animais (ALENCAR et al., 2005; CORRÊA et al., 2009; CARDOSO; TEMPELMAN, 2012; MOTA et al., 2016). Para Falconer e Mackay (1996), uma característica mensurada em ambientes diferentes, pode ser interpretada como sendo características diferentes, pois os genes que a controlam em um determinado ambiente podem ou não ser diferentes dos que a controlam em outro ambiente.

De acordo com Calus (2006) a IGA resulta em três efeitos possíveis, sendo a primeira o efeito de escala, que é a heterogeneidade de variações genéticas entre diferentes ambientes; a reclassificação dos animais em diferentes ambientes com base nos valores genéticos estimados, e a heterogeneidade de correlações entre diferentes características entre os diferentes ambientes. O autor ainda relata que se não houver reclassificação dos animais, a IGA é geralmente considerada irrelevante se ocorrer apenas o efeito de escala.

O conhecimento das causas e efeitos da IGA consiste na inclusão automática do ambiente no objetivo de seleção e algumas características podem se tornar interessantes economicamente por serem mais plásticas ou mais robustas, como no caso de em características reprodutivas que tendem a ser mais plásticas e características ligadas à sanidade que tendem a serem mais robustas (DE JONG; BIJMA, 2002).

\subsection{Descritor ambiental}

A definição do descritor ambiental é muito importante para estudos de IGA que utilizam modelos de normas de reação (SANTANA et al., 2015). Entretanto o descritor ambiental tem 
sido definido de diferentes formas e de acordo com Calus et al. (2004), essa definição tem uma forte influência nos resultados.

Fikse et al. (2003) testaram diversas variáveis para definir rebanho, manejo, constituição genética da linha e condições climáticas combinadas com regiões em que se encontravam as linhas de quatro países. Alencar et al. (2005) consideraram o ambiente apenas como a época de nascimento do animal, sendo dividido em semestres. No mesmo ano, Mulder e Bijma (2005) consideram dois tipos de ambientes para estimar a perda de ganho genético devido à IGA, que são: o ambiente de seleção em que todos os animais candidatos à seleção são incluídos na análise e o ambiente de produção, composto por animais que não foram selecionados.

Pesquisas realizadas sobre o efeito do IGA em bovinos de corte têm utilizado mais comumente o descritor ambiental pelo grupo de contemporâneos (GC), incluindo o criador, rebanho, ano de nascimento, estação de nascimento entre outros fatores significativos para o conjunto de dados a serem analisados, ou seja, o GC é a entidade ambiental mais basal a qual o desempenho dos animais está sujeito (MATTAR et al., 2011).

\subsection{Métodos de predição da IGA}

A IGA pode ser avaliada de diferentes formas, como por meio de análise multicaracterísticas, em que se considera uma mesma característica como diferente quando mensurada em ambientes diferentes (FALCONER, 1952), sendo que para cada animal é atribuído um valor genético para cada ambiente, ou seja, previsões pontuais, o ambiente é considerado uma variável discreta, entretanto o número de ambientes não pode ser muito elevado.

Existe ainda a interação touro x ambiente que envolve a estimação de componentes de variância da IGA, usando técnicas de análise de variância, no qual há inclusão desse fator no modelo de avaliação genética e a partir dele se obtém um único valor genético por animal, não há limite de ambientes a serem estudados, sendo que essa variável é considerada discreta, ou seja, comparação de modelos contendo um fator aleatório atribuído a IGA (KENNEDY; HENDERSON, 1975; ELER et al., 2000).

Woltereck (1909), ao estudar estirpes morfologicamente distintas das espécies Daphnia e Hyalodaphnia de diferentes lagos alemães, constatou que o fenótipo de linhagens puras foi afetado por fatores ambientais, no entanto a resposta do fenótipo à mesma mudança ambiental 
não foi idêntica em diferentes linhagens puras, dessa forma Woltereck desenhou "curvas fenotípicas" para representar esse fenômeno e essas curvas foram alteradas para cada nova variável considerada. Assim, havia potencialmente um número quase infinito deles, no qual o autor cunhou o termo "Reaktionsnorm" ou norma de reação para indicar a totalidade dos relacionamentos incorporados neles.

Por meio da estatística, o modelo de norma de reação (MNR) pode ser empregado para um número infinito de ambientes, além de permitir a atribuição de vários valores genéticos para um mesmo animal e permite verificar a expressão fenotípica de um genótipo continuamente em um gradiente ambiental (DE JONG, 1995). Para autores como Kolmodin e Bijma (2004), Cardoso et al., (2011), Santana et al. (2015; 2018) e Ambrosini et al. (2016a) a aplicação dos MNR é eficiente para estudos de IGA, uma vez que a previsão de resposta à seleção pode ser mais acurada, pois os componentes de variância são estimados com maior confiabilidade e pelas respostas diretas e correlacionadas de todos os pontos ao longo de uma trajetória, sendo muito útil quando os genótipos mudam gradualmente ao longo do gradiente ambiental. Além disso, MNR podem ser úteis para descrever a sensibilidade ambiental dos animais, permitindo a identificação de genótipos mais ou menos sensíveis a mudanças no desempenho dos animais de acordo com o gradiente ambiental (SANTANA et al., 2018).

O MNR de regressão linear é uma função de covariância que confere para cada animal dois coeficientes de regressão, o intercepto e a inclinação, que predizem o valor genético para cada ambiente estudado (RODRIGUES, 2012). Segundo Valente (2007) o coeficiente linear, é o intercepto, que representa a média para o valor genético aditivo ao longo do gradiente ambiental e o coeficiente angular é a inclinação da reta da NR, que mede o aumento ou redução no desempenho do genótipo para cada ambiente. Maiores valores da inclinação indicam maior sensibilidade ambiental ou capacidade de resposta às mudanças ambientais.

Utilizando-se dos MNR é possível a inclusão da sensibilidade ambiental como um dos critérios de seleção, pois o mesmo pode auxiliar no controle do comportamento dos fenótipos em função do ambiente, pois a sensibilidade ambiental é definida como a primeira derivada da função da norma de reação, ou seja, a inclinação do MNR (DE JONG, 1995). Mudança na sensibilidade ambiental pode ser o resultado da ação da seleção nos coeficientes da norma de reação ou uma resposta correlacionada à seleção para valores fenotípicos dentro de diferentes ambientes (VIA; LANDE, 1985). 
A escolha da metodologia a ser utilizada em estudos que consideram a IGA deve levar em consideração os dados disponíveis para análise e o delineamento experimental a ser empregado no estudo.

\subsection{Importância da IGA no melhoramento genético animal}

Por meio desta metodologia, estudos constataram o efeito da IGA sobre rebanhos Nelore em diversas regiões do Brasil. Com o objetivo de avaliar a IGA e estimar parâmetros e tendências genéticas para características de crescimento de Nelore em três regiões brasileiras, Souza et al. (2018) relataram a existência da IGA para as características avaliadas e que touros selecionados com base em um mérito genético elevado para uma região podem não ser os melhores para outras.

Ambrosini et al. (2016a), relataram a existência de variação genética na sensibilidade dos animais em diferentes ambientes, inferindo a importância de selecionar animais com genótipos mais adequados para produção em um determinado ambiente. Ribeiro et al. (2015) estudaram o efeito da IGA sobre peso á desmama e encontraram que há efeito da interação o ranking dos touros.

Santana et al. (2015), ao analisarem o ganho de peso pós-desmame, o perímetro escrotal e a produtividade média anual de vacas, concluíram que a resposta à seleção varia de acordo com o ambiente, principalmente para peso pós-desmame e produtividade média anual de vacas. Chiaia et al. (2015) avaliaram o efeito da IGA sobre idade ao primeiro parto, perímetro escrotal e peso ao sobreano e relataram que as correlações genéticas entre as mesmas características em diferentes ambientes tiveram diferentes magnitudes identificando IGA. Raidan et al. (2015) avaliaram o efeito da IGA sobre o desempenho individual e testes de progênie em bovinos Nelore para as características peso final, ganho médio diário e perímetro escrotal, e constataram que características com menor herdabilidade foram mais suscetíveis a IGA.

Sabe-se que melhorias na eficiência reprodutiva de bovinos de corte podem ser alcançadas por meio de manejo nutricional e sanitário adequados, bem como condições favoráveis de bem-estar, deste modo, por se tratarem de fatores não genéticos é fundamental avaliar os efeitos da IGA sobre essas características, visto que por serem de grande importância quando se visa o aumento do desfrute do rebanho. 


\subsection{O grande problema dos programas de melhoramento genético brasileiros em não incluir a IGA}

Nos principais programas de melhoramento genético de bovinos de corte brasileiros, a pressuposição geralmente assumida nas avaliações genéticas é que não existe IGA e que as variâncias residuais e genéticas são consideradas constantes. Entretanto sabe-se que existe o efeito dessa interação, e quando a mesma não é devidamente detectada pode implicar em uma predição viesada dos valores genéticos e consequentemente uma redução no progresso genético (RIBEIRO et al., 2009; LIMA SILVA et al., 2019), resultando em perda econômica para o produtor, já que a mudança genética obtida por seleção é transferível por meio de venda de reprodutores, inseminação artificial ou transferência de embriões, por esse motivo ao adquirir sêmen ou um animal considerado muito bom em um determinado ambiente, o mesmo pode ser ruim em outro levando ao prejuízo econômico.

Outro fato importante a ser citado é que, no geral, a seleção conduzida por programas de melhoramento genético de bovinos de corte é realizada sob melhores condições ambientais que permitem alta performance dos reprodutores, entretanto devido a presença da IGA, a classificação desses reprodutores pode mudar se sua progênie for criada em ambientes considerados desfavoráveis ou intermediários, com baixo nível nutricional ou condições climáticas mais extremas, ou qualquer outro fator ambiental que afete o ganho genético (MULDER; BIJMA 2005; CARDOSO; TEMPELMAN, 2012; MOTA et al, 2019a).

Para minimizar os efeitos da IGA em situações em que a progênie é criada em condição ambiental diferente dos pais, os programas devem visar animais mais adaptados a diferentes ambientes (Kolmodin e Bijma, 2004). Para Mulder e Bijma (2005) quando há evidência da ocorrência da IGA, a seleção pode ser direcionada para a identificação de genótipo com melhor desempenho em diferentes ambientes, o que leva a um aumento na robustez frente a variação ambiental. 


\section{HIPÓTESES}

- Não existe efeito da IGA para as características e linhas de seleção analisadas.

- Diferentes objetivos de seleção afetam da mesma forma a sensibilidade ambiental dos animais estudados. 


\section{OBJETIVOS DO ESTUDO}

\subsection{Objetivo geral}

Avaliar a importância da interação genótipo x ambiente (IGA) e o efeito de diferentes práticas de seleção sobre a sensibilidade ambiental de características de crescimento e reprodutivas em machos e fêmeas de bovinos da raça Nelore provenientes de três linhas de seleção (NeC=Nelore Controle, $\mathrm{NeS}=$ Nelore Seleção, e NeT=Nelore Tradicional) do rebanho experimental do Centro Avançado de Pesquisa em Bovinos de Corte, do Instituto de Zootecnia/APTA/SAA.

\subsection{Objetivos específicos}

1) Estimar os componentes de (co)variância e parâmetros genéticos para peso ao desmame padronizado, o peso à seleção, a altura da garupa, o perímetro escrotal e os dias para o primeiro parto, para as três linhas de seleção, utilizando um modelo animal padrão e modelo de normas de reação.

2) Comparar a qualidade de ajuste aos dados do modelo animal padrão e do modelo de norma de reação de forma a identificar o melhor modelo para avaliações genéticas das linhas de seleção.

3) Verificar a presença e a importância da interação genótipo x ambiente sobre as características estudadas.

4) Estimar a tendência genética para cada linha de seleção e característica tanto para o nível geral de produção (intercepto da norma de reação) quanto para a habilidade específica de resposta a variações ambientais (inclinação da norma de reação).

5) Identificar potenciais mudanças na classificação dos $25 \%$ melhores touros de cada linha de seleção para cada modelo em diferentes ambientes. 


\section{MATERIAL E MÉTODOS}

\subsection{Descrição dos dados}

O experimento foi realizado no Centro Avançado de Pesquisa em Bovinos de Corte, do Instituto de Zootecnia/APTA/SAA localizado no município de Sertãozinho, São Paulo, Brasil. Um total de 9.315 registros de peso ao desmame padronizado (P210) para machos e fêmeas nascidos entre 1981 e 2018; 8.757 informações de peso a seleção (PS) de machos e fêmeas nascidos entre 1981 e 2017; 7.799 registros de altura da garupa (ALT) de machos nascidos entre 1986 e 2017 e fêmeas nascidas entre 1985 e 2017; 3.331 registros de perímetro escrotal em machos nascidos entre 1990 e 2017; e 2.311 registros de dias para o primeiro parto de fêmeas nascidas entre 1981 e 2015 foram utilizados nas análises.

O programa de seleção de bovinos de corte do Centro foi implantado com o compromisso de obter resultados práticos sobre os efeitos da seleção das principais características de interesse econômico. A criação dos animais a pasto serve para que seus resultados sejam compatíveis com as condições brasileiras. O rebanho de bovinos Nelore do Centro oferece uma adequada estrutura de dados para se avaliar o efeito de práticas de seleção sobre a sensibilidade ambiental dos animais. Em 1976 o objetivo do Instituto era iniciar um projeto de seleção para aumentar o peso pós-desmama de zebuínos com base no desempenho individual, que visa à maximização do progresso genético anual (RAZOOK et al., 1997; MERCADANTE et al., 2003).

No ano de 1980, o rebanho Nelore foi dividido em três linhas de seleção, a linha Controle $(\mathrm{NeC})$, uma linha fechada em que eram utilizados reprodutores do próprio Centro, sendo que os animais eram selecionados para o peso médio pós-desmame. As linhas Seleção (NeS) que também era uma linha fechada e Tradicional (NeT) que era uma linha aberta que, eventualmente, recebeu touros de outros rebanhos dentro e fora do Centro, especialmente nos primeiros anos do programa de melhoramento genético (RAZOOK et al., 1997; MERCADANTE et al., 2003), sendo que as duas últimas linhas, os animais eram selecionados para os maiores diferenciais para o aumento do peso pós-desmame. A partir de 2012, a linha NeT também foi selecionada para consumo alimentar residual (BENFICA et al., 2020). 


\subsection{Definição das características}

Para a realização da prova de ganho de peso (PGP) realizado no Centro Avançado de Pesquisa em Bovinos de Corte, os animais foram alojados em piquetes de $3.600 \mathrm{~m}^{2}$, com alimentação ad libitum fornecida duas vezes ao dia. O manejo alimentar consistiu de silagem de milho, feno de brachiária, farelo de soja, milho moído e sal mineral com ureia (67\% de NDT, 13\% de PB). Inicialmente os animais foram pesados após um jejum alimentar e hídrico (peso inicial) e seus pesos foram padronizados para os 210 dias de idade, tomando como base o ganho médio diário do nascimento a desmama, conforme equação abaixo:

$$
\text { P210 }=\frac{\text { Peso inicial }- \text { Peso ao nascer }}{\text { Idade ao peso inicial }} \times 210+\text { Peso ao nascer }
$$

Após a pesagem, todos os machos foram direcionados para a PGP, onde foram pesados três vezes durante a prova. Os mesmos permaneceram confinados por 168 dias, sendo que os primeiros 56 dias foram para adaptação e não foram contabilizados. Sendo assim, o ganho médio diário foi obtido no período de 112 dias (G112) da seguinte forma:

$$
\text { G112 }=\frac{\text { Peso Final na PGP }- \text { Peso após } 56 \text { dias de adaptação }}{112}
$$

E por fim, o peso final padronizado aos 378 dias (P378) para machos foi obtido da seguinte forma:

$$
\mathrm{P} 378=\mathrm{P} 210+(\mathrm{G} 112 \times 168)
$$

Após o desmame, todas as fêmeas foram encaminhadas para o pasto e lá elas foram pesadas entre três a quatro vezes, por um período de 340 dias, sendo que os dias em pasto total (DPT) foi obtido a partir da diferença entre a data da última pesagem e a data da desmama, deste modo, o ganho de peso no pasto (GDP) foi dado como:

$$
\mathrm{GDP}=\frac{\text { Peso da última pesagem }-\mathrm{P} 210}{\mathrm{DPT}}
$$


E por fim, o peso final padronizado aos 550 dias (P550) para fêmeas foi obtido da seguinte forma:

$$
\mathrm{P} 550=\mathrm{P} 210+(\text { GDP } \times 340)
$$

O critério de seleção utilizado para machos foi o peso ajustado aos 378 dias de idade e para fêmeas o peso ajustado aos 550 dias de idade. Neste estudo, estes pesos foram considerados como sendo a mesma característica, o peso de seleção (PS). Devido ao fato de apenas os machos serem confinados logo após o desmame e as fêmeas serem encaminhadas ao pasto, a seleção das fêmeas foi mais tardia. Além do PS para machos, o perímetro escrotal (PE) foi medido em centímetros ao final da prova.

A altura da garupa (ALT) foi coletada em diferentes períodos para cada sexo, enquanto que para machos a altura da garupa foi coletada em torno de 378 dias idade e para as fêmeas foi coletada aos 550 dias, seguindo os critérios de seleção para o peso pós-desmame a que todos os animais foram submetidos. No entanto, assim como a característica peso à seleção, a altura da garupa foi considerada única, pela mesma razão descrita para o peso à seleção. Assim como a altura da garupa em machos, o perímetro escrotal foi medido em centímetros por volta dos 378 dias de idade, no final da prova, sendo esse um possível indicador de precocidade sexual.

Conforme descrito por Mercadante et al., (2003), a característica dias para o primeiro parto (DPP) foi obtida para todas as novilhas que entraram na estação reprodutiva, nas quais a diferença de dias foi contada entre a data do início da estação reprodutiva até data do parto. Durante o controle de qualidade dos dados, foram descartadas informações de abortos, parto fora da estação do nascimento e inseminação artificial. Os registros das novilhas que não pariram foram incluídos e um valor projetado foi atribuído a cada registro de acasalamento. $\mathrm{O}$ maior registro de DPP dentro de cada grupo contemporâneo composto por ano e linha de nascimento foi identificado e 21 dias foram adicionados a esse registro para gerar o valor projetado para novilhas que não pariram (JOHNSTON; BUNTER, 1996).

\subsection{Descritor ambiental}

Uma análise preliminar de variância foi realizada usando o procedimento GLM do programa SAS (SAS Inst. Inc., Cary, NC, EUA), a fim de determinar quais efeitos não genéticos devem ser incluídos no modelo, tais como ano de nascimento, linha de seleção, classe de mês 
de nascimento, sexo, interações entre sexo e linha de seleção e efeito de touro de monta apenas para a característica DPP. Com o intuito de estabelecer um descritor ambiental foram considerados os seguintes efeitos fixos na definição dos grupos de contemporâneos (GC) para cada característica: para P210 foram incluídos linha de seleção e ano de nascimento; para PS foram linha de seleção, sexo e ano de nascimento; para ALT foram linha de seleção, sexo e ano de nascimento, e para PE foram linha de seleção e ano de nascimento. No entanto, apenas as soluções de GC correspondentes a linha $\mathrm{NeC}$ foram utilizadas, pois descreveriam de maneira mais confiável as condições ambientais, sem alterações devido a tendências genéticas desde o início do programa de seleção. Para a característica DPP, o GC incluiu apenas o efeito do ano de nascimento, com registros de todos os animais das três linhas de seleção, porque a linha $\mathrm{NeC}$ não possuía registros para todos os anos estudados, portanto, para não ficar sem solução ou com menos de 10 informações por $\mathrm{GC}$, foram considerados os registros de todos os animais. As soluções de CG foram obtidas ajustando um modelo animal padrão aos dados de todos os animais estudados, visto que o GC representa bem as condições ambientais que os animais foram submetidos ao longo dos anos de seleção (MATTAR et al., 2011; SANTANA et al., 2015).

\subsection{Controle de qualidade dos dados}

Para o controle de qualidade dos dados, GCs com menos de 10 animais; GC com progênie de um único touro, bem como animais com problemas de saúde, sem registro de idade, sem registro da idade da vaca ao parto ou sem peso na entrada da estação de monta (para DPP) foram excluídos. Devido ao baixo volume de dados, para a característica DPP foram mantidos GCs com mais de quatro observações.

Para as características P210, PS e ALT os efeitos fixos incluídos nos modelos foram sexo e classe de mês de nascimento definidos como agosto (1), setembro (2), outubro (3) e novembro e dezembro juntos (4). Para o PE só foi incluso no modelo o efeito de mês de nascimento, e para o DPP o efeito fixo incluído no modelo foi o efeito de touro de monta. O modelo também incluiu as covariáveis: idade do animal na mensuração como efeito linear para todas as características; idade da mãe no parto como efeitos lineares e quadráticos para P210, PS, ALT e PE; e efeito do peso na entrada da estação de monta para DPP. Na Tabela 1 foi apresentada uma descrição do arquivo de dados utilizado após efetuado o controle de qualidade. 
Tabela 1. Descrição do conjunto de dados de bovinos Nelore das três linhas de seleção: Controle (NeC), Seleção (NeS), e Tradicional (NeT).

\begin{tabular}{|c|c|c|c|}
\hline \multicolumn{4}{|c|}{ Peso a Desmama Padronizado (P210) } \\
\hline & $\mathrm{NeC}$ & NeS & NeT \\
\hline Animais com pedigree & 2087 & 4023 & 5425 \\
\hline Touros & 89 & 142 & 188 \\
\hline Vacas & 453 & 919 & 1200 \\
\hline Animais com registros & 1666 & 3308 & 4341 \\
\hline Machos & 853 & 1638 & 2181 \\
\hline Fêmeas & 813 & 1670 & 2160 \\
\hline Grupo de Contemporâneos & 38 & 38 & 38 \\
\hline Média da característica em kg (desvio padrão) & $166,6(22,6)$ & $191,7(28,8)$ & $195,4(30,7)$ \\
\hline \multicolumn{4}{|c|}{ Peso a Seleção (PS) } \\
\hline Animais com pedigree & 1964 & 3756 & 4975 \\
\hline Touros & 86 & 138 & 180 \\
\hline Vacas & 437 & 899 & 1150 \\
\hline Animais com registros & 1592 & 3146 & 4019 \\
\hline Machos & 820 & 1562 & 1979 \\
\hline Fêmeas & 772 & 1584 & 2040 \\
\hline Grupo de Contemporâneos & 74 & 74 & 74 \\
\hline Média da característica em kg (desvio padrão) & $264,7(33,2)$ & $310,83(48,7)$ & $314,6(51,2)$ \\
\hline \multicolumn{4}{|c|}{ Altura da Garupa (ALT) } \\
\hline Animais com pedigree & 1833 & 3518 & 4685 \\
\hline Touros & 77 & 129 & 171 \\
\hline Vacas & 403 & 817 & 1054 \\
\hline Animais com registros & 1410 & 2792 & 3597 \\
\hline Machos & 701 & 1369 & 1773 \\
\hline Fêmeas & 709 & 1423 & 1824 \\
\hline Grupo de Contemporâneos & 65 & 65 & 65 \\
\hline Média da característica em cm (desvio padrão) & $127,6(4,8)$ & $133,7(4,9)$ & $133,5(5,2)$ \\
\hline \multicolumn{4}{|c|}{ Perímetro Escrotal (PE) } \\
\hline Animais com pedigree & 1204 & 2468 & 3159 \\
\hline Touros & 66 & 114 & 146 \\
\hline Vacas & 276 & 566 & 692 \\
\hline Machos com registros & 601 & 1188 & 1542 \\
\hline Grupo de Contemporâneos & 28 & 28 & 28 \\
\hline Média da característica em cm (desvio padrão) & $21,9(2,4)$ & $22,9(2,5)$ & $23,6(2,9)$ \\
\hline \multicolumn{4}{|c|}{ Dias para o Primeiro Parto (DPP) } \\
\hline Animais com pedigree & 893 & 1469 & 1860 \\
\hline Touros & 73 & 125 & 141 \\
\hline Vacas & 242 & 516 & 548 \\
\hline Novilhas com registros & 450 & 926 & 935 \\
\hline Grupo de Contemporâneos & 35 & 35 & 35 \\
\hline Média de idade de entrada na monta (desvio padrão) & $774,9(23,2)$ & $769,8(24,9)$ & $771,6(24,9)$ \\
\hline Média da característica em dias (desvio padrão) & $340,9(35,6)$ & $349,4(36,3)$ & $346,1(35,7)$ \\
\hline
\end{tabular}




\subsection{Análise de dados}

Para a análise dos dados, inicialmente foram adotados três modelos: o modelo animal (MA) que ignora a IGA e os modelos de norma de reação (MNR) com resíduos homocedástico e heterocedástico proposto por Kolmodin et al., (2002) que primeiramente prediz o valor genético do animal pelo modelo animal sem considerar a IGA, porém permite obter estimativas de soluções de grupos GC, conforme descrito abaixo:

$$
\mathrm{y}=\mathrm{X} \beta+\mathrm{Z}_{1} a+\mathrm{Z}_{2} m+\mathrm{Z}_{3} p m+e
$$

em que: $\mathrm{y}=\mathrm{o}$ vetor de fenótipos do animal; $\beta=$ vetor de efeitos fixos (grupo de contemporâneos, classe de mês de nascimento (para P210, PS, ALT e PE), touro de serviço (para DPP) e as covariáveis, idade do animal a mensuração (linear) e idade da vaca ao parto (linear e quadrático, exceto para DPP) ou peso de entrada na estação de monta (para DPP); $\mathbf{Z} a=$ vetor de efeitos genéticos aditivos do animal; $\mathbf{Z} m=$ vetor de efeitos aleatórios aditivos maternos (apenas para a variável P210); Z pm = vetor de efeitos aleatórios de ambiente permanente materno devido aos múltiplos partos das mães dos animais com fenótipos (apenas para a variável P210); $e=$ vetor de resíduos aleatórios; e $\mathrm{X}, \mathrm{Z}_{1}, \mathrm{Z}_{2}$ e $\mathrm{Z}_{3}=$ correspondem às matrizes de incidência que relaciona $\mathrm{y}$ aos efeitos $\beta, a, m p m$, respectivamente.

Posteriormente, foi utilizado o modelo de normas de reação (MNR), onde o valor genético foi expresso em função do descritor ambiental (FALCONER, 1990), descrito abaixo:

$$
\mathrm{y}_{i j}=\mathrm{fixo}_{\mathrm{i}}+\varphi_{f} \phi_{f}\left(\mathrm{GC}_{j}\right)+a_{j} \phi_{f}\left(\mathrm{GC}_{j}\right)+m_{j} \phi_{f}\left(\mathrm{GC}_{j}\right)+p m_{j} \phi_{f}\left(\mathrm{GC}_{j}\right)+e_{i j}
$$

onde: $\mathrm{y}_{i j}$ é o fenótipo do animal $i$ no ambiente $j$; fixo $i$ são os efeitos fixos sexo (para P210, PS e ALT), classe de mês de nascimento (para P210, PS, ALT, PE), touro de serviço (para DPP) e, como covariáveis, idade do animal à mensuração (linear), idade da vaca no parto (linear e quadrático, exceto para DPP), e peso de entrada da monta (para DPP)); $\varphi_{f}$ são os coeficientes de regressão fixos em $\Phi_{f} ; \Phi_{f}$ é o polinômio de Legendre de segunda ordem correspondentes às soluções de $\mathrm{GC}_{j}$ (ou seja, descritor ambiental) aninhada ao sexo (PS e ALT); $\alpha_{j} m_{j} p m_{j}$ são os coeficientes de regressão aleatória dos efeitos genético aditivo direto, aditivo materno e 
ambiente permanente materno (apenas para a variável P210) para cada animal $i$ no $\mathrm{CG}_{j}$, e $e_{i j}$ resíduo aleatório associado com cada animal $i$ no ambiente $\mathrm{GC}_{j}$.

Depois, foram feitas duas pressuposições diferentes sobre variância residual: para MNR homocedástico (com resíduo homogêneo): $\mathrm{e}_{\mathrm{i}} \sim \mathrm{N}\left(0, \sigma_{e}^{2}\right)$; e para o MNR heterocedástico (resíduo heterogêneo), onde maiores efeitos ambientais foram associados a maiores variações residuais (FALCONER; MACKAY, 1996): $\mathrm{e}_{\mathrm{i}} \sim \mathrm{N}\left(0, \sigma_{e i j}^{2}\right)$. Neste estudo, o descritor ambiental foi dividido igualmente em 3 ambientes: favoráveis, intermediários e desfavoráveis; e cada termo de erro tem a sua variância residual específica como uma função da (co)variável ambiental associada (CARDOSO et al., 2005). Entretanto devido ao baixo número de registros das características reprodutivas (PE e DPP) e pela distribuição desigual de animais entre os três ambientes selecionados como favorável, intermediário de desfavorável, optamos por excluir o MNR heterocedástico.

As variâncias genéticas aditivas diretas e maternas para um determinado ambiente $X$ foram obtidas por meio do MNR como:

$$
\begin{gathered}
\sigma_{a}^{2} \mid \mathrm{X}=\sigma_{a}^{2}+\mathrm{X}^{2} \sigma_{b}^{2}+2 \mathrm{X} \sigma_{a, b} \\
\sigma_{m}^{2} \mid \mathrm{X}=\sigma_{m}^{2}+\mathrm{X}^{2} \sigma_{b m}^{2}+2 \mathrm{X} \sigma_{a m, b m}
\end{gathered}
$$

em que: $\sigma_{a}^{2}=$ variância genética aditiva direta para o intercepto das normas de reação; $\sigma_{m}^{2}=$ variância genética aditiva materna para o intercepto das normas de reação (apenas para a variável P210); $\sigma_{b}^{2}=$ variância genética aditiva direta de inclinações das normas de reação; $\sigma_{\mathrm{bm}}^{2}$ = variância genética aditiva materna de inclinações das normas de reação (apenas para a variável P210) e $\sigma_{a, b ;} \sigma_{a m, b m}=$ covariância entre o intercepto e a inclinação para efeito genético aditivo direto e aditivo materno (apenas para a variável P210), respectivamente.

Os componentes de (co)variância para as características foram estimados usando o software GIBBS2F90 (MISZTAL et al., 2002), por meio de inferência Bayesiana via amostrador de Gibbs, empregando-se um modelo animal uni-característica. Houve diferença entre o número de ciclos, dependendo da característica e da linha de seleção estudada. As análises consistiram em uma única cadeia de 2.500 .000 ciclos, com um período de burn-in de 100.000 ciclos e um intervalo de descarte amostral ("thinning") de 480 ciclos para os modelos estudados, com exceção da características ALT e PE, ambos para a linha NeT em que as análises consistiram de uma cadeia única de 2.750 .000 ciclos, com um período de burn-in de 100.000 
ciclos e um intervalo 530 ciclos para os MNR e MA, respectivamente. E para a característica DPP, também para a linha NeT, porém a cadeia única consistiu em 3.500 .000 ciclos, com o mesmo período de burn-in e com um intervalo de 680 ciclos. Assim, os componentes de variância para os coeficientes de regressão e parâmetros genéticos foram estimados a partir das 5.000 amostras restantes.

As inferências para todos os componentes de (co) variância e parâmetros genéticos foram baseadas na média, desvio padrão e probabilidade posterior de $95 \%$. As estimativas a posteriori foram obtidas utilizando o software POSTGIBBSF90 (MISZTAL et al., 2002). Devido à complexidade dos modelos e ao baixo volume de registros disponíveis, vários testes com diferentes cadeias e ciclos foram realizados usando o pacote BOA (Bayesian Output Analysis) implementado via linguagem de programação R (R Core Team, R Foundation for Statistical Computing, Vienna, Austria, 2007), até ocorrer a convergência, para todos os parâmetros pelo critério de Geweke (GEWEKE, 1992) e baixa autocorrelação entre as amostras. O diagnóstico de convergência baseado no critério de Geweke baseia-se no teste $\mathrm{Z}$ de igualdade de médias do logaritmo da distribuição condicional dos dados, indicado pelas primeiras amostras (10\% iniciais) e pela última parte da cadeia de Markov (últimas 50\%).

O critério de informação de deviance (DIC) foi utilizado para avaliar a qualidade do ajuste dos modelos aos dados, o que sugere que a comparação dos modelos se baseia na distribuição a posteriori da deviance de cada modelo. Valores mais baixos de DIC indicam melhor ajuste do modelo (SPIEGELHALTER et al., 2002). A deviance do modelo $i$ pode ser definida como:

$$
\mathrm{DIC}=2 \overline{\mathrm{D}}_{\mathrm{i}}-\mathrm{D}\left(\bar{\theta}_{\mathrm{M}}\right)=\overline{\mathrm{D}}+\mathrm{P}_{\mathrm{D}(\mathrm{i})}
$$

em que: $\bar{\theta}_{\mathrm{M}}$ é o vetor de valores médios para todos os parâmetros em um determinado modelo (M) no final do processo de uma amostra MCMC. A complexidade do modelo (M) como número efetivo de parâmetros é dada por $P_{\mathrm{D}}=\bar{D}_{i}-\mathrm{D}\left(\bar{\theta}_{\mathrm{M}}\right)$ que representa a diferença entre a média posterior do desvio e o desvio com base na posterior médias dos parâmetros sob modelo.

\subsection{Tendência genética e sensibilidade ambiental}

Após preditos os valores genéticos foram computadas tendências genéticas baseadas nas médias das estimativas do intercepto (nível geral de produção) e inclinação (sensibilidade ambiental) das normas de reação dos animais para todas as características de acordo com o ano 
de nascimento. Um modelo de regressão linear simples foi aplicado a esses dados a fim de avaliar a significância das tendências genéticas. Dessa forma, foram avaliados possíveis impactos do tipo de seleção praticada ao longo dos anos, sobre o mérito genético geral e sobre a sensibilidade ambiental dos animais.

\subsection{Plasticidade fenotípica}

A plasticidade fenotípica dos indivíduos foi classificada de acordo com o valor absoluto de $b_{j} .\left|b_{\mathrm{j}}\right|<\sigma_{\mathrm{b}}=$ genótipo robusto; $\sigma_{\mathrm{b}} \leq\left|\mathrm{b}_{\mathrm{j}}\right|<2 \sigma_{\mathrm{b}}=$ genótipo plástico; e $\left|\mathrm{b}_{\mathrm{j}}\right| \geq 2 \sigma_{\mathrm{b}}=$ genótipo extremamente plástico (MATTAR et al., 2011). Também foi calculada a razão entre variância da inclinação e a variância do intercepto para se inferir sobre a variabilidade genética associada à sensibilidade ambiental da norma de reação dos animais.

\subsection{Classificação dos touros}

Para identificar possíveis alterações na classificação dos touros (ranking), foram selecionados os $25 \%$ melhores touros de cada linha de seleção com pelo menos 5 progênies, por cada modelo. O número de touros por linha para cada característica foi: 85; 140 e 170 touros para as linhas $\mathrm{NeC}, \mathrm{NeS}$ e NeT, respectivamente para P210; 82; 135 e 164 touros para as linhas $\mathrm{NeC}, \mathrm{NeS}$ e NeT, respectivamente para PS; 73; 122 e 155 touros para as linhas $\mathrm{NeC}, \mathrm{NeS}$ e $\mathrm{NeT}$, respectivamente para ALT; 56; 94; e 117 touros para as linhas $\mathrm{NeC}$, NeS e $\mathrm{NeT}$, respectivamente para o $\mathrm{PE}$; e 51; 94; e 91 touros para as linhas $\mathrm{NeC}$, $\mathrm{NeS}$ e $\mathrm{NeT}$, respectivamente para a característica DPP. A correlação de classificação de Spearman foi usada como estatística para avaliar a possível reclassificação de touros ao utilizar um ou outro modelo, analisando a proporção de touros selecionados em comum entre MNR e MA e em diferentes ambientes, dentro de cada linha de seleção.

As amplitudes das soluções dos GC, representando os ambientes desfavoráveis, intermediários e favoráveis, respectivamente, para o P210 foram de 131, 146 e 159 kg; para o PS foram de 180, 206 e $250 \mathrm{~kg}$ para machos e 115, 149 e $180 \mathrm{~kg}$ para fêmeas; para o ALT foram de 92, 96 e $101 \mathrm{~kg}$ para machos e 76, 80 e $86 \mathrm{~kg}$ para fêmeas; para PE foram -1,59, 0,54 e 2,57 cm, e para DPP foram 484, 518 e 560 dias. Estes ambientes (desfavorável, intermediário e favorável) refletem a expectativa da qualidade do ambiente proporcionado aos animais ao longo dos anos de seleção. 


\section{RESULTADOS}

O MNR homocedástico se ajustou melhor aos dados deste estudo em comparação com o MA padrão, resultado evidenciado pelo DIC em que valores menores proporcionam os melhores ajustes, com exceção da característica DPP para os animais da linha NeS (Tabela 2). O número efetivo de parâmetros (NFP) mostra a complexidade dos modelos analisados, sendo o MNR foi mais complexo que o MA, exceto a característica PE para os animais da linha NeS, onde o número efetivo de parâmetros do MNR era menor que o MA.

Tabela 2. Comparação da qualidade do ajuste entre modelo animal (MA) e o modelo de norma de reação homocedástico $\left(\mathrm{MNR}_{\mathrm{HO}}\right)$ para peso a desmama padronizado $(\mathrm{P} 210, \mathrm{~kg})$, peso a seleção (PS, $\left.\mathrm{kg}\right)$, altura da garupa $(\mathrm{ALT}, \mathrm{cm})$, perímetro escrotal $(\mathrm{PE}, \mathrm{cm})$ e dias para o primeiro parto (DPP, dias) para as três linhas de seleção (NeC, linha controle; NeS, linha seleção; NeT, linha tradicional) de bovinos da raça Nelore.

\begin{tabular}{|c|c|c|c|c|c|c|}
\hline \multicolumn{7}{|c|}{ P210 } \\
\hline \multirow[t]{2}{*}{ Modelos } & \multicolumn{2}{|c|}{$\mathrm{NeC}$} & \multicolumn{2}{|c|}{$\mathrm{NeS}$} & \multicolumn{2}{|c|}{ NeT } \\
\hline & DIC & NEP & DIC & NEP & DIC & NEP \\
\hline MA & $13.934,80$ & 418,6 & $28.715,70$ & $1.203,90$ & $38.138,80$ & $1.864,80$ \\
\hline MNRHO $_{\text {HN }}$ & $13.883,80$ & 539,2 & $28.695,30$ & $1.278,80$ & $38.044,60$ & $1.987,90$ \\
\hline \multicolumn{7}{|c|}{ PS } \\
\hline & DIC & NEP & DIC & NEP & DIC & NEP \\
\hline MA & $14.296,60$ & 660,4 & $29.795,50$ & $1.043,50$ & $39.049,50$ & $1.454,00$ \\
\hline MNRHO $_{\text {HO }}$ & $14.244,10$ & 681,6 & $29.661,30$ & $1.152,80$ & $38.751,80$ & $1.761,70$ \\
\hline \multicolumn{7}{|c|}{ ALT } \\
\hline & DIC & NEP & DIC & NEP & DIC & NEP \\
\hline MA & $7.521,10$ & 566,0 & 14.973 .9 & $1.108,8$ & $19.253,70$ & $1.545,40$ \\
\hline MNR $_{\text {HO }}$ & $7.098,00$ & 644,5 & 14.963 .9 & $1.123,4$ & $18.946,30$ & $1.784,10$ \\
\hline \multicolumn{7}{|c|}{ PE } \\
\hline & DIC & NEP & DIC & NEP & DIC & NEP \\
\hline MA & $2.279,80$ & 257,3 & $4.784,60$ & 459,5 & $6.651,70$ & 673,4 \\
\hline MNR $_{\text {HO }}$ & $2.246,20$ & 281,9 & $4.769,50$ & 428,0 & $6.470,30$ & 751,6 \\
\hline \multicolumn{7}{|c|}{ DPP } \\
\hline & DIC & NEP & DIC & NEP & DIC & NEP \\
\hline MA & $4.426,00$ & 167,5 & $9.081,40$ & 210,2 & $9.250,30$ & 205,0 \\
\hline MNR $_{\text {HO }}$ & $4.417,90$ & 181,9 & $9.084,30$ & 225,1 & $9.214,40$ & 270,3 \\
\hline
\end{tabular}

Os valores estimados para médias, desvios e os intervalos de alta densidade (HPD 95\%) dos componentes de variância e parâmetros genéticos para P210, PS, ALT, PE e DPP pelo MA foram apresentados na Tabela 3. 
Tabela 3. Análise descritiva dos parâmetros genéticos para peso a desmama padronizado (P210, kg), peso a seleção (PS, kg), altura da garupa (ALT, cm), perímetro escrotal $(\mathrm{PE}, \mathrm{cm})$ e dias para o primeiro parto (DPP, dias) de cada linha de seleção pelo modelo animal padrão (MA).

\begin{tabular}{|c|c|c|c|c|c|c|c|c|c|c|}
\hline & \multicolumn{2}{|c|}{ P210 } & \multicolumn{2}{|c|}{ PS } & \multicolumn{2}{|c|}{ ALT } & \multicolumn{2}{|c|}{ PE } & \multicolumn{2}{|c|}{ DPP } \\
\hline & Média (DP) & 95\% HPD & Média (DP) & 95\% HPD & Média (DP) & 95\% HPD & Média (DP) & 95\% HPD & Média (DP) & $95 \%$ HPD \\
\hline \multicolumn{11}{|c|}{ Controle (NeC) } \\
\hline$\sigma^{2} a$ & $32,6(16,1)$ & 8,$2 ; 70,2$ & $416,1(79,6)$ & 270,$8 ; 578,6$ & $9,9(1,4)$ & 7,$4 ; 12,8$ & $2,1(0,6)$ & 1,$1 ; 3,4$ & $334,5(159,9)$ & 72,$8 ; 691,3$ \\
\hline$\sigma^{2} m$ & $115,4(32,3)$ & 59,$1 ; 185,1$ & NA & NA & NA & NA & NA & NA & NA & NA \\
\hline$\sigma^{2} p m$ & $69,5(22,1)$ & 23,$1 ; 115,4$ & NA & NA & NA & NA & NA & NA & NA & NA \\
\hline$\sigma^{2} e$ & $196,1(12,3)$ & 171,$1 ; 219,2$ & $310,9(44,1)$ & 227,$0 ; 398,6$ & $8,2(0,8)$ & 6,$7 ; 9,8$ & $1,7(0,4)$ & 1,$0 ; 2,5$ & $767,0(122,4)$ & 525,$3 ; 1004,0$ \\
\hline $\mathrm{h}^{2} a$ & $0,08(0,04)$ & 0,$02 ; 0,16$ & $0,57(0,08)$ & 0,$41 ; 0,72$ & $0,55(0,06)$ & 0,$44 ; 0,65$ & $0,54(0,11)$ & 0,$32 ; 0,76$ & $0,30(0,13)$ & 0,$07 ; 0,56$ \\
\hline $\mathrm{h}^{2} m$ & $0,28(0,07)$ & 0,$15 ; 0,42$ & NA & NA & NA & NA & NA & NA & NA & NA \\
\hline \multicolumn{11}{|c|}{ Seleção (NeS) } \\
\hline$\sigma^{2} a$ & $122,2(21,5)$ & 82,$9 ; 167,3$ & $470,7(38,2)$ & 400,$7 ; 545,7$ & $10,1(0,9)$ & 8,$3 ; 12,0$ & $2,1(0,4)$ & 1,$4 ; 2,9$ & $113,6(63,9)$ & 11,$9 ; 260,1$ \\
\hline$\sigma^{2} m$ & $156,0(35,3)$ & 93,$6 ; 231,4$ & NA & NA & NA & NA & NA & NA & NA & NA \\
\hline$\sigma^{2} p m$ & $134,3(24,0)$ & 89,$3 ; 184,1$ & NA & NA & NA & NA & NA & NA & NA & NA \\
\hline$\sigma^{2} e$ & $240,1(13,6)$ & 212,$3 ; 266,75$ & $546,3(25,0)$ & 959,$1 ; 1076,8$ & $8,4(0,5)$ & 7,$4 ; 9,5$ & $2,2(0,3)$ & 1,$8 ; 2,8$ & $852,4(65,5)$ & 723,$4 ; 977,8$ \\
\hline $\mathrm{h}^{2} a$ & $0,19(0,03)$ & 0,$13 ; 0,25$ & $0,46(0,03)$ & 0,$41 ; 0,52$ & $0,54(0,04)$ & 0,$47 ; 0,61$ & $0,49(0,07)$ & 0,$35 ; 0,62$ & $0,12(0,06)$ & 0,$01 ; 0,26$ \\
\hline $\mathrm{h}^{2} m$ & $0,24(0,05)$ & 0,$15 ; 0,34$ & NA & NA & $\mathrm{NA}$ & NA & NA & NA & NA & NA \\
\hline \multicolumn{11}{|c|}{ Tradicional (NeT) } \\
\hline$\sigma^{2} a$ & $214,5(26,3)$ & 165,$5 ; 269,5$ & $667,8(45,0)$ & 582,$6 ; 759,9$ & $11,03(0,8)$ & 9,$5 ; 12,7$ & $3,2(0,4)$ & 2,$5 ; 3,9$ & $92,7(64,2)$ & 7,$4 ; 244,4$ \\
\hline$\sigma^{2} m$ & $117,2(33,5)$ & 58,$0 ; 189,4$ & NA & NA & NA & NA & NA & NA & NA & NA \\
\hline$\sigma^{2} p m$ & $134,6(23,1)$ & 91,$0 ; 180,7$ & NA & NA & NA & NA & NA & NA & NA & NA \\
\hline$\sigma^{2} e$ & $249,7(15,4)$ & 219,$4 ; 279,2$ & $677,3(28,4)$ & 621,$9 ; 734,6$ & $8,1(0,5)$ & 7,$2 ; 9,0$ & $2,7(0,3)$ & 2,$2 ; 3,2$ & $935,2(69,3)$ & 795,$5 ; 1067,0$ \\
\hline $\mathrm{h}^{2} a$ & $0,30(0,03)$ & 0,$23 ; 0,37$ & $0,50(0,02)$ & 0,$45 ; 0,54$ & $0,58(0,03)$ & 0,$52 ; 0,64$ & $0,54(0,05)$ & 0,$44 ; 0,64$ & $0,09(0,06)$ & 0,$01 ; 0,23$ \\
\hline $\mathrm{h}^{2} m$ & $0,16(0,04)$ & 0,$08 ; 0,25$ & NA & NA & NA & NA & NA & NA & NA & NA \\
\hline
\end{tabular}


As estimativas médias de herdabilidade direta para o P210 obtidas pelo MNR para a linha $\mathrm{NeC}$ em ambientes favoráveis e intermediárias foram próximas às obtidas pelo MA e superiores nos ambientes desfavoráveis (variando de 0,08 a 0,26). Para a linha NeS, as estimativas de herdabilidade direta nos ambientes intermediários foram próximas as obtidas no MA, inferiores nos ambientes desfavoráveis e superiores nos ambientes favoráveis (variando de 0,16 a 0,25$)$. E para a linha NeT, as estimativas obtidas pelo MNR foram próximas as obtidas pelo MA em todo o descritor ambiental (variando de 0,30 a 0,36) (Fig. 1).

As estimativas médias de herdabilidade materna para P210 obtidas pelo MNR para as linhas $\mathrm{NeC}$ e $\mathrm{NeT}$ foram superiores em todo o descritor ambiental (variando de 0,32 a 0,40 e 0,18 a 0,21 para as linhas $\mathrm{NeC} \mathrm{e} \mathrm{NeT,} \mathrm{respectivamente)} \mathrm{comparadas} \mathrm{as} \mathrm{estimativas} \mathrm{obtidas} \mathrm{pelo}$ MA. Para a linha NeS, as estimativas de herdabilidade materna nos ambientes favoráveis e intermediários foram próximas as obtidas no MA e superiores nos ambientes desfavoráveis em comparação ao MA (variando de 0,24 a 0,33).

Pelo MNR, as estimativas médias de herdabilidade direta para o PS para machos foram superiores as estimadas pelo MA em todos os níveis do descritor ambiental para as três linhas (variando de 0,56 a 0,$75 ; 0,51$ a 0,62 ; e 0,53 a 0,65 para as linhas $\mathrm{NeC}, \mathrm{NeS}$ e $\mathrm{NeT}$, respectivamente) e superiores as obtidas para fêmeas, sendo que os valores estimados para as fêmeas foram próximos aos valores estimados pelo MA (variando de 0,39 a 0,56; 0,37 a 0,51; e 0,53 a 0,64 , para as linhas $\mathrm{NeC}, \mathrm{NeS}$ e $\mathrm{NeT}$, respectivamente), com exceção da linha $\mathrm{NeT}$ em que as estimativas das fêmeas foram superiores as estimadas pelo MA em todos os níveis do descritor ambiental e praticamente iguais aos machos da mesma linha (Fig. 1).

As estimativas médias da herdabilidade direta para ALT estimadas pelo MNR foram, no geral, mais elevadas que as estimadas pelo MA em todos os níveis do descritor ambiental para as três linhas de seleção (Fig. 1), sendo que os valores estimados para as fêmeas foram mais próximos dos valores estimados pelo MA em comparação aos machos, sendo que os valores dos coeficientes de herdabilidade variaram de 0,61 a 0,$64 ; 0,69$ a 0,79 ; e 0,60 e 0,62 para machos e 0,58 a 0,59; 0,52 a 0,61; e 0,61 a 0,70 para fêmeas das linhas $\mathrm{NeC}, \mathrm{NeS}$ e $\mathrm{NeT}$, respectivamente.

As estimativas médias da herdabilidade direta para PE estimadas pelo MNR foram ligeiramente superiores aos valores estimados pelo MA, em todo o descritor ambiental para os animais das linhas $\mathrm{NeC}$ e $\mathrm{NeT}$ (variando de 0,55 a 0,66 e 0,56 a 0,68, respectivamente). Para 
linha NeS, os valores foram próximos aos estimados pelo MA nos ambientes desfavoráveis e superiores nos ambientes intermediários e superiores (variando de 0,46 a 0,58).

Para o DPP, as estimativas médias de herdabilidade direta estimadas pelo MNR foram próximas às estimadas no MA apenas nos ambientes desfavoráveis, enquanto que nos ambientes favoráveis a herdabilidade foi superior à obtida no MA, para todas as linhas de seleção, sendo que os valores dos coeficientes de herdabilidade variaram de 0,26 a 0,57; 0,10 a 0,26; e 0,06 a 0,44 para as linhas $\mathrm{NeC}, \mathrm{NeS}$ e $\mathrm{NeT}$, respectivamente.
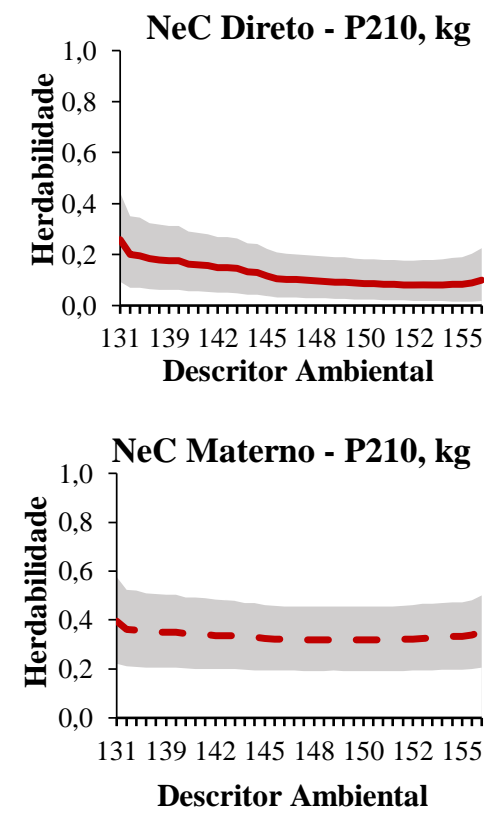

NeC Machos - PS, kg

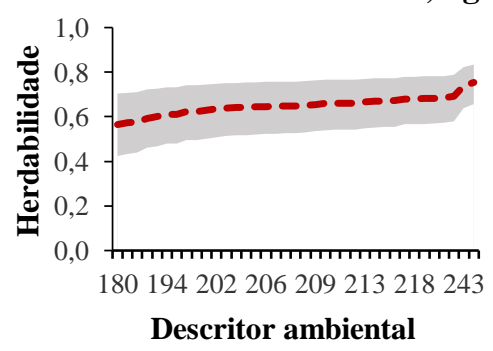

NeC Fêmeas - PS, kg

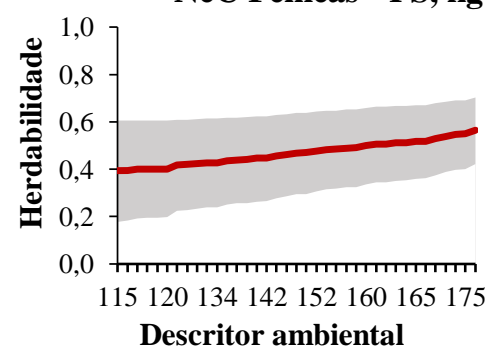

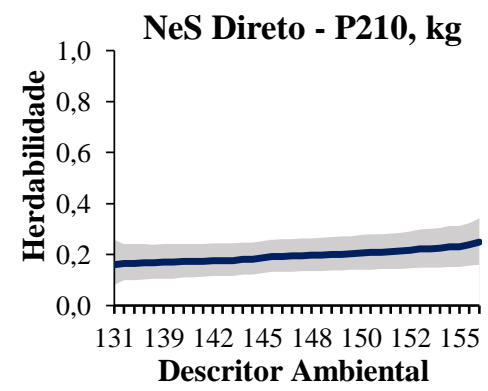

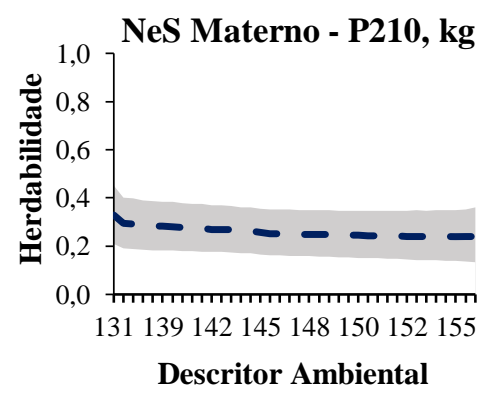

NeS Machos - PS, kg

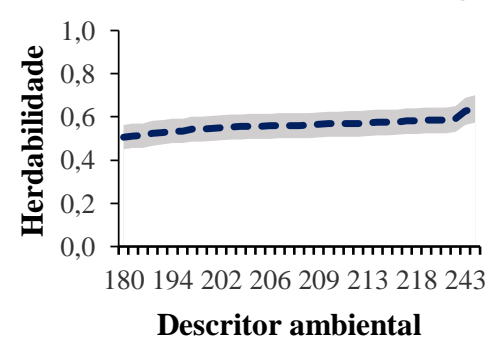

NeS Fêmeas - PS, kg

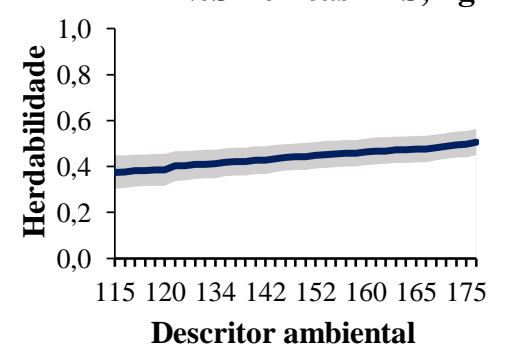

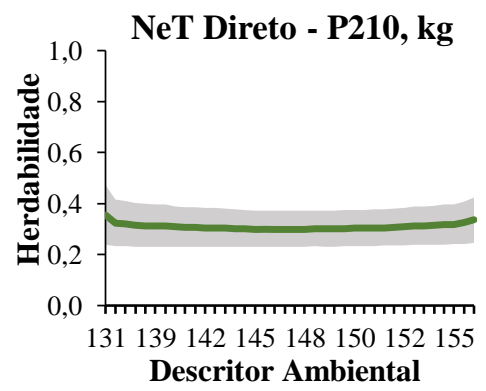

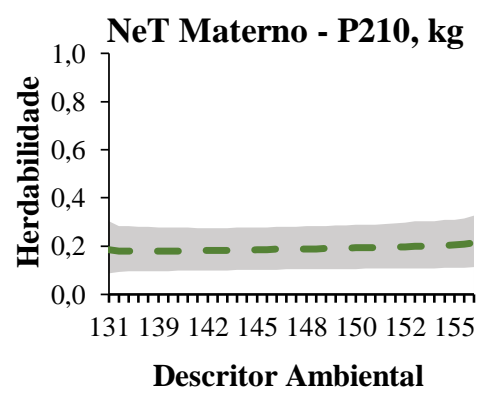

NeT Machos - PS, kg

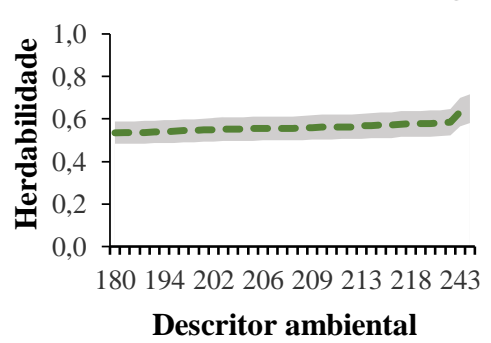

NeT Fêmeas - PS, kg

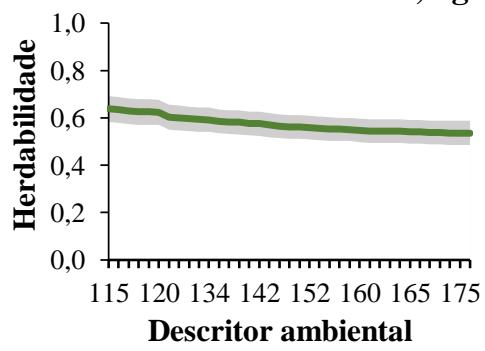



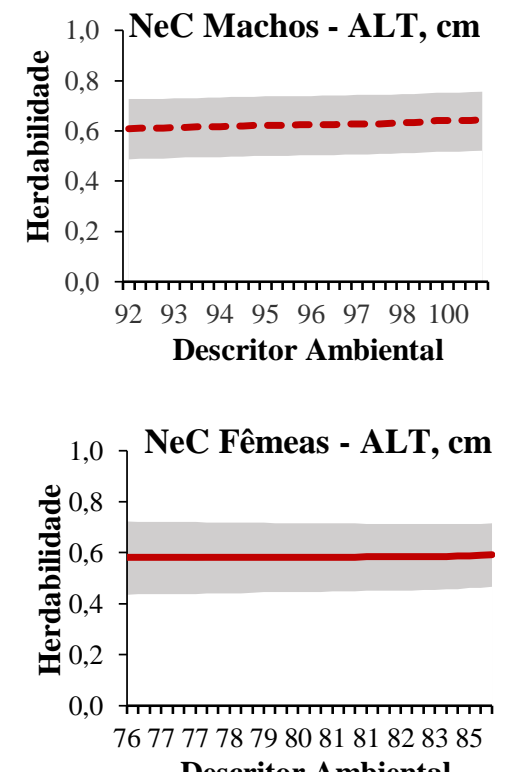

Descritor Ambiental
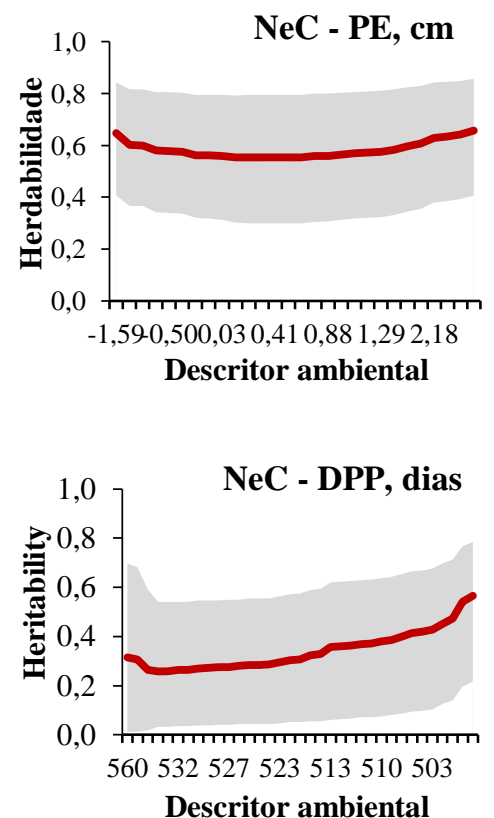
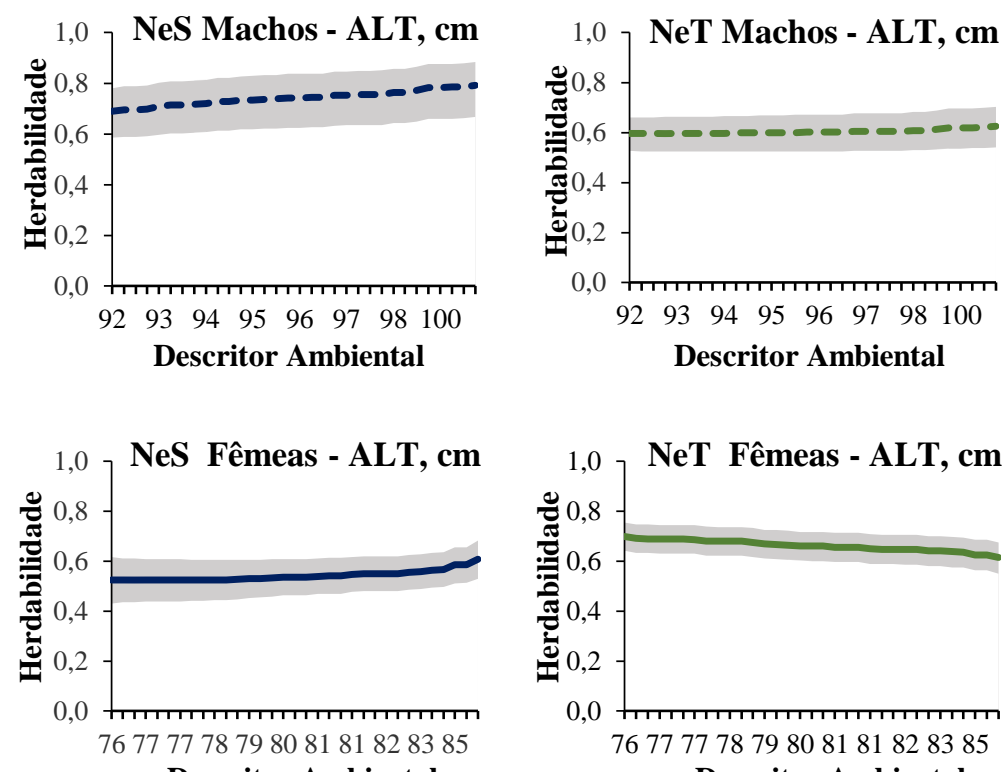

Descritor Ambiental
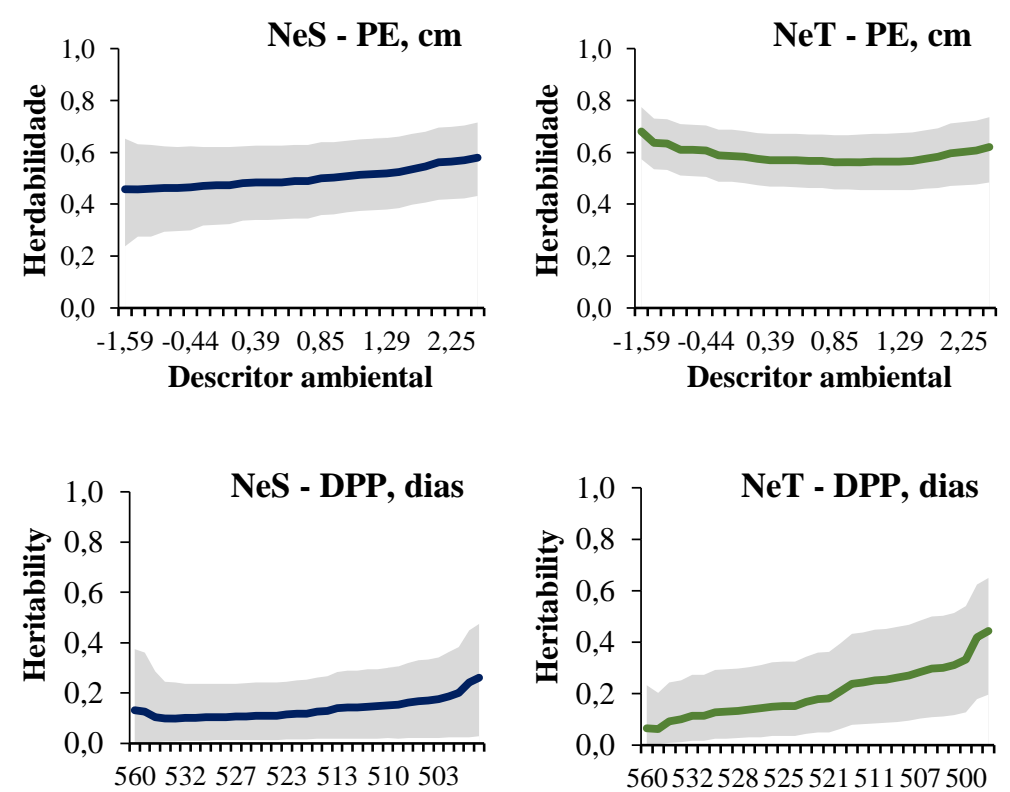

Descritor ambiental

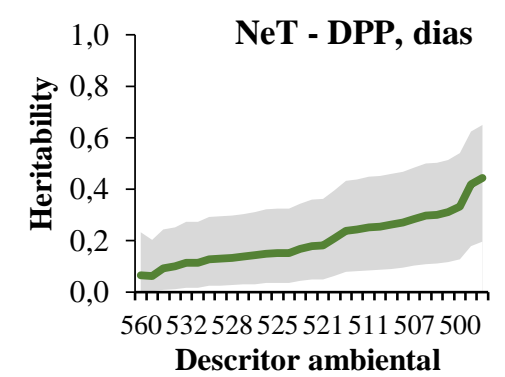

Figura 1. Coeficientes de herdabilidade diretos e maternos ao longo do descritor ambiental determinado pelas amplitudes das soluções dos GC para peso a desmama padronizado (P210, kg), diretos para peso a seleção (PS, $\mathrm{kg}$ ) de machos e fêmeas, altura da garupa (ALT, $\mathrm{cm}$ ) de machos e fêmeas, perímetro escrotal (PE, cm) e dias para o primeiro parto (DPP, dias) para as três linhas de seleção (NeC, linha controle; $\mathrm{NeS}$, linha seleção; NeT, linha tradicional) de bovinos Nelore.

Por meio da Figura 1, foi possível observar que para a linha $\mathrm{NeC}$, ocorreu um ligeiro decréscimo das estimativas de dos coeficientes de herdabilidade direta e materna para P210 de acordo com a melhoria do ambiente. A média de herdabilidade direta do P210 para linha NeS foi crescente e materna ligeiramente decrescente em resposta a melhoria do ambiente. Já a linha $\mathrm{NeT}$ apresentou pouca variação entre os extremos opostos tanto para a herdabilidade direta, quanto para a materna do P210. 
As estimativas médias dos coeficientes de herdabilidade para o efeito aditivo para o PS obtidas em ambientes extremo opostos foram em sua maioria crescente em resposta a melhoria do ambiente, com exceção das fêmeas da linha NeT que apresentaram herdabilidade direta decrescente ao longo do descritor ambiental (Fig. 1). Estes resultados indicam que a resposta à seleção pode ser diferente dependendo do ambiente e até mesmo do sexo. Os coeficientes de herdabilidade diretas para ALT em ambientes extremos opostos foram próximas, tanto para machos quanto para fêmeas da linha $\mathrm{NeC}$ e machos da linha $\mathrm{NeT}$, para as demais linhas houve uma pequena diferença (Fig. 1). Também foi possível observar que a linha NeS mostrou uma herdabilidade direta ligeiramente crescente em resposta à melhoria do ambiente.

Os coeficientes de herdabilidade obtidos para PE em ambientes extremos opostos foram próximos para animais das linhas $\mathrm{NeC}$ e $\mathrm{NeT}$, e para a linha $\mathrm{NeS}$ houve uma pequena diferença, sendo possível observar que essa linha apresentou estimativa de herdabilidade ligeiramente crescente em resposta à melhoria do ambiente. Nesse sentido, a resposta à seleção pode ser diferente dependendo do ambiente (Fig. 1). Observou-se uma tendência crescente de herdabilidade direta para DPP em resposta à melhoria do ambiente para as três linhas de seleção (Fig. 1), sendo que a linha NeS foi o que apresentou o menor aumento, diferentemente das demais características.

As correlações genéticas diretas e maternas entre o intercepto e a inclinação para o P210 foram, respectivamente, $-0,62(0,24)$ e $-0,29(0,20) ; 0,32(0,26)$ e $-0,21(0,23)$ e $-0,02(0,15)$ e $0,10(0,26)$ para as linhas $\mathrm{NeC}$, NeS e NeT, respectivamente, com exceção da correlação genética para a linha $\mathrm{NeC}$, as demais podem ser consideradas baixas ou até mesmo nulas, pois devido ao alto desvio-padrão das mesmas foram estatisticamente iguais a zero, podendo implicar na reclassificação dos animais em ambientes distintos.

As correlações genéticas entre o intercepto e a inclinação da norma de reação para PS foram $0,75(0,14)$ e $0,81(0,13)$ para as linhas $\mathrm{NeC}$ e NeS, respectivamente e nula para a linha NeT 0,03 (0,06). A correlação nula entre a intercepção e a inclinação obtida para a linha NeT pode implicar na reclassificação dos animais em ambientes distintos, sendo que a seleção para PS, basicamente, levará a pouca ou nenhuma resposta correlacionada na sensibilidade ambiental dos animais. As correlações genéticas diretas entre o intercepto e a inclinação para ALT foram 0,29 $(0,26)$ para a linha NeC; $0,63(0,12)$ para a linha NeS e $-0,19(0,07)$ para a linha NeT. A linha NeT apresentou correlação entre a intercepção e a inclinação negativa podendo novamente implicar na reclassificação dos animais em diferentes ambientes. Embora 
o valor estimado para a linha $\mathrm{NeC}$ seja mediano, seu desvio-padrão foi elevado, sugerindo uma possível reclassificação dos animais em ambientes distintos.

As correlações genéticas entre o intercepto e a inclinação para PE foram 0,02 (0,22); $0,39(0,33)$ e $-0,14(0,12)$ para as linhas $\mathrm{NeC}$, NeS e NeT, respectivamente, sendo estas consideradas baixas ou até mesmo nulas, devido ao alto desvio-padrão, o que também pode implicar na reclassificação dos animais das três linhas de seleção em ambientes distintos, indicando que os melhores animais em um ambiente não são necessariamente os mesmos no outro.

Para a DPP, as correlações genéticas entre o intercepto e a inclinação foram de -0,49 $(0,44) ;-0,42(0,54)$ e $-0,87(0,17)$ para as linhas $\mathrm{NeC}, \mathrm{NeS}$ e NeT, respectivamente, assim como ocorreu com outras características, as correlações das linhas $\mathrm{NeC} \mathrm{e} \mathrm{NeS} \mathrm{podem} \mathrm{ser} \mathrm{consideradas}$ nulas devido ao alto desvio padrão associado, indicando que o intercepto e a inclinação parecem ser geneticamente independentes, o que também pode ser indicativo de reclassificação dos animais em diferentes ambientes. O que não foi observado para a linha $\mathrm{NeT}$, pois à medida que o ambiente melhorou os animais responderam com redução de DPP.

As correlações genéticas diretas entre os P210 nos ambientes extremos opostos foram consideradas: baixa para a linha $\mathrm{NeC}(-0,11)$ e moderadas para as linhas $\mathrm{NeS}$ e $\mathrm{NeT}(0,67$ e 0,52 , respectivamente). Estes resultados indicam que para a característica P210, nas linhas NeS e NeT uma parte dos mesmos genes são responsáveis por essas características em ambientes opostos. As correlações genéticas entre os P210 nos ambientes intermediários e extremos também foram altas para as três linhas variando entre 0,80 e 0,96 para os ambientes favoráveis e entre moderado e alto para ambientes desfavoráveis com valores variando entre 0,50 e 0,96 (Fig. 2). As correlações genéticas maternas entre os P210 nos ambientes extremos opostos foram consideradas: moderadas para as três linhas sendo 0,31, 0,66 e 0,62 para as linhas $\mathrm{NeC}$, $\mathrm{NeS}$ e NeT, respectivamente. Estes resultados implicam que para o efeito materno da característica P210, principalmente para as linhas NeS e NeT uma parte dos mesmos genes são responsáveis por essas características em ambientes opostos. As correlações genéticas maternas entre os P210 nos ambientes intermediários e extremos também foram altas para as três linhas variando entre 0,82 e 1,0 para os ambientes favoráveis e variando entre 0,80 e 1,0 para ambientes desfavoráveis (Fig. 2) indicando IGA tipo escala.

As correlações genéticas entre os PS nos ambientes extremos opostos foram consideradas altas para todas as linhas, sendo 0,95 e 0,$80 ; 0,98$ e 0,95 , e 0,78 e 0,81 para machos 
e fêmeas das linhas $\mathrm{NeC}, \mathrm{NeS}$ e $\mathrm{NeT}$, respectivamente. As correlações genéticas entre os PS nos ambientes intermediários e extremos também foram altas tanto machos quanto para fêmeas das três linhas variando entre 0,92 e 1 para os ambientes favoráveis e entre 0,93 e 0,99 para os desfavoráveis (Fig. 2) também indicando IGA tipo escala. As correlações genéticas entre os ALT nos ambientes extremos opostos foram consideradas altas para todas as linhas, sendo 0,98 e 0,97; 0,97 e 0,79, e 0,92 e 0,93 para machos e fêmeas das linhas $\mathrm{NeC}, \mathrm{NeS}$ e $\mathrm{NeT}$, respectivamente. As correlações genéticas entre os ALT nos ambientes intermediários e os extremos também foi alta tanto machos quanto para fêmeas das três linhas variando entre 0,94 e 0,99 para os ambientes favoráveis e entre 0,96 e 0,99 para os desfavoráveis, semelhantes aos resultados encontrados para a característica PS (Fig. 2).

As correlações genéticas entre os PE nos ambientes extremos opostos foram moderadas para as linhas $\mathrm{NeC}, \mathrm{NeS}$ e $\mathrm{NeT}(0,28,0,69$ e 0,38, respectivamente) (Fig. 2). As correlações genéticas entre os PE nos ambientes intermediários e os extremos também foi elevada tanto para os ambientes favoráveis $(0,81,0,93$ e 0,91 para as linhas $\mathrm{NeC}, \mathrm{NeS}$ e $\mathrm{NeT}$, respectivamente) quanto para os desfavoráveis $(0,79,0,90$ e 0,85 para as linhas $\mathrm{NeC}, \mathrm{NeS}$ e $\mathrm{NeT}$, respectivamente). Diferentemente do observado nas demais características, as correlações genéticas entre os DPP nos ambientes extremos opostos foram baixas para todas as linhas, sendo $-0,15 ;-0,04$ e $-0,15$ para as linhas $\mathrm{NeC}$, NeS e NeT, respectivamente (Fig. 2). Esses resultados sugerem importante efeito da IGA para essa característica em diferentes ambientes. As correlações genéticas entre os DPP nos ambientes intermediários e os extremos também foi alta para as três linhas variando entre 0,84 e 0,96 para os ambientes favoráveis e variando entre moderada a baixa para as correlações genéticas com os ambientes desfavoráveis $(0,12$ a 0,50$)$.

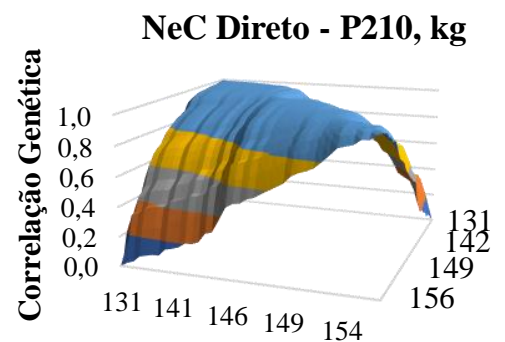

Descritor ambiental

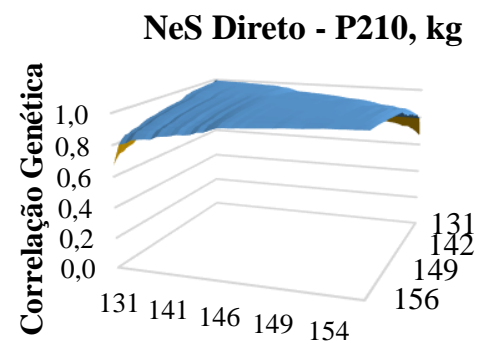

Descritor ambiental

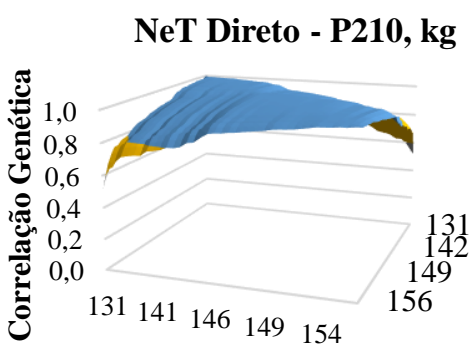

Descritor ambiental 


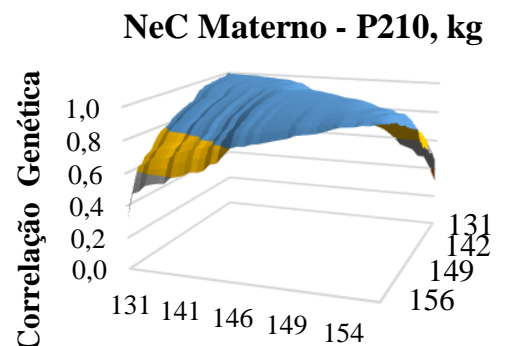

Descritor ambiental

NeC Machos - PS, kg

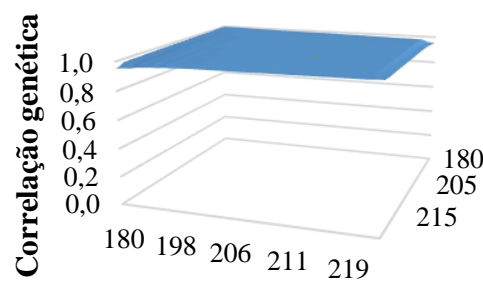

Descritor ambiental

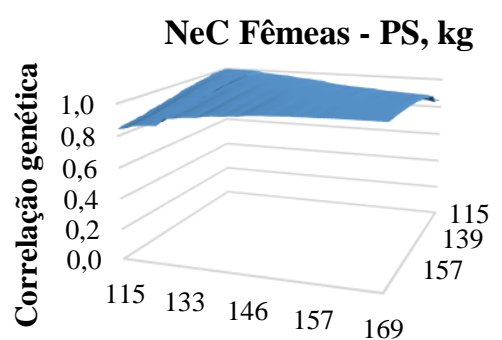

Descritor ambiental

NeC Machos - ALT, cm

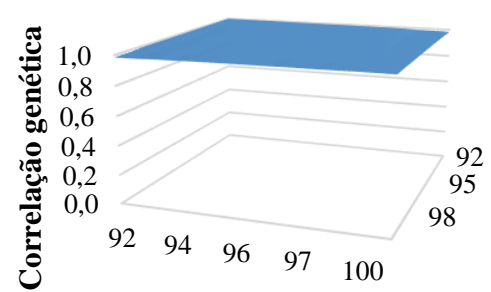

Descritor ambiental

NeC Fêmeas - ALT, cm

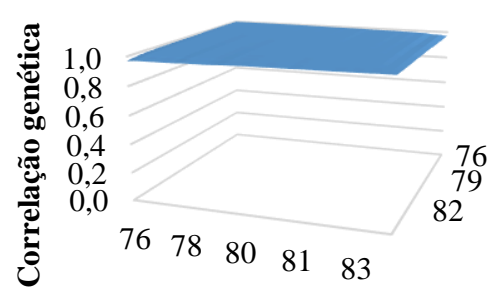

Descritor ambiental

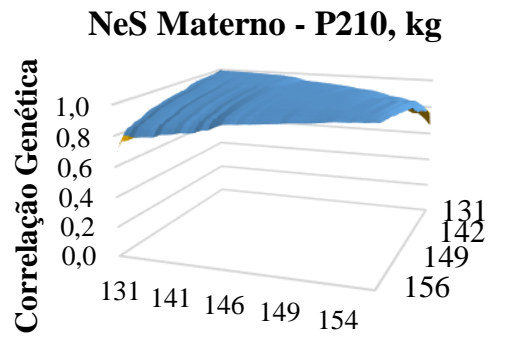

Descritor ambiental

NeS Machos - PS, kg

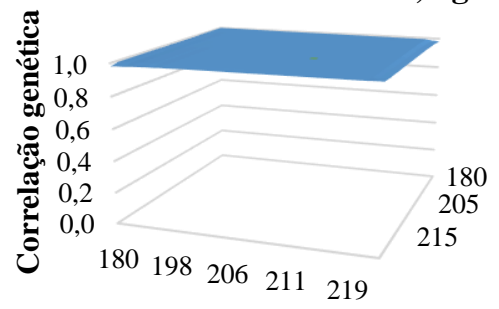

Descritor ambiental

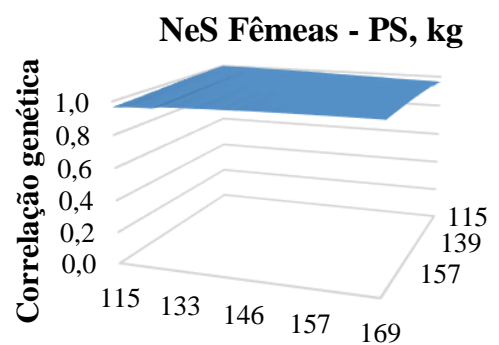

Descritor ambiental

NeS Machos - ALT, cm

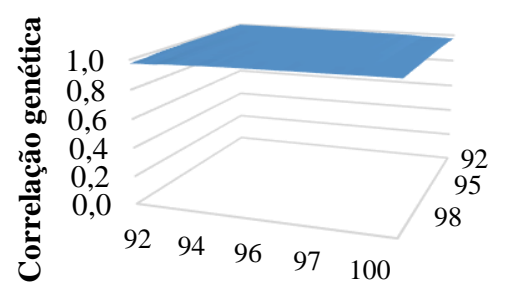

Descritor ambiental

NeS Fêmeas - ALT, cm

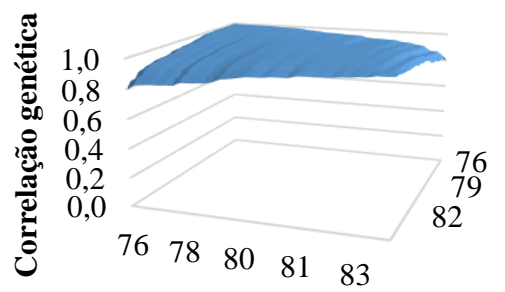

Descritor ambiental

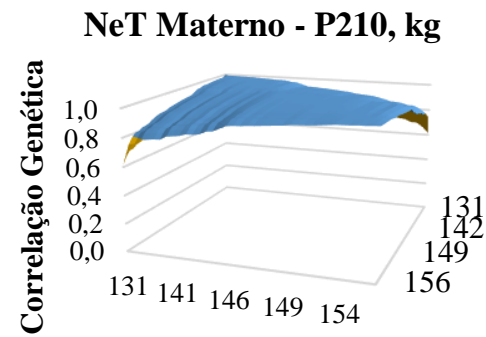

Descritor ambiental

NeT Machos - PS, kg

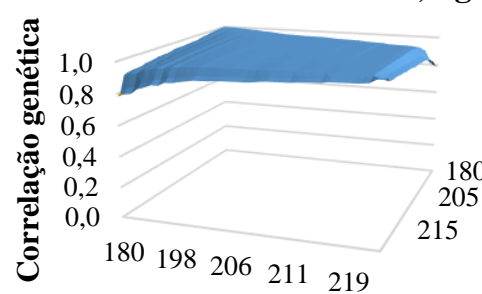

Descritor ambiental

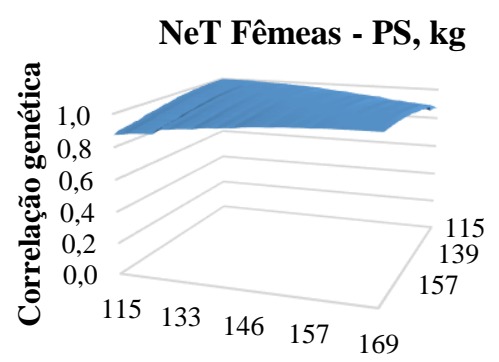

Descritor ambiental

NeT Machos - ALT, cm

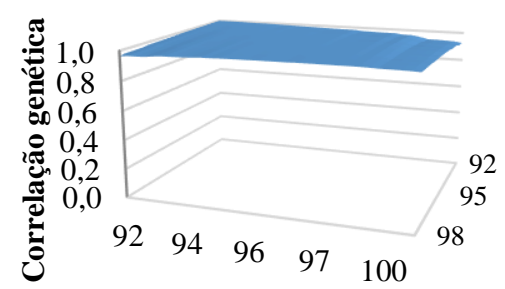

Descritor ambiental

NeT Fêmeas - ALT, cm

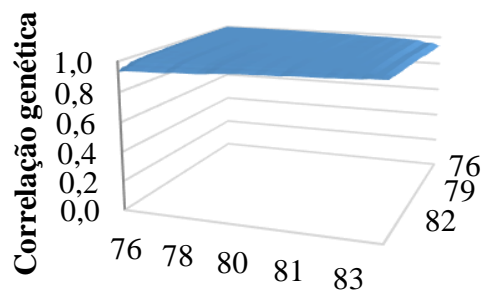

Descritor ambiental 


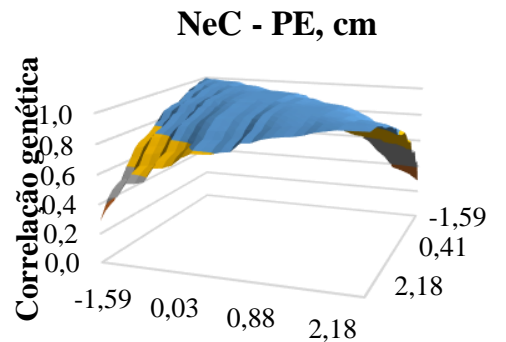

Descritor ambiental

NeC - DPP, dias

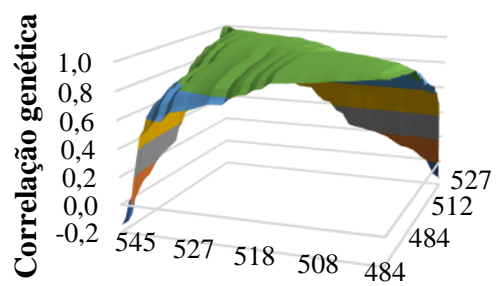

Descritor ambiental

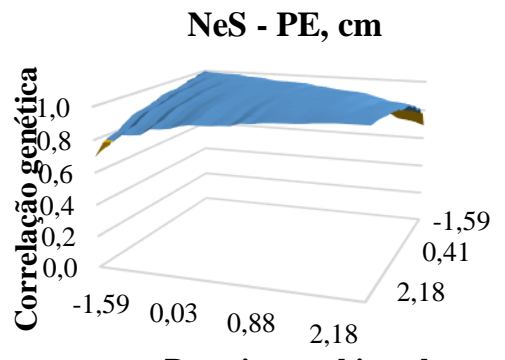

Descritor ambiental

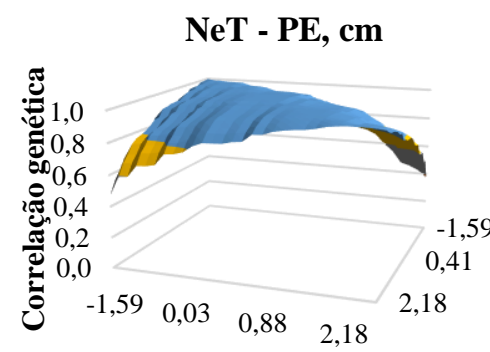

Descritor ambiental

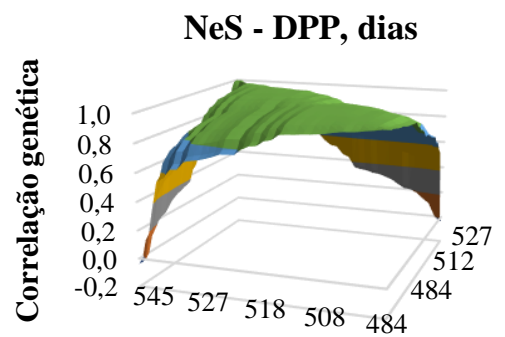

Descritor ambiental

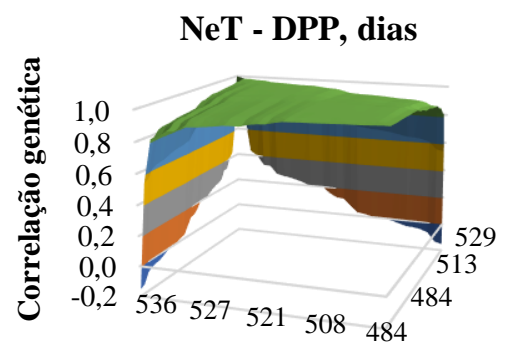

Descritor ambiental

Figura 2. Correlações genéticas diretas e maternas para peso a desmama padronizado (P210); diretas para peso a seleção (PS, kg) de machos e fêmeas; altura da garupa (ALT, cm) de machos e fêmeas; perímetro escrotal (PE, $\mathrm{cm}$ ); e dias para o primeiro parto (DPP, dias) ao longo do descritor ambiental determinado pelas amplitudes das soluções dos GC para as três linhas de seleção (NeC, linha controle; NeS, linha seleção; e NeT, linha tradicional) de bovinos Nelore.

As tendências genéticas diretas e maternas observadas para os coeficientes de regressão relacionados ao P210 (intercepto da norma de reação) foram, respectivamente, 0,01 $(0,01)$ e $0,03(0,04) ; 0,85(0,05)$ e $0,36(0,05)$; e $1,26(0,06)$ e $0,36(0,02) \mathrm{kg} /$ ano para as linhas $\mathrm{NeC}$, $\mathrm{NeS}$ e NeT, respectivamente, sendo que a tendências genéticas tanto direta quanto materna da linha $\mathrm{NeC}$ não foram estatisticamente significativas $(\mathrm{P}>0,05)$ (Fig. 3), indicando que apenas os animais das linhas NeS e NeT tendem a apresentar níveis mais altos de produção para essa característica, além de evidenciar efeito materno significativo para essas linhas, indicando importante melhoria da habilidade materna.

As tendências genéticas diretas observadas para os coeficientes de regressão relacionados ao PS (intercepto da norma de reação) foram de -0,01 $(0,05)$ e $0,09(0,06) ; 2,60$ $(0,13)$ e 2,81 (0,14); e 3,23 (0,18) e 3,52 (0,23) kg/ano para machos e fêmeas, de cada uma das linhas $\mathrm{NeC}, \mathrm{NeS}$ e $\mathrm{NeT}$, respectivamente (Fig. 3), sendo que a tendência genética para a linha $\mathrm{NeC}$ também não foi estatisticamente significativa (P>0,05). As linhas $\mathrm{NeS}$ e NeT tenderam a um nível de produção mais elevado, em especial a linha NeT, o que era esperado uma vez que ambos foram selecionados para maior diferencial de peso pós-desmama. 
Para ALT, as tendências genéticas observadas para os coeficientes de regressão relacionados ao intercepto da norma de reação foram de -0,02 (0,01) e -0,005 $(0,01) ; 0,29(0,03)$ e $0,37(0,02)$; e $0,30(0,02)$ e $0,33(0,03) \mathrm{cm} /$ ano para machos e fêmeas, para as linhas $\mathrm{NeC}$, NeS e NeT, respectivamente, e embora negativos, as tendências para machos e fêmeas da linha $\mathrm{NeC}$ não foram estatisticamente significativas ( $\mathrm{P}>0,05)$ (Fig. 3). As tendências para machos e fêmeas para as linhas NeS e NeT foram significativas e positivas, indicando que apenas os animais destas linhas tenderam a um maior nível de produção.

Para PE, as tendências genéticas observadas para os coeficientes de regressão relacionados ao intercepto da norma de reação foram de $0,01(0,01) ; 0,06(0,01)$ e $0,08(0,01)$ $\mathrm{cm}$ /ano para as linhas $\mathrm{NeC}, \mathrm{NeS}$ e NeT, respectivamente (Fig. 3), e tendência genética da linha $\mathrm{NeC}$ também não foi estatisticamente significativa $(\mathrm{P}>0,05)$, indicando novamente, que apenas os animais das linhas $\mathrm{NeS}$ e NeT tendem a apresentar níveis mais altos de produção para essa característica.

Para DPP, as tendências genéticas observadas para os coeficientes de regressão relacionados ao intercepto da norma de reação foram decrescentes e com valores de -0,56 $(0,06) ;-0,19(0,02)$ e $-0,12(0,01)$ dias/ano para as linhas $\mathrm{NeC}, \mathrm{NeS}$ e NeT, respectivamente (Fig. 3), resultando em novilhas que tendem a ciclar e a parir cada vez mais cedo para todos as linhas, principalmente para a linha $\mathrm{NeC}$.
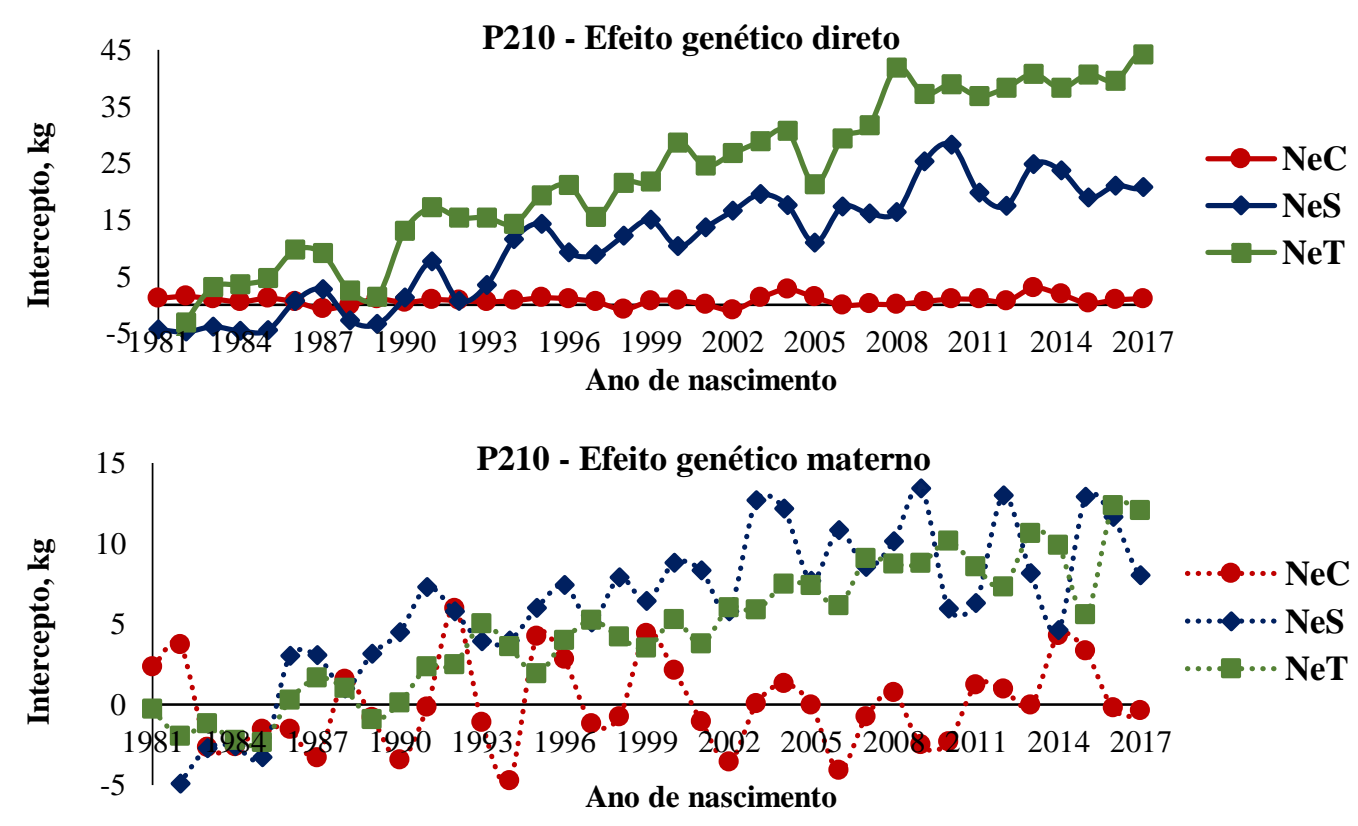

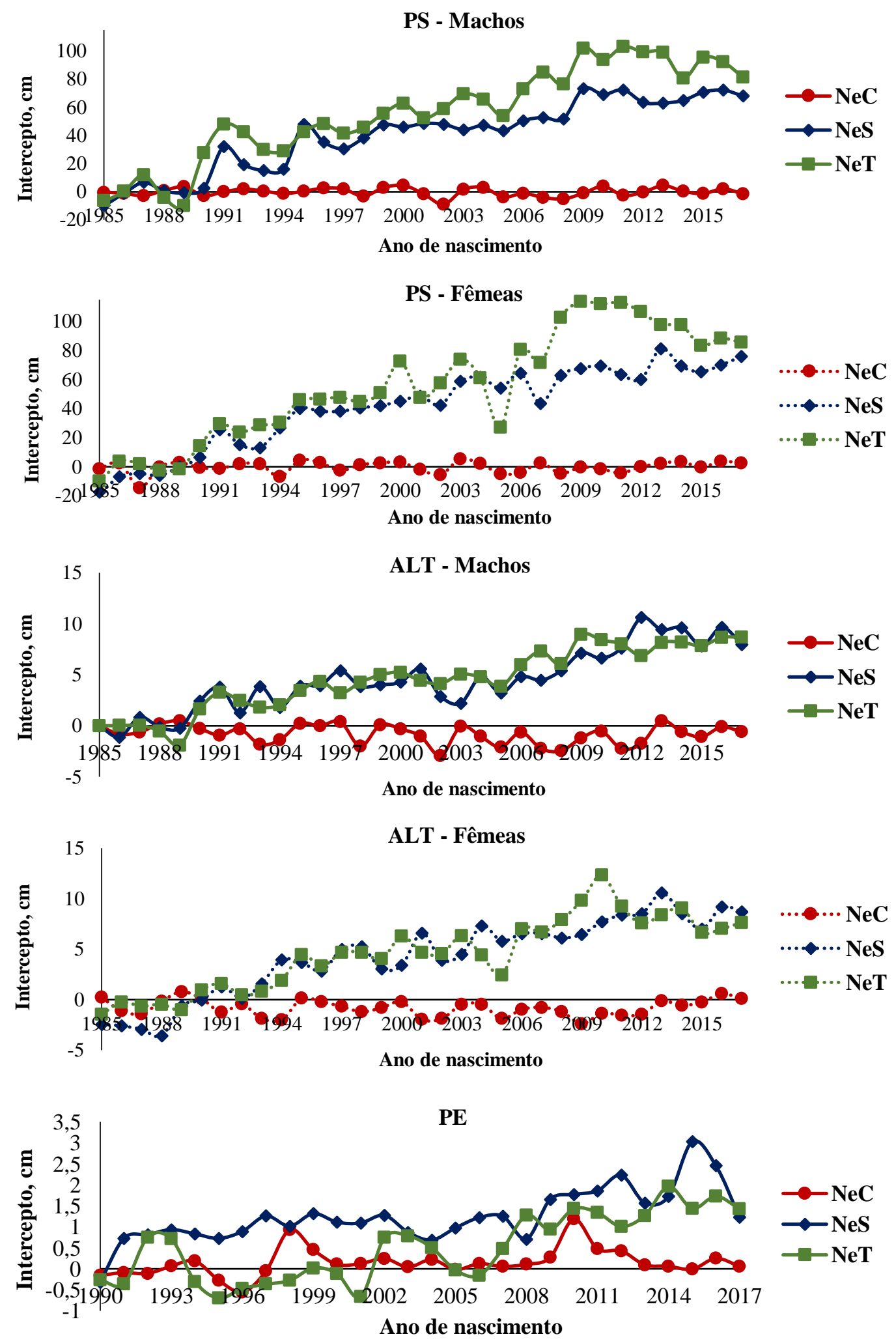


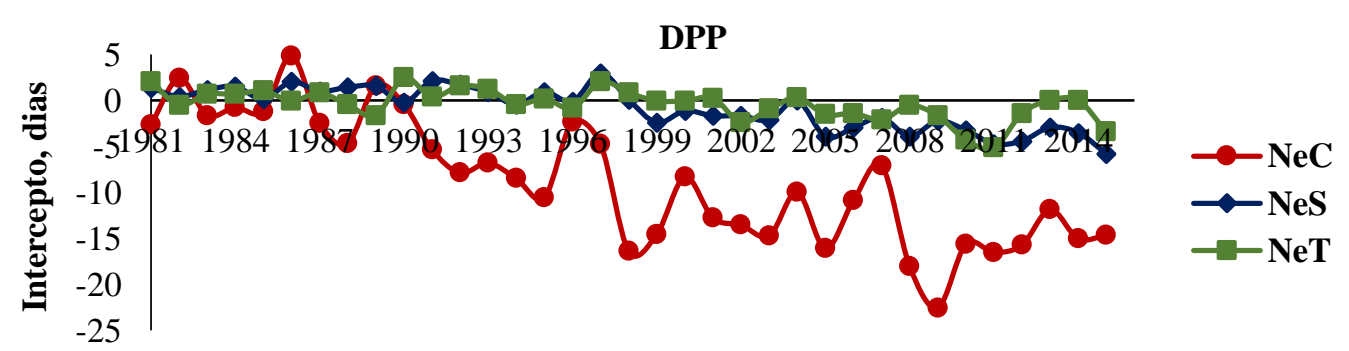

Ano de nascimento

Figura 3. Tendências genéticas dos efeitos diretos e maternos observadas para os coeficientes de regressão relacionados ao intercepto da norma de reação para peso a desmama padronizado (P210, kg), e diretos para peso a seleção (PS, kg) de machos e fêmeas, altura da garupa (ALT, $\mathrm{cm}$ ) de machos e fêmeas, perímetro escrotal (PE, $\mathrm{cm})$ e dias para o primeiro parto (DPP, dias) para as três linhas de seleção estudadas (NeC, linha controle; NeS, linha seleção; e NeT linha tradicional).

As tendências genéticas dos efeitos genéticos direto e materno observadas para os coeficientes de regressão relacionados ao P210 (inclinação da norma de reação) foram, respectivamente $0,003(0,005)$ e $0,02(0,01) ; 0,10(0,01)$ e $-0,003(0,005)$; e $0,10(0,01)$ e 0,05 $(0,003) \mathrm{kg} / \mathrm{ano}$ para as linhas $\mathrm{NeC}, \mathrm{NeS}$ e NeT, respectivamente, (Fig. 4), sendo que os coeficientes de regressão dos efeitos genéticos direto e materno obtidos para linha $\mathrm{NeC}$ e materno para a linha $\mathrm{NeS}$ não foram estatisticamente significativos $(\mathrm{P}>0,05)$, resultado esse que indica que apenas as linhas $\mathrm{NeS}$ e $\mathrm{NeT}$ tendem a um aumento na capacidade desses animais de responder às mudanças ambientais.

As tendências genéticas observadas para os coeficientes de regressão relacionados ao PS (inclinação da norma de reação) foram - $0,003(0,01)$ e $0,004(0,02) ; 0,39(0,02)$ e 0,42 $(0,02)$; e $-0,14(0,06)$ e $-0,13(0,07) \mathrm{kg} / \mathrm{ano}$ para machos e fêmeas da as linhas $\mathrm{NeC}, \mathrm{NeS}$ e $\mathrm{NeT}$, respectivamente (Fig. 4). Os coeficientes de regressão obtidos para ambos os sexos na linha $\mathrm{NeC}$ também não foram estatisticamente significativos $(\mathrm{P}>0,05)$, assim como as fêmeas da linha NeT. Apenas os animais da linha NeS estão se movendo em direção a uma maior sensibilidade, ou seja, estão se tornando mais responsivos às mudanças ambientais.

As tendências genéticas observadas para os coeficientes de regressão relacionados à ALT (inclinação da norma de reação) foram 0,0001 (0,001) e 0,0003 $(0,001) ; 0,05(0,003)$ e $0,05(0,004)$; e $-0,03(0,01)$ e $-0,03(0,01)$ cm/ano para machos e fêmeas das linhas $\mathrm{NeC}, \mathrm{NeS}$ e NeT, respectivamente (Fig. 4), com coeficientes de regressão obtidos para os animais da linha $\mathrm{NeC}$ não foi estatisticamente significativo $(\mathrm{P}>0,05)$, resultado que indica que novamente, apenas os animais da linha NeS tendem a aumentar a capacidade desses animais de responder ao descritor ambiental ao longo dos anos de seleção. Já a linha NeT, que tende a diminuir essa capacidade, para ambos os sexos, sendo menos responsivos a essas mudanças. 
Para PE, as tendências genéticas observadas para os coeficientes de regressão relacionados a inclinação da norma de reação foram -0,004 (0,001); $0,01(0,001)$ e -0,01 $(0,003)$ $\mathrm{cm}$ /ano para as linhas $\mathrm{NeC}, \mathrm{NeS}$ e NeT, respectivamente (Fig. 4), em que mais uma vez, apenas a linha NeS está se movendo em direção a uma maior sensibilidade ou maior capacidade de responder ao meio ambiente. O que não acontece com as linhas $\mathrm{NeC}$ e $\mathrm{NeT}$ que tenderam a diminuir sua capacidade de resposta.

Para a DPP, as tendências genéticas observadas para os coeficientes de regressão relacionados à inclinação da NR foram de $0,17(0,02) ; 0,06(0,01)$ e $0,06(0,01)$ dias/ano para as linhas $\mathrm{NeC}$, NeS e $\mathrm{NeT}$, respectivamente (Fig. 4), indicando que as três linhas, mesmo que lentamente, também estão se movendo em direção a uma maior sensibilidade, para essa característica, principalmente para a linha $\mathrm{NeC}$ que foi a linha que apresentou maiores tendências para intercepto.
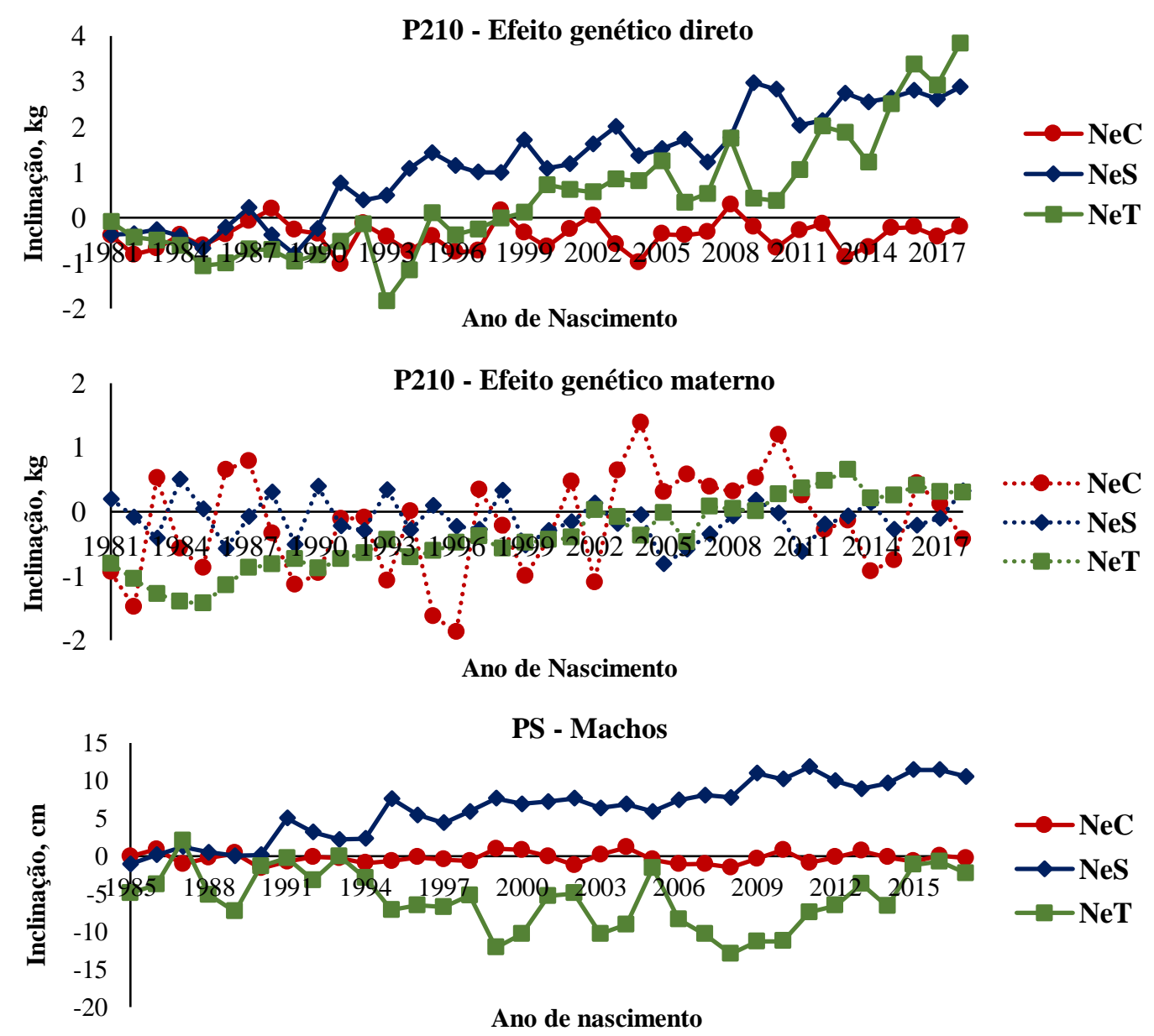

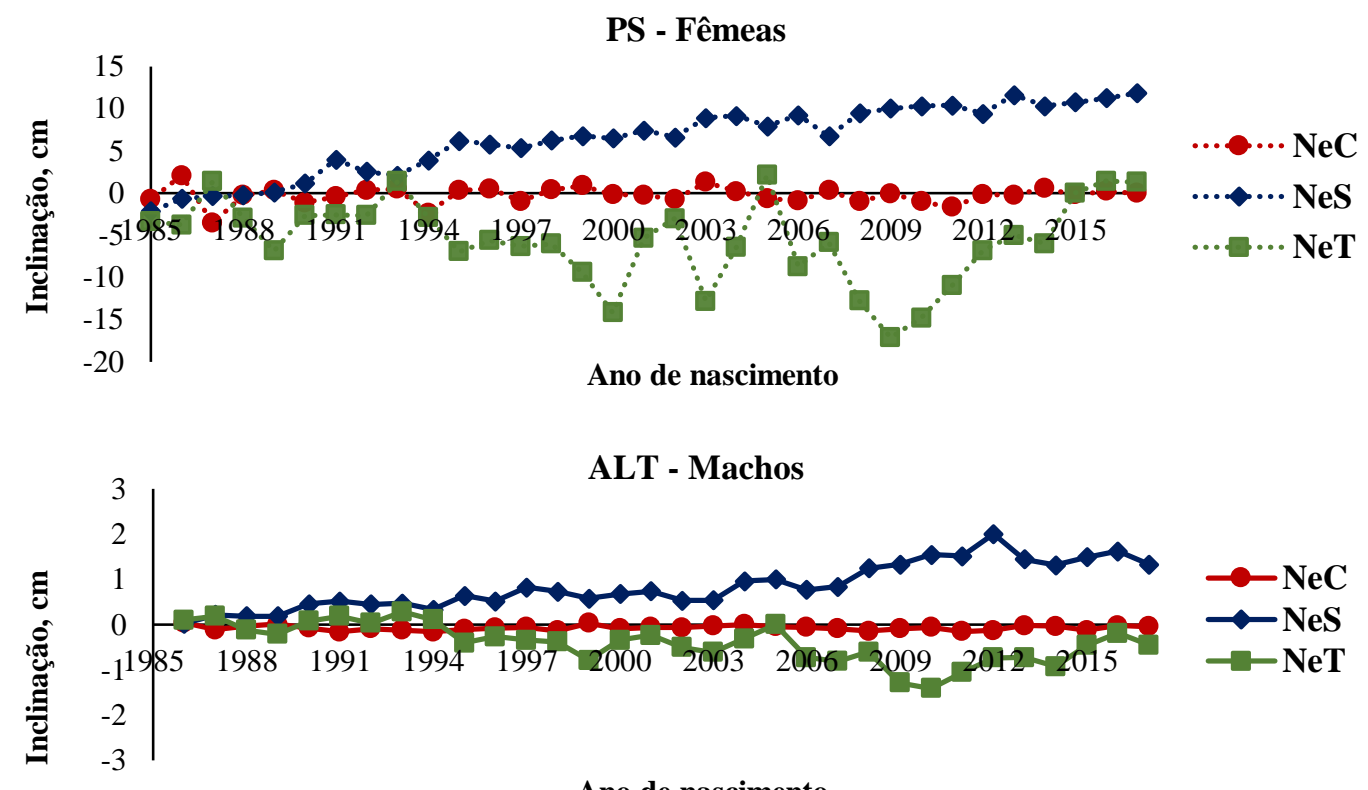

Ano de nascimento

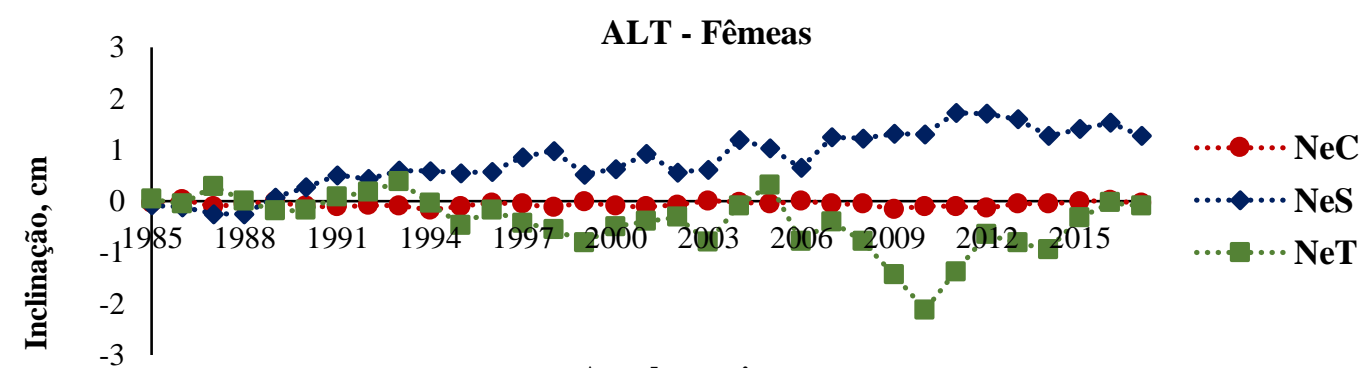

Ano de nascimento

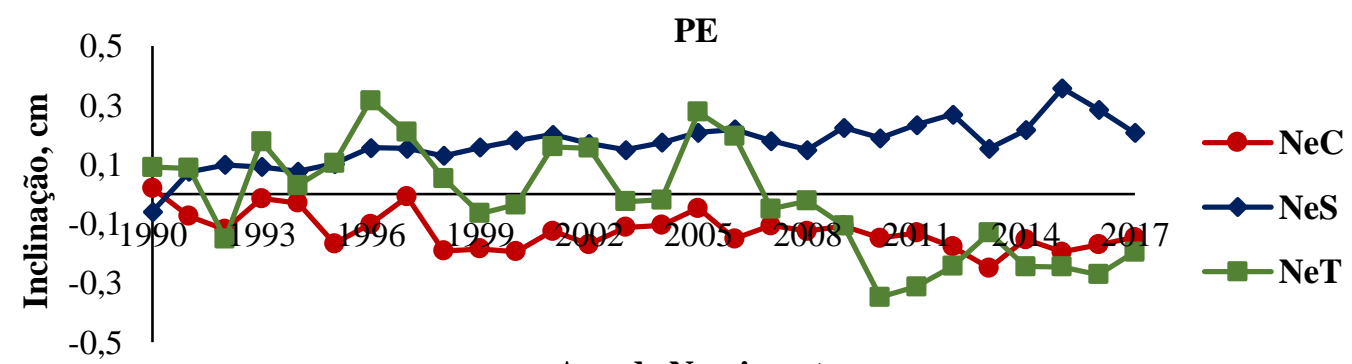

Ano de Nascimento

\section{DPP}

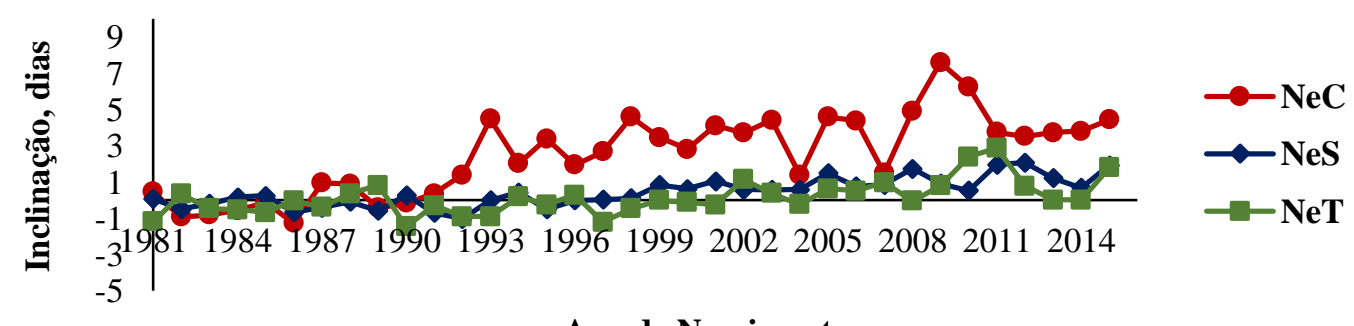

Ano de Nascimento

Figura 4. Tendências genéticas dos efeitos direto e materno observadas para os coeficientes de regressão relacionados a inclinação da norma de reação para peso a desmama padronizado (P210, kg), e diretos para peso a seleção (PS, kg) de machos e fêmeas, altura da garupa (ALT, cm) de machos e fêmeas, perímetro escrotal (PE, $\mathrm{cm})$ e dias para o primeiro parto (DPP, dias) para as três linhas de seleção estudadas (NeC, linha controle; NeS, linha seleção; e NeT linha tradicional). 
As frequências observadas de genótipos robustos, plásticos e extremamente plásticos para P210 evidenciam maior porcentagem de animais robustos nas três linhas, principalmente as linhas $\mathrm{NeC}$ e $\mathrm{NeT}$ (Fig. 5). A linha NeS apresentou maior porcentagem de animais plásticos e extremamente plásticos em relação as demais linhas, com cerca de 48,31\% contra 28,27\% e $22,25 \%$ para as linhas $\mathrm{NeC} \mathrm{e} \mathrm{NeT,} \mathrm{respectivamente.} \mathrm{As} \mathrm{razões} \mathrm{entre} \mathrm{as} \mathrm{variâncias} \mathrm{da} \mathrm{inclinação}$ e do intercepto do efeito aditivo direto para P210 foram 0,40; 0,07; e 0,10 para as linhas $\mathrm{NeC}$, $\mathrm{NeS}$ e NeT, respectivamente, indicando que as linhas NeS e NeT tem menor variabilidade genética associada à sensibilidade ambiental. Para o efeito genético materno, a proporção de genótipos robustos também foi elevada nas três linhas, porém sem muita diferença entre as mesmas, e o mesmo ocorre com os genótipos plástico e extremamente plástico, com proporções praticamente iguais $(30,45 ; 30,35$ e 33,45\% para as linhas $\mathrm{NeC}, \mathrm{NeS}$ e $\mathrm{NeT}$, respectivamente). Já as razões entre as variâncias da inclinação e do intercepto foram 0,18; 0,07; e 0,07 para as linhas $\mathrm{NeC}, \mathrm{NeS}$ e $\mathrm{NeT}$, respectivamente, menores que a as razões estimadas para o efeito aditivo direto (Fig. 5).

Os resultados para PS indicam que foi possível verificar diferenças importantes na sensibilidade ambiental, principalmente a linha NeS, sendo que a linha com maior proporção de genótipos plásticos e extremamente plásticos com 54,80\% para machos e 56,31\% para fêmeas. Para as demais linhas as porcentagens foram 30,98\% e 30,83\% para machos e fêmeas da linha $\mathrm{NeC}$ e 38,91\% e 35,51\% para machos e fêmeas da linha NeT (Fig. 5). A razão entre as variâncias da inclinação e do intercepto para PS foram 0,13; 0,04; e 0,20 para as linhas $\mathrm{NeC}$, $\mathrm{NeS}$ e NeT, respectivamente, indicando que a linha NeS tem menor variabilidade genética associada à sensibilidade ambiental proporcionalmente ao intercepto, ao contrário da linha $\mathrm{NeT}$ que foi a que apresentou a maior variabilidade entre as linhas. Os resultados para ALT mostram uma porcentagem maior de animais robustos nas linhas $\mathrm{NeC}$ e $\mathrm{NeT}$, enquanto a linha $\mathrm{NeS}$ tem uma porcentagem maior de animais plásticos e extremamente plásticos, cerca de 52,30\% dos machos e 54,39\% das fêmeas. Nas demais linhas, esse percentual foi de $31,95 \%$ e $36,11 \%$, e $35,42 \%$ e 33,06\% para machos e fêmeas das linhas $\mathrm{NeC}$ e NeT, respectivamente (Fig. 5). A razão entre as variâncias para cada linha foram 0,$03 ; 0,16$ e 0,10 , sendo que para essa característica a linha $\mathrm{NeC}$ foi a que apresentou menor variabilidade genética associada à sensibilidade ambiental.

Os resultados para PE, seguiram a tendência dos resultados encontrados para as demais características, indicando que também foi possível verificar diferenças importantes na sensibilidade ambiental em relação a essa característica, principalmente para a linha NeS que 
apresentou genótipos mais plásticos, corroborando a tendência genética positiva para inclinação, com percentual de genótipos plásticos e extremamente plásticos sendo 34,28\%; $51,26 \%$ e 32,23\%, para as linhas $\mathrm{NeC}$, NeS e NeT, respectivamente (Fig. 5). A razão entre inclinação e intercepto para PE foram 0,19;0,06; e 0,15 para as linhas $\mathrm{NeC}, \mathrm{NeS}$ e $\mathrm{NeT}$, respectivamente, indicando que a linha $\mathrm{NeS}$ também tem menor variabilidade genética associada à sensibilidade ambiental proporcionalmente ao intercepto. Os resultados da razão entre as variâncias da inclinação e do intercepto para DPP foram 0,44;0,36; e 0,39 para as linhas $\mathrm{NeC}, \mathrm{NeS}$ e $\mathrm{NeT}$, respectivamente, indicado uma maior variabilidade genética associada à sensibilidade ambiental para DPP, porém essa característica possui uma alta porcentagem de animais robustos nas três linhas $(58,76 \%, 67,39 \%$ e 67,38\% para as linhas NeC, NeS e NeT, respectivamente) (Fig. 5). No entanto, foi possível notar pelas tendências genéticas para os coeficientes de regressão relacionados a inclinação que, mesmo com uma alta porcentagem de animais robustos, foi constatada tendência crescente da sensibilidade ambiental desses animais.
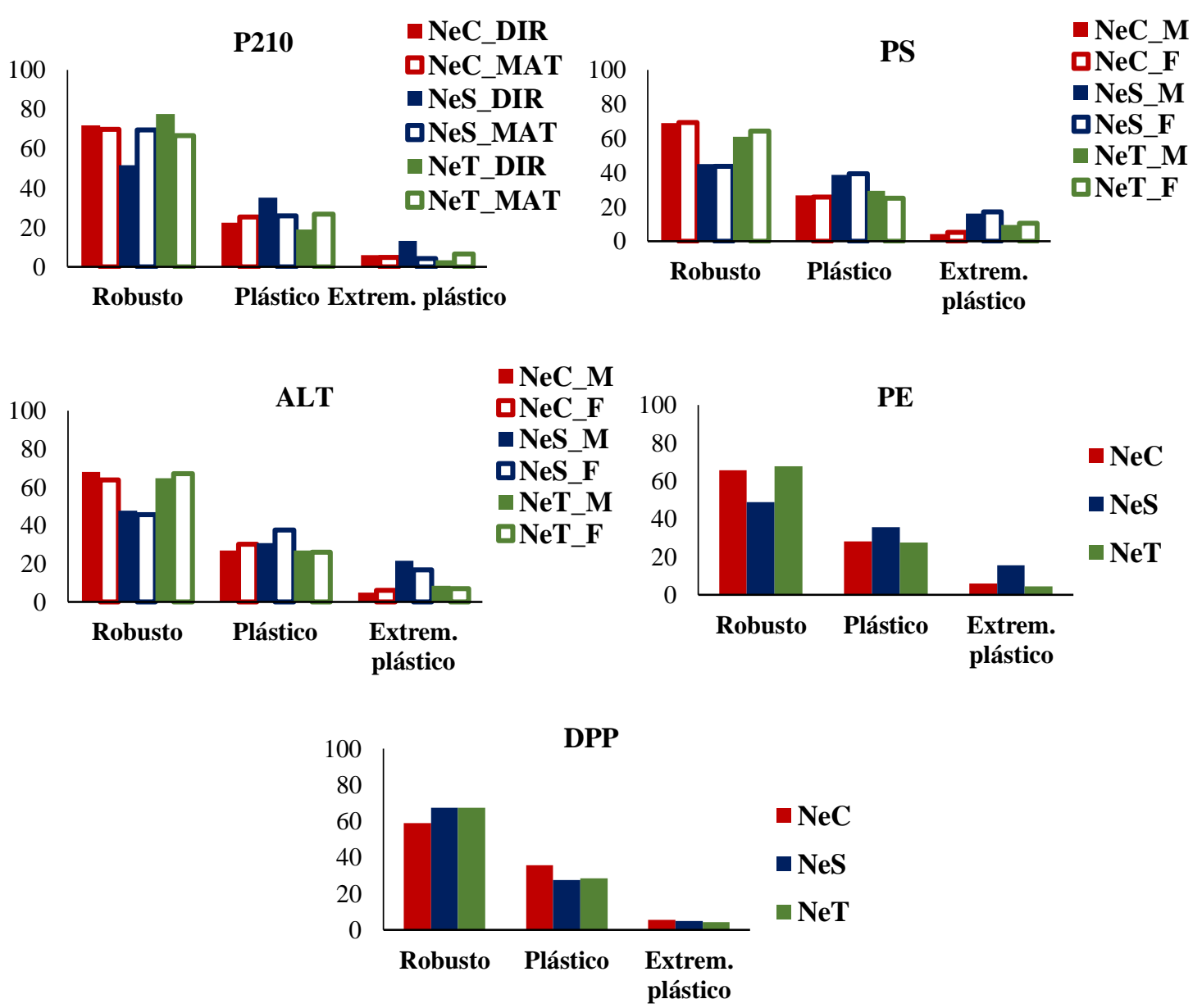

Figura 5. Frequências observadas de genótipos robustos, plásticos e extremamente plásticos para peso a desmama padronizado (P210, kg), peso a seleção (PS, kg), altura da garupa (ALT, cm), perímetro escrotal (PE, cm) e dias 
para o primeiro parto (DPP, dias) para as três linhas estudadas para as três linhas de seleção estudadas; $\mathrm{NeC}$, linha controle; NeS, linha seleção; e NeT linha tradicional; _M, machos; _F, fêmeas; _DIR, efeito genético aditivo direto;_MAT, efeito genético aditivo materno.

Por meio das correlações de Spearman, foi possível identificar potenciais mudanças na classificação dos $25 \%$ melhores reprodutores de cada linha de seleção em diferentes ambientes (Tabela 4). As correlações entre o ambiente favorável e o MA para a característica P210 foram: baixa e não significativa $(\mathrm{P}>0,05)$ para a linha $\mathrm{NeC}$ e altas para as demais. A correlação entre os ambientes favorável e o intermediário também foi baixa e não significativa $(\mathrm{P}>0,05)$ para a linha $\mathrm{NeC}$ e alta para as demais. Já a correlação entre os ambientes favorável e desfavorável foi baixa, negativa e não significativa $(\mathrm{P}>0,05)$ para a linha $\mathrm{NeC}$, alta para a linha $\mathrm{NeS}$ e moderada para a linha NeT.

Para o PS, as correlações entre o ambiente favorável e o MA foram moderadas para as linhas $\mathrm{NeC}$ e $\mathrm{NeT}$ e alta para a linha $\mathrm{NeS}$, assim como as correlações entre os ambientes favorável e o intermediário que também foram medianas para as linhas $\mathrm{NeC}$ e $\mathrm{NeT}$ e alta para a linha NeS, já as correlações entre os ambientes favorável e desfavorável foram baixas e não significativas $(\mathrm{P}>0,05)$ para as linhas $\mathrm{NeC}$ e $\mathrm{NeT}$ e alta para a linha NeS. As correlações entre o ambiente favorável e o MA para a característica ALT foram baixas e não significativas $(\mathrm{P}>0,05)$ todas as linhas. A correlação entre os ambientes favorável e o intermediário foi alta apenas para a linha $\mathrm{NeC}$ e moderada para as demais. A correlação entre os ambientes favorável e desfavorável também foi alta para a linha $\mathrm{NeC}$, e moderada para as demais linhas.

Para o PE, as correlações entre o ambiente favorável e o MA foram altas para as linhas $\mathrm{NeC}$ e NeS e moderada para a linha NeT, assim como ocorreu com as correlações entre melhor ambiente com o intermediário. Já as correlações entre os ambientes opostos foram medianas para as linhas $\mathrm{NeC}$ e $\mathrm{NeT}$ e alta para a linha NeS. Sendo que todas as correlações da linha NeT foram menores que 0,80. Para o DPP, todas as correlações entre o ambiente favorável e o MA, o ambiente favorável e os intermediário e desfavoráveis foram menores que 0,80 , para todas as linhas, sendo que apenas as correlações da linha NeS foram significativas $(\mathrm{P}<0,05)$, indicando reclassificação dos animais de todas as linhas para essa característica. 
Tabela 4. Correlações de Spearman entre 25\% melhores touros por valores genéticos para peso ao desmame padronizado (P210, $\mathrm{kg}$ ), peso a seleção (PS, kg), altura da garupa (ALT, cm), perímetro escrotal (PE, cm) e dias para o primeiro parto (DPP, dias) para as três linhas estudadas ( $\mathrm{NeC}$, linha controle; $\mathrm{NeS}$, linha seleção; $\mathrm{NeT}$, linha tradicional), obtidos pelo modelo animal padrão (MA) e pelo modelo de norma de reação (MNR) em diferentes ambientes (favorável com maiores valores das soluções dos GC; médio, com as soluções intermediárias dos GC; e desfavorável, com os valores mais baixos das soluções dos GC).

\begin{tabular}{|c|c|c|c|c|c|c|c|c|c|}
\hline \multicolumn{10}{|c|}{ P210 } \\
\hline & \multicolumn{3}{|c|}{$\mathrm{NeC}$} & \multicolumn{3}{|c|}{ NeS } & \multicolumn{3}{|c|}{ NeT } \\
\hline & Desfavorável & Médio & MA & Desfavorável & Médio & MA & Desfavorável & Médio & MA \\
\hline Favorável & $-0,19^{\mathrm{NS}}$ & $0,26^{\mathrm{NS}}$ & $0,33^{\mathrm{NS}}$ & $0,90^{* *}$ & $0,97^{* *}$ & $0,95^{* *}$ & $0,58^{* *}$ & $0,88^{* *}$ & $0,87^{* *}$ \\
\hline \multicolumn{10}{|c|}{ PS } \\
\hline & Desfavorável & Médio & MA & Desfavorável & Médio & MA & Desfavorável & Médio & MA \\
\hline Favorável & $0,18^{\mathrm{NS}}$ & $0,67^{* * *}$ & $0,64^{* *}$ & $0,81^{\text {*** }}$ & $0,95^{* *}$ & $0,92^{* *}$ & $0,07^{* *}$ & $0,41^{* *}$ & $0,42^{* *}$ \\
\hline \multicolumn{10}{|c|}{ ALT } \\
\hline & Desfavorável & Médio & MA & Desfavorável & Médio & MA & Desfavorável & Médio & MA \\
\hline Favorável & $0,84^{\text {*** }}$ & $0,91^{\text {*** }}$ & $-0,26^{\mathrm{NS}}$ & $0,51^{\text {*** }}$ & $0,76^{* *}$ & $0,02^{\mathrm{NS}}$ & $0,46^{* *}$ & $0,63^{* *}$ & $0,03^{\mathrm{NS}}$ \\
\hline \multicolumn{10}{|c|}{ PE } \\
\hline & Desfavorável & Médio & MA & Desfavorável & Médio & MA & Desfavorável & Médio & MA \\
\hline Favorável & $0,56^{*}$ & $0,83^{* *}$ & $0,80^{* *}$ & $0,87^{* *}$ & $0,96^{* *}$ & $0,96^{* *}$ & $0,46^{*}$ & $0,78^{* *}$ & $0,74^{* *}$ \\
\hline \multicolumn{10}{|c|}{ DPP } \\
\hline & Desfavorável & Médio & MA & Desfavorável & Médio & MA & Desfavorável & Médio & MA \\
\hline Favorável & $0,28^{\mathrm{NS}}$ & $0,28^{\mathrm{NS}}$ & $0,35^{\mathrm{NS}}$ & $0,55^{* *}$ & $0,67^{* *}$ & $0,74^{* *}$ & $-0,37^{\mathrm{NS}}$ & $-0,36^{\mathrm{NS}}$ & $-0,19^{\mathrm{NS}}$ \\
\hline
\end{tabular}

${ }^{* *} \mathrm{P}<0,01 ;{ }^{*} \mathrm{P}<0,05 ;$ NS, não significativo.

Correlações abaixo de 0,80 para a mesma característica entre o ambiente favorável estimado pelo MNR e o MA indicam que apenas parte dos animais selecionados em um modelo foram selecionados no outro e esse resultado indica que avaliações genéticas que não consideram a IGA podem levar ao uso equivocado desses reprodutores. Para características com correlação baixa ou moderada entre os ambientes também indicam reclassificação dos animais. Já correlações altas indicam que para determinada característica e linha de seleção não há indício de reclassificação dos animais e que estes touros podem ser utilizados em todos os ambientes. 


\section{DISCUSSÕES}

O MNR com resíduo homogêneo se ajustou melhor dados deste estudo, corroborando com Ambrosini et al. (2016a) que concluíram que o MNR homocedástico apresentou melhor ajuste aos dados. Corrêa et al. (2010) ao comparar modelos para ajuste do ganho pós-desmama também observou que o MNR se ajustou melhor aos dados em relação ao MA, assim como Cardoso e Tempelman et al. (2012) revisando os métodos de avaliação genética sob a presença da IGA também obtiveram um ajuste mais pobre do MA frente à modelos de MNR.

Para o MA, as estimativas de herdabilidade direta para o P210 deste estudo foram próximas às divulgadas no Sumário do Instituto de Zootecnia (SUMÁRIO IZ, 2019), que relataram herdabilidade tanto direta, quanto materna de 0,14 , já a herdabilidade materna foi inferior a estimada neste estudo. Porém é preciso salientar que esses resultados divulgados foram para as três linhas de seleção em conjunto. Ambrosini et al. (2016a) estimaram herdabilidade direta de 0,34 para peso aos 205 dias de idade de animais Nelore, valor superior as estimativas obtidas neste estudo para as três linhas estudadas. Os substanciais valores de herdabilidade materna encontrados neste estudo indicam que, na fase que os bezerros ficam sob cuidados maternos, seus desempenhos foram fortemente influenciados por suas mães, deste modo a inclusão do efeito materno no modelo fornece maior precisão na partição das variâncias, principalmente pelo fato de que nas linhas $\mathrm{NeC}$ e $\mathrm{NeS}$ a herdabilidade materna foi superior a direta, sendo ainda bem elevada para a linha NeT.

As estimativas de herdabilidade média para o PS estimadas pelo MA foram superiores as divulgadas no Sumário, entretanto no sumário, as estimativas de herdabilidade foram para o peso padronizado para os 378 de idade para machos $(0,39)$ e peso padronizado para os 550 dias de idade para fêmeas $(0,45)$ separadamente e para as três linhas de seleção em conjunto (SUMÁRIO IZ, 2019). Em estudo com bovinos Nelore, Paterno et al. (2017), estimaram herdabilidade para peso aos 450 dias de idade de 0,48, valor próximo aos coeficientes de herdabilidade estimados para as linhas $\mathrm{NeS}$ e NeT, e inferior ao obtido para a linha $\mathrm{NeC}$. A herdabilidade direta obtida para ALT pelo MA também foram próximas às divulgadas no Sumário $(0,59)$, porém para os animais das três linhas em conjunto (SUMÁRIO IZ, 2019). Os valores de herdabilidade para essa característica estão dentro do encontrado na literatura para animais zebuínos, no qual a herdabilidade variou entre 0,28 a 0,67 (RILEY et al., 2002; SILVA et al., 2003; YOKOO et al., 2007; PEREIRA et al., 2010; SILVEIRA et al., 2017). 
A herdabilidade estimada pelo MA para PE neste estudo, também foi bem próxima às divulgadas no Sumário $(0,52)$ (SUMÁRIO IZ, 2019), e a estimada nos estudos de Raidan et al. (2015), que foi de 0,53 para animais Nelore criados à pasto. Ainda pelo MA, as estimativas de herdabilidade direta para o DPP das linhas NeS e NeT foram próximas às divulgadas no Sumário, que foi de 0,12 para as três linhas em conjunto (SUMÁRIO IZ, 2019), porém a estimativa para a linha $\mathrm{NeC}$ foi superior $(0,30)$. No entanto, neste estudo, a característica estudada foi dias para o primeiro parto, usando apenas novilhas, e a característica publicada no Sumário considera registros de novilhas e vacas.

Neste estudo as estimativas médias de herdabilidade direta e materna para P210 mostraram tendências diferentes para cada linha de seleção (Fig. 1). Enquanto a linha $\mathrm{NeC}$ apresentou tendência decrescente, a linha NeS apresentou tendência crescente, corroborando com Ambrosini et al. (2016a) e Mota et al. (2019b), que também encontraram tendência crescente com a melhoria do ambiente. Já para linha NeT foi possível observar coeficientes de herdabilidade quase constantes ao longo do descritor ambiental. As estimativas de herdabilidade materna para o P210 estimados pelo MNR foram ligeiramente superiores ao do MA para todos os ambientes. Ambrosini et al. (2016a) obtiveram herdabilidade materna estimadas pelo MNR inferiores as obtidas neste estudo, e superiores às obtidas pelo MA, porém só em ambientes favoráveis. Estimativas de herdabilidade materna inferiores foram encontradas em estudos como os de Ribeiro et al. (2015) e Santana et al. (2013) 0,06 e 0,05, respectivamente. Esses resultados sugerem que nessa fase ainda há grande influência da mãe sobre o desempenho do bezerro.

No geral, as estimativas médias de herdabilidade para PS estimadas pelo MNR foram, em sua maioria, mais altas que as estimadas pelo MA em todos os níveis do descritor ambiental. Os coeficientes de herdabilidade obtidos neste estudo para as linhas $\mathrm{NeC}$ e $\mathrm{NeS}$ foram maiores nos ambientes mais favoráveis, assim como no estudo de Araújo Neto et al. (2018) reportaram estimativas de herdabilidade variando entre 0,28 e 0,55 com a mesma tendência. Em contrapartida, a linha NeT apresentou leve decréscimo da herdabilidade, indicando que pode existir modificação nos parâmetros genéticos em função do ambiente, porém nesse caso, em ambientes desfavoráveis. As estimativas médias da herdabilidade direta para a ALT estimadas pelo MNR também foram, no geral, mais elevadas que as estimadas pelo MA em todos os níveis do descritor ambiental, sendo que, para os animais da linha $\mathrm{NeS}$, as estimativas mais elevadas de herdabilidade foram observadas em ambientes favoráveis. Corroborando com os estudos de Araújo Neto et al. (2018) e Chiaia et al. (2015), que também obtiveram estimativas de 
herdabilidade mais elevadas em ambientes favoráveis. As demais linhas apresentaram tendência de herdabilidade praticamente constante ao longo do descritor ambiental ou com leve decréscimo, indicando que pode haver modificação nos parâmetros genéticos em função do ambiente.

Chiaia et al. (2015) reportaram estimativas de herdabilidade para PE variando entre 0,51 e 0,67 , similar ao estimado neste estudo, entretanto os autores reportaram que a herdabilidade foi crescente à medida que o ambiente se tornou menos restrito, o que ocorreu apenas com a linha NeS. Para as demais linhas, foi observado que as estimativas dos coeficientes de herdabilidade foram similares em ambientes extremo opostos e inferiores em ambientes intermediários corroborando com Santana et al., (2013). Para essas linhas, pode se dizer que essa característica deve responder satisfatoriamente à seleção em ambientes diferentes. As estimativas de herdabilidade para a DPP foram crescentes para as três linhas de seleção, com os maiores valores de herdabilidade estimados em ambientes favoráveis, indicando uma provável maior resposta à seleção nesses ambientes. Assim, é possível selecionar novilhas que tendem a ciclar e a parir mais cedo nos ambientes favoráveis, corroborando com Chiaia et al. (2015), Lemos et al. (2015) e Ambrosini et al. (2016b), que observaram que o valor da herdabilidade das características reprodutivas das fêmeas Nelore aumentou à medida que os ambientes se tornaram menos restritos.

As correlações genéticas diretas e maternas entre intercepto e a inclinação do P210 foram negativas, baixas e até mesmo nulas, para todos as linhas, indicando que o intercepto e a inclinação são geneticamente independentes, o que pode ser indicativo de reclassificação dos animais em diferentes ambientes. De acordo com Su et al. (2006), reclassificação significa que o melhor animal em um ambiente não é necessariamente o melhor em outro ambiente. Ambrosini et al. (2016a) e Ribeiro et al. (2015) encontraram valores de correlação direta entre intercepto e inclinação superiores aos estimados neste estudo (0,92 e 0,75, respectivamente).

As correlações genéticas entre intercepto e a inclinação do PS para NeC e NeS indicaram que nestas linhas, animais com alto nível de produção tendem a melhorar seu desempenho com as melhorias ambientais. Embora essa tendência seja interessante, pois facilitaria a seleção dos melhores animais, ela pode ser prejudicial em ambientes desfavoráveis, pois os animais podem apresentar desempenho ruim. Essas tendências corroboram os achados relatados por Santana et al. (2013). Na linha NeT, a correlação nula indicou possível reclassificação de animais em diferentes ambientes, corroborando os achados de Ribeiro et al. (2017) e Araújo Neto et al. (2018). As correlações genéticas entre intercepto e inclinação da ALT foram diferentes entre as 
linhas estudadas, enquanto nas linhas $\mathrm{NeC}$ e $\mathrm{NeS}$ as correlações genéticas foram positivas, na linha NeT a correlação foi baixa e negativa. Entretanto, mesmo positiva, a correlação da linha $\mathrm{NeC}$ foi baixa podendo ser quase nula devido ao seu alto desvio-padrão, também indicando possibilidade de reclassificação dos animais. Santana et al., (2013), Ambrosini et al. (2016a) e Araújo Neto et al. (2018) que estimaram correlações genéticas entre intercepto e inclinação variando de baixa a moderada reportando a reclassificação dos animais de seus respectivos estudos.

Com respeito as características relacionadas à reprodução, enquanto as correlações entre intercepto e inclinação para PE foram positivas para as linhas $\mathrm{NeC}$ e NeS, para o DPP, as correlações foram negativas. Entretanto devido ao elevado desvio padrão, ambas características apresentaram correlações que indicam reclassificação dos animais dessas linhas. A linha NeT apresentou correlação negativa para ambas características, entretanto para o PE a correlação foi praticamente nula, enquanto para o DPP a correlação foi forte, ambas indicando reclassificação dos valores genéticos em ambientes distintos, em concordância com Santana et al., (2013), que encontraram correlação genética entre intercepto e inclinação para perímetro escrotal de 0,14 indicando a reclassificação.

Robertson (1959), sugeriu que a correlação inferior a 0,80 de uma característica avaliada em diferentes ambientes poderia indicar importante reclassificação dos animais com base no valor genético, indicando um importante efeito biológico da IGA de uma característica. As correlações genéticas entre os P210 nos ambientes extremos opostos para todas as linhas foram inferiores a 0,80, indicando reclassificação dos animais. Em relação as correlações entre os ambientes extremos e os intermediários, foi possível verificar que as correlações foram mais altas entre os ambientes favoráveis e intermediários, assim como os resultados obtidos por Ambrosini et al. (2016a) que obtiveram correlações acima de 0,90 entre ambientes favoráveis e intermediários, e abaixo de 0,80 para correlações genéticas entre ambientes opostos.

Resultados semelhantes foram encontrados para as características PS e ALT, sendo que as correlações genéticas para essas características nos ambientes extremos opostos foram altas para todos as linhas, com exceção dos machos da linha NeT. Para os ambientes extremos e os intermediários, as correlações tanto entre o PS, quanto entre ALT também foram todas altas, indicando que a seleção em qualquer ambiente deve levar a progresso genético nos demais, facilitando o processo de seleção em diferentes ambientes. A expressão dessa característica foi essencialmente a mesma entre ambientes, assim como constatado por Santana et al. (2013). 
As correlações genéticas entre os PE nos ambientes extremos opostos foram todas abaixo de 0,80, demonstrando importante efeito da IGA para essa característica e que pode haver reclassificação dos animais nos ambientes. As correlações genéticas entre os PE nos ambientes intermediários e os extremos para as linhas NeS e NeT foram altas tanto para os ambientes favoráveis, quanto para os desfavoráveis, corroborando com os estudos de Santana et al. (2015). As correlações genéticas entre os DPP nos ambientes extremos opostos também foram todas menores que 0,80 , sendo essas negativas para todas as linhas, assim como nos estudos de Chiaia et al. (2015), que encontraram correlação genética para idade ao primeiro parto de $-0,27$, em ambientes opostos demonstrando importante IGA entre esses ambientes.

As tendências genéticas observadas para os coeficientes de regressão relacionados ao intercepto da norma de reação para a linha $\mathrm{NeC}$ apresentou coeficientes de regressão não estatisticamente significativos para as características P210, PS, ALT e PE. As linhas NeS e NeT apresentaram tendências positivas e crescentes, indicando ganho genético ao longo dos anos de ambas as linhas selecionadas para maior diferencial para o aumento do peso pós-desmame.

Como houve ganho genético para as características PE e ALT evidenciado pelas tendências genéticas observadas para os coeficientes de regressão relacionados ao intercepto da norma de reação (Fig. 3), pode-se supor que a seleção para maior diferencial para o aumento do peso pós-desmame teve efeito positivo ou nulo sobre essas características, nas linhas NeS e NeT por serem linhas selecionadas para maior peso pós-desmama. De acordo com Pires et al. (2016) a correlação genética entre peso ao ano e perímetro escrotal mensurado também ao ano foi de 0,47. Pereira et al. (2010) estimaram correlação genética entre peso ao sobreano e altura da garupa mensurada na mesma idade de 0,50. Em relação ao P210, diversos estudos na literatura mostram a elevada correlação entre o peso a desmama e peso ao ano e sobreano (ARAUJO et al, 2014; FERREIRA et al, 2014; PIRES et al, 2016).

Todas as linhas apresentaram ganho genético para DPP, com tendências negativas indicando que a cada ano que passa as novilhas tendem emprenhar mais cedo durante a estação de monta, entretanto a tendência mais negativa foi a da linha $\mathrm{NeC}$ e um dos motivos para que isso tenha ocorrido foi que talvez a característica DPP pode ter sofrido efeito colateral negativo pela seleção maior diferencial para o aumento do peso pós-desmame, ou seja, é possível que a seleção realizada possa ter prejudicado o desempenho reprodutivo das novilhas das linhas NeS e NeT, ao menos em comparação com a linha $\mathrm{NeC}$, conforme evidenciado na Fig. 3. 
As tendências genéticas observadas para os coeficientes de regressão relacionados às características P210, PS e ALT (inclinação da norma de reação) para a linha $\mathrm{NeC}$, não foram estatisticamente significativas, entretanto as linhas NeS e NeT seguiram tendências opostas para as características PS e ALT, sendo que para os animais da linha NeS, as tendências genéticas para todas as características estudadas indicam que esta linha está se movendo para uma maior sensibilidade, ou seja, sendo mais responsivos às mudanças ambientais e com um significativo ganho genético demonstrado pelos coeficientes associados ao nível de produção (intercepto). Entretanto, para os animais da linha NeT, as tendências genéticas observadas para os coeficientes de regressão relacionados ao PS e ALT (inclinação da norma de reação) indicaram decréscimo da capacidade da linha em responder às mudanças ambientais, sendo que os animais desta linha também apresentaram um significativo ganho genético, sendo por vezes superior ao ganho genético dos animais da linha NeS.

As tendências genéticas observadas para os coeficientes de regressão relacionados às características PE (inclinação da norma de reação) foram negativas para as linhas $\mathrm{NeC} \mathrm{e} \mathrm{NeT}$ e positiva para a linha $\mathrm{NeS}$, e novamente foi possível verificar tendências opostas entre as linhas selecionadas para maior diferencial de peso pós-desmama. Em que animais das linhas $\mathrm{NeC} \mathrm{e}$ NeT tenderam a diminuir sua capacidade de responder às mudanças ambientais, corroborando com Santana et al. (2015), que relataram tendência genética negativa do PE relacionados a sensibilidade ambiental de bovinos Nelore. Para o DPP, as tendências genéticas observadas para os coeficientes de regressão relacionados inclinação mostraram coeficientes de regressão positivos para todas as linhas, indicando que os animais dessas três linhas estão se movendo em direção a uma maior sensibilidade, principalmente a linha NeC. Mota et al. (2020) também observou importante sensibilidade ambiental para dias para o primeiro parto, resultando em potencial reclassificação de novilhas em condições ambientais restritivas.

Para Tonsor et al. (2013), o custo da plasticidade fenotípica, também chamada de sensibilidade ambiental, pode significar uma redução da herdabilidade e consequentemente, na resposta à seleção. Os coeficientes de herdabilidade das características PS e PE estimadas na linha NeS apresentaram valores relativamente mais baixos comparadas às estimativas dos coeficientes de herdabilidade para estas características nas linhas NeT e NeC. No caso da linha $\mathrm{NeS}$ os animais foram selecionados exclusivamente para maiores diferenciais para o aumento do peso pós-desmame resultando em maior pressão de seleção para peso (diminuindo a variabilidade genética para peso), e como consequência da alta correlação genética que existe entre peso e perímetro escrotal, temos também a resposta correlacionada para PE. A linha NeT 
foi selecionada para maior diferencial para o aumento do peso pós-desmame e também para consumo alimentar residual, fazendo com que a pressão de seleção sobre o peso, fosse menor nessa linha.

A robustez e a plasticidade fenotípica estão intimamente relacionadas à IGA, e se diferentes genótipos apresentam uma norma de reação variada, é sinal da ocorrência da IGA (DE JONG; BIJMA, 2002; SOUZA et al. 2016), assim como observado neste estudo. Foi observada mudança genética na sensibilidade ambiental para as todas as características para os animais da linha NeS. Para linha NeT, apenas foi observada mudança genética na sensibilidade ambiental para o P210 e DPP e para a linha NeC só para DPP.

Para as características PS, PE e ALT, os animais das linhas $\mathrm{NeC}$ e $\mathrm{NeT}$ foram considerados mais robustos, com tendências nulas ou negativas, indicando que os animais dessas linhas tendem a responder de forma mais modesta às alterações ambientais, porém no caso da linha $\mathrm{NeT}$, o desempenho foi evidentemente maior do que a linha $\mathrm{NeC}$ e até maior que a linha NeS. Já os animais da linha NeS foram mais sensíveis às mudanças ambientais, evidenciado pela maior frequência de animais plásticos e ou extremamente plásticos, sendo maior que $50 \%$ e pela tendência positiva dos coeficientes relacionados a inclinação da norma de reação. A característica mais plástica foi o DPP, sendo que todas as linhas foram consideradas plásticas para essa característica e com maior variabilidade genética (DE JONG E BIJMA, 2002). Ainda que a proporção de animais robustos para essa característica seja maior, os animais tenderam a uma maior sensibilidade, principalmente a linha $\mathrm{NeC}$, conforme tendências ascendentes dos coeficientes relacionados a inclinação da norma de reação.

Para Strandberg et al. (2000), um sistema de produção ideal seria aquele em que os genótipos apresentaram alto desempenho com inclinação próxima a zero, ou seja, animais mais robustos com um bom desempenho em diferentes ambientes, que poderia ser o caso dos animais da linha NeT, que possuem um desempenho elevado, em média, superior ao desempenho dos animais da linha $\mathrm{NeS}$, porém foram, no geral mais robustos, com tendências descendente ou aproximadamente nula dos coeficientes relacionados a inclinação da norma de reação, para PS, ALT e PE.

Considerando os top 25\% melhores touros dentro de cada linha de seleção comparando o ambiente favorável com o MA, foi possível observar que para a linha $\mathrm{NeC}$, apenas a correlação para PE foi superior a 0,80. Para a linha NeS, as correlações para P210, PS e PE foram superiores ao valor usado como referência. E para a linha NeT apenas a correlação para 
P210 foi superior a esse valor. Estes resultados indicam que para essas características e linhas específicas não houve reclassificação importante entre os modelos e que a maioria dos touros selecionados em pelo MA foram selecionados pelo MNR. Todas as outras correlações abaixo de 0,80 , indicam que avaliações genéticas que não consideram a IGA podem levar ao uso equivocado desses touros.

Para os top $25 \%$ melhores touros dentro de cada linha de seleção em diferentes ambientes, foi possível observar que para a linha $\mathrm{NeC}$, as correlações foram em sua maioria menores que 0,80. Esses resultados indicam a ocorrência de reclassificação dos touros desta linha para todas as características em diferentes ambientes, exceto para ALT, evidenciando assim a clara importância de incluir a IGA nas análises genéticas para essas características como descrito por autores como Ambrosini et al. (2016) e Corrêa et al. (2010) que relataram que mesmo as correlações medianas podem levar à reclassificação importante dos animais em diferentes ambientes. Para os touros da linha NeS, foi possível verificar que ao contrário das demais linhas, as correlações foram superiores ao valor usado como referência $(0,80)$ para as características P210, PS e PE, e inferiores para ALT e DPP, indicando reclassificação dos touros para essas últimas característica. Para a linha NeT, foi possível observar que houve reclassificação dos touros para todas as características. Conforme descrito em seus estudos, Santos et al. (2008) relatam que as correlações mais baixas ocorrem entre ambientes opostos, assim como o evidenciado neste estudo.

Com base nos resultados deste estudo, foi possível verificar que existe efeito importante da seleção sobre a sensibilidade ambiental. Também foi possível observar efeito colateral da seleção para maior diferencial de peso pós-desmame sobre as características estudadas, no qual a característica DPP pode ter sofrido efeito colateral negativo ao longo dos anos de seleção, e o mesmo não parece ter ocorrido com as características P210, ALT e PE, talvez pelo fato de não serem características tão plásticas, como relatado por Santana et al. (2013) para a característica PE. Entretanto a intrigante diferença entre a plástica linha NeS e a robusta linha $\mathrm{NeT}$ pode ser devido a muitos fatores, um deles foi pelo fato da linha NeS ter sofrido maior pressão de seleção por ser selecionada apenas para maior diferencial de peso pós-desmama e a linha NeT também ser selecionada para consumo alimentar residual. Outro fator pode ser pelo fato de que a linha $\mathrm{NeT}$ foi a única a receber animais de fora e de dentro do Centro de pesquisa. 


\section{CONSIDERAÇÕES FINAIS}

Os resultados indicam que as diferentes práticas de seleção interferiram na sensibilidade ambiental dos animais deste estudo. Enquanto os animais da linha $\mathrm{NeC}$ apresentaram as tendências genéticas observadas para os coeficientes de regressão relacionados inclinação aproximadamente nulas, as tendências genéticas das linhas NeS e NeT foram diferentes de zero. Enquanto a linha NeS mostrou maior sensibilidade ambiental, a linha NeT se mostrou mais robusta e menos responsiva as mudanças ambientais. O que não ocorreu com o P210 e o DPP, pois ambas as linhas se mostraram mais sensíveis às mudanças ambientais, e no caso do DPP, todas as linhas de seleção se mostraram mais sensíveis.

Os resultados também sugerem que a seleção para aumento do peso pós-desmame pode afetar a sensibilidade ambiental dos animais, incluindo seus parâmetros genéticos e classificação dos touros, além de um provável efeito colateral sobre as características reprodutivas.

Também foi possível observar que o MNR foi útil para a constatar da presença de IGA para todas as características estudadas, evidenciado pela diferença das estimativas de herdabilidade ao longo do descritor ambiental, pelas baixas correlações genéticas entre ambientes extremo opostos e pela reclassificação dos $25 \%$ melhores touros entre os MA e MNR e entre os diferentes ambientes, principalmente para as linhas NeC e NeT e para DPP.

A partir dos resultados obtidos neste estudo, a IGA é um fator importante a ser levado em conta nas avaliações genéticas. A sensibilidade dos animais é uma característica importante a ser incluída nos índices de seleção para características de crescimento e reprodutivas de bovinos Nelore. 


\section{REFERÊNCIAS BIBLIOGRÁFICAS}

AGUILAR, I.; MISZTAL, I.; TSURUTA, S. Genetic trends of milk yield under heat stress for US Holsteins. Journal of Dairy Science, v.93, n.4, p.1754-1758, 2010.

ALENCAR, M. M.; MASCIOLI, A. S.; FREITAS, A. R. Evidências de interação genótipo x ambiente sobre características de crescimento em bovinos de corte. Revista Brasileira de Zootecnia, Viçosa, v.34, n.2, p.489-495, 2005.

AMBROSINI, D. P.; MALHADO, C. H. M.; MARTINS FILHO, R.; CARNEIRO, P. L. S. Interação genótipo $\mathrm{x}$ ambiente via modelos de normas de reação para características de crescimento em bovinos Nelore. Pesquisa Agropecuária Brasileira, Brasília, v.51, n.2, p.177186, 2016 .

AMBROSINI, D. P., MALHADO, C. H. M., MARTINS FILHO, R., CARDOSO, F. F., CARNEIRO, P. L. S. Genotypex environment interactions in reproductive traits of Nellore cattle in northeastern Brazil. Tropical animal health and production, v.48, n.7, p. 1401-1407, 2016b.

ARAUJO NETO, F. R., PEGOLO, N. T., ASPILCUETA-BORQUIS, R. R., PESSOA, M. C., BONIFÁCIO, A., LOBO, R. B., DE OLIVEIRA, H. N. Study of the effect of genotypeenvironment interaction on age at first calving and production traits in Nellore cattle using multi-trait reaction norms and Bayesian inference. Animal Science Journal, v.89, n.7, p.939945, 2018.

BENFiCA, L. F., SAKAMOTO, L. S., MAGAlHÃES, A. F. B. OLIVEIRA, M. H. V.; AlBUQUERQUE, L. G., CAVAlHEIRO, R., Branco, R. H., CYRILlO, J. N. S. G., Mercadante, M. E. Z. Genetic association among feeding behavior, feed efficiency and growth traits in growing indicine cattle. Journal of Animal Science, 2020. doi: https://doi.org/10.1093/jas/skaa350

CALUS, M.P.L.; BIJMA, P.; VEERKAMP, R.F. Effects of data structure on the estimation of covariance functions to describe genotype by environment interactions in a reaction norm model. Genetic Selection Evolution, Paris, v.36, p.489-507, 2004.

CALUS, M.P.L. Estimation of genotypex environment interaction for yield, health and fertility in dairy cattle. 2006. 181f. Tese (Doutorado), Department Animal Breeding and Genetics, Wageningen University, 2006.

CARABAÑO, M.J.; RAMÓN, M.; MENÉNDEZ-BUXADERA, A.; MOLINA, A.; DÍAZ, C. Selecting for heat tolerance. Animal Frontiers, v. 9, n.1, p.62-68, 2019.

CARDOSO, F. F.; ROSA, G. J. M.; TEMPELMAN, R. J. Multiple-breed genetic inference using heavy-tailed structural models for heterogeneous residual variances. Journal of Animal Science, Champaign, v. 83, n. 8, p. 1766-1779, 2005. 
CARDOSO, L. L. Modelos de normas de reação para estudo da interação genótipo $\mathbf{x}$ ambiente. Dissertação (mestrado). Universidade Federal do Rio Grande do Sul, 2009, 65p.

CARDOSO, L. L.; BRACCINI NETO, J.; CARDOSO, F. F.; COBUCI, J. A.; BIASSUS, I. O.; BARCELLOS, J. O. J. Hierarchical Bayesian models for genotype environment estimates in post-weaning gain of Hereford bovine via reaction norms. Brazilian Journal of Animal Science, v. 40, p. 294-300, 2011.

CARDOSO, F. F.; TEMPELMAN, R. J. Linear reaction norm models for genetic merit prediction of Angus cattle under genotype by environment interaction. Journal of Animal Science, Champaign, v. 90, n. 7, p. 2130-2141, 2012.

CHIAIA, H. L. J.; DE LEMOS, M. V. A.; VENTURINI, G. C.; ABOUJAOUDE, C.; BERTON, M. P.; FEITOSA, F. B.; CARVALHEIRO, R.; ALBUQUERQUE, L. G.; OLIVEIRA, H. N.; BALDI, F. Genotype x environment interaction for age at first calving, scrotal circumference, and yearling weight in Nellore cattle using reaction norms in multi-trait random regression models. Journal of Animal Science, Champaign, v.93, n.4, p.1503-1510, 2015.

CORRÊA M. B. B.; DIONELLO N. J. L.; CARDOSO F. F. Caracterização da interação genótipo-ambiente e comparação entre modelos para ajuste do ganho pós-desmama de bovinos Devon via normas de reação. Revista Brasileira de Zootecnia, Viçosa, v. 38, p. 1468-1477, 2009.

CORREAA, M.B.B.; DIONELLO, N.J.L.; CARDOSO, F.F. Genetic evaluation of Devon Cattle using a reaction norms model. Revista Brasileira de Zootecnia, v.39, p.128-133, 2010.

DE JONG, G. Phenotypic plasticity as a product of selection in a variable environment. The American Naturalist, Chicago, v. 145, n. 4, p. 493-512, 1995.

DE JONG, G.; BIJMA, P. Selection and phenotypic plasticity in evolutionary biology and animal breeding. Livestock Production Science, Shannon, v. 78, n.3, p. 195-214, 2002.

ELER, J.P.; FERRAZ, J.B.S.; GOLDEN, B.L.; PEREIRA, E. Influência da interação touro x rebanho na estimação da correlação entre efeitos genéticos direto e materno em bovinos da raça Nelore. Revista Brasileira de Zootecnia, v.29, n.6, p.1642-1648, 2000.

FALCONER, D. S. The problem of environment and selection. The American Naturalist, v. 86, p. 293-298, 1952.

FALCONER, D.S. Selection in different environments: effects on environmental sensitivity (reaction norm) and on mean performance. Genetical Research, Cambridge, v. 56, p. 57-70, 1990.

FALCONER, D. S.; MACKAY, T. F. Introduction to quantitative genetics. 4th ed. Harlow: Pearson Education Limited; 1996.

FERREIRA, J. L.; LOPES, F. B.; MARQUES, E. G.; DA SILVA, M. C.; DE ASSIS, A. S.; DE SOUSA PEREIRA, L.; NEPOMUCENO, L. L. Estudo genético quantitativo em características produtivas de bovinos da raça Nelore criados na Região Norte do Brasil. Brazilian Journal of Veterinary Medicine, v.36, n.1, p.11-17, 2014. 
FIKSE, W.F.; REKAYA, R.; WEIGEL, K.A. Assessment of environmental descriptors for studying genotype by environment interaction. Livestock Production Science, Amsterdam, v.82, p.223-231, 2003.

GEWEKE, J. Evaluating the accuracy of sampling-based approaches to the calculation of posterior moments. Bernardo, J.M., Berger, J.O., Dawid, A.P., Smith, A.F.M., editors. v. 4, Bayesian statistics. New York, USA: Oxford University Press. p. 625-631,1992.

GIANNONI, M.A.; GIANNONI, M.L. Genética e melhoramento de rebanhos nos trópicos. 2 ed. São Paulo: Nobel, 1987, 463p.

IBGE - Instituto Brasileiro de Geografia e Estatística, Produção da Pecuária Municipal PPM 2019 Disponível em: < https://www.ibge.gov.br/estatisticas/economicas/agricultura-epecuaria/9107-producao-da-pecuaria-municipal.html?=\&t=destaques $>$. Acesso em 03 de novembro de 2020.

JOHNSTON, D. J.; K. L. BUNTER. Days to calving in Angus cattle: Genetic and environmental effects, and covariances with other traits. Livestock Production Science. 45:13-22, 1996.

KENNEDY, B.W.; HENDERSON, C.R. Components of variance of growth traits among Hereford and Aberdeen Angus calves. Canadian Journal of Animal Science, v.55, n.4, p.493$502,1975$.

KING, R.; STANSFIELD, W.D.; MULLIGAN, P.K. A Dictionary of Genetics. 7 ed. Nova Iorque: Oxford University, 2006.

KOLMODIN, R.; STRANDBERG, E.; MADSEN, P.; JENSEN, J.; JORJANI, H. Genotype by environment interaction in Nordic dairy Cattle studied using reaction norms. Acta Agriculturae Scandinavica, Section A-Animal Science. Stockholm, v.52, n.1, p.11-24, 2002.

KOLMODIN, R.; BIJMA, P. Response to mass selection when the genotype by environment interaction is modelled as a linear reaction norm. Genetics Selection Evolution, London, v. 36, n. 4, p. 1, 2004.

LEMOS, M. V. A.; CHIAIA, H. L. J.; BERTON, M. P.; FEITOSA, F. L. B., ABOUJAOUDE, C.; VENTURINI, G. C.; OLIVEIRA, H. N.; ALBUQUERQUE, L. G.; BALDI, F. Reaction norms for the study of genotype-environment interaction for growth and indicator traits of sexual precocity in Nellore cattle. Genetics and Molecular Research, 14(Suppl. 2), 7151$7162,2015$.

LIMA SILVA, T.; CARNEIRO, P. L. S., AMBROSINI, D. P., LÔBO, R. B., MARTINS FILHO, R.; MALHADO, C. H. M. Genotype-environment interaction in the genetic variability analysis of reproductive traits in Nellore cattle. Livestock Science, 230, 103825, 2019.

MATTAR, M.; SILVA, L. O. C.; ALENCAR, M. M.; CARDOSO, F. F. Genotype × environment interaction for long-yearling weight in Canchim cattle quantified by reaction norm analysis. Journal of Animal Science, Champaign, v. 89, p. 2349-2355, 2011. 
MERCADANTE, M. E. Z.; PASCKER, I. U.; RAZOOK, A. G.; CYRILLO, J. N. S. G.; FIGUEIREDO, L. A. Direct and correlated responses to selection for yearling weight on reproductive performance of Nelore cows. Journal of Animal Science, v.81, p. 376-84, 2003.

MISZTAL, I.; TSURUTA, S.; STRABEL, T.; AUVRAY, B.; DRUET, T.; LEE, D. H. BLUPF90 and related programs. In: INRA, editor. 7th World Congress on Genetics Applied to Livestock Production. Montpellier, France; 2002. p. 4.

MOTA, R. R.; TEMPELMAN, R. J.; LOPES, P. S.; AGUILAR, I.; SILVA, F. F.; CARDOSO, F. F. Genotype by environment interaction for tick resistance of Hereford and Braford beef cattle using reaction norm models. Genetics Selection Evolution, London, v.48, n. 1, p.1, 2016.

MOTA, L. F. M. (2019). Estimation of genotype-environment interaction using genomic reaction norm and analysis of gene network for reproductive traits in Nellore cattle. 2019. 87f. Tese (Doutorado) School of Agricultural and Veterinarian Sciences, São Paulo State University, Jaboticabal, SP, 2019a.

MOTA, L. F. M.; COSTA, L. S.; GARZÓN, N. A.; PASSAFARO, T. L.; SILVA, D. O.; ABREU, L. R.; VENTURA, H. T. Unraveling the effect of body structure score on phenotypic plasticity for body weight at different ages in Guzerat cattle. Livestock Science, v.229, p.98104, 2019b.

MOTA, L. F. M.; LOPES, F. B.; JÚNIOR, G. A. F.; ROSA, G. J.; MAGALHÃES, A. F., CARVALHEIRO, R.; ALBUQUERQUE, L. G. (2020). Genome-wide scan highlights the role of candidate genes on phenotypic plasticity for age at first calving in Nellore heifers. Scientific reports, v.10, n.1, p.1-13, 2020.

MULDER, H.A.; BIJMA, P. Effect of genotype x environment interaction on genetic gain in breeding programs. Journal of Animal Science, v.83, p.49-61, 2005.

MULDER, H.A.; VEERKAMP, R.F.; DUCRO, B.J.; VAN ARENDONK, J.A.M.; BIJMA, P. Optimization of Dairy Cattle Breeding Programs for Different Environments with Genotype by Environment Interaction. Journal of Dairy Science, v.89, p.1740-1752, 2006

PATERNO, F. M.; BUZANSKAS, M. E.; KOURY FILHO, W.; LÔBO, R. B.; QUEIROZ, S. A. Genetic analysis of visual assessment and body weight traits and their relationships with reproductive traits in Nellore cattle. The Journal of Agricultural Science, v.155, n.4, p.679687, 2017.

PEREIRA, M. C.; YOKOO, M. J.; BIGNARDI, A. B.; SEZANA, J. C.; ALBUQUERQUE, L. G. D. Altura da garupa e sua associação com características reprodutivas e de crescimento na raça Nelore. Pesquisa Agropecuária Brasileira, 45(6), 613-620, 2010.

PIRES, B. C.; THOLON, P.; BUZANSKAS, M. E.; SBARDELlA, A. P.; ROSA, J. O.; CAMPOS DA SILVA, L. O.; TORRES JÚNIOR, R. A. A.; MUNARI, D. P.; MELLO DE ALENCAR, M. Genetic analyses on bodyweight, reproductive, and carcass traits in composite beef cattle. Animal Production Science, v.57, n.3, p.415-421, 2016. 
RAIDAN, F. S. S.; PASSAFARO, T. L.; FRAGOMENI, B. O.; JOSAHKIAN, L. A.; PEREIRA, I. G.; TORAL, F. L. B. Genotype $x$ environment interaction in individual performance and progeny tests in beef cattle. Journal of Animal Science, Champaign,v.93, n.3, p.920-933, 2015.

RAZOOK, A. G.; FIGUEIREDO, L. A.; CYRILLO, J. N. S. G.; PACOLA, L. J.; BONILHA NETO, L. M.; TROVO, J. B. F.; RUGGIERI, A. C.; MERCADANTE, M. E. Z. Prova de Ganho de Peso: Normas adotadas pela Estação Experimental de Zootecnia de Sertãozinho. Nova Odessa (SP), Instituto de Zootecnia. 1997. 42 p. (Boletim Técnico n ${ }^{\circ}$.40).

RIBEIRO, S.; ELER, J. P.; BALIEIRO, J. C. C.; FERRAZ, J. B. S.; PEDROSA, V. B.; MATTOS, E. C. Influência da interação genótipo x ambiente sobre o peso à desmama em bovinos da raça Nelore. Arquivo Brasileiro de Medicina Veterinária e Zootecnia, Belo Horizonte, v. 61, n. 3, p. 668-675, 2009.

RIBEIRO, S.; ELER, J.P.; PEDROSA, V.B.; ROSA, G.J.M.; FERRAZ, J.B.S.; BALIEIRO, J.C.C. Genotype x environment interaction for weaning weight in Nellore cattle using reaction norm analysis. Livestock Science, Amsterdam, v.176, p.40-46, 2015.

RIBEIRO, S.; ELER, J. P.; PEDROSA, V. B.; ROSA, G. J. D. M.; FERRAZ, J. B. S.; BALIEIRO, J. C. D. C. Genotype by environment interaction for yearling weight in Nellore cattle applying reaction norms models. Animal Production Science, v.58, n.11, p.1996-2002, 2017.

RILEY, D.G.; CHASE JUNIOR, C.C.; HAMMOND, A.C.; WEST, R.L.; JOHNSON, D.D.; OLSON, T.A.; COLEMAN, S.W. Estimated genetic parameters for carcass traits of Brahman cattle. Journal of Animal Science, v.80, p.955-962, 2002.

ROBERTSON. A. The sampling variance of the genetic correlation coefficient. Biometrics 15: 469-485, 1959.

RODRIGUES, D. T. Interação genótipos ambientes em animais via modelos de normas de reação. 2012. 86f. Dissertação (Mestrado). Universidade Federal de Viçosa, Viçosa, Minas Gerais, 2012.

SANTANA, M. L.; ELER, J. P.; CARDOSO, F. F.; ALBUQUERQUE, L. G.; FERRAZ, J. B. S. Phenotypic plasticity of composite beef cattle performance using reaction norms model with unknown covariate. Animal, v. 7, n. 2, p. 202-210, 2013.

SANTANA, M. L.; ELER, J. P.; BIGNARDI, A. B.; MENÉNDEZ-BUXADERA, A.; CARDOSO, F. F.; FERRAZ, J. B. S. Multi-trait linear reaction norm model to describe the pattern of phenotypic expression of some economic traits in beef cattle across a range of environments. Journal of Applied Genetics, Heidelberg, v.56, n.2, p.219-229, 2015.

SANTANA, M. L.; ELER, J. P.; OLIVEIRA JR, G. A.; BIGNARDI, A. B.; PEREIRA, R. J.; FERRAZ, J. B. S. Genetic variation in Nelore heifer pregnancy due to heat stress during the breeding season. Livestock Science, v. 218, p. 101-107, 2018.

SANTOS, G.G.; CORRÊA, G.S.S.; VALENTE, B.D.; SILVA, M.A.; CORRÊA, A.B.; FELIPE, V.P.S.; WENCESLAU, R.R. Sensibilidade dos valores genéticos de codornas de corte 
em crescimento às modificações de níveis de proteína das dietas. Arquivo Brasileiro de Medicina Veterinária e Zootecnia, v.60, p.1188-1196, 2008.

SILVA, J.A. de V.; VAN MELIS, M.H.; ELER, J.P.; FERRAZ, J.B.S. Estimação de parâmetros genéticos para probabilidade de prenhez aos 14 meses e altura na garupa em bovinos da raça Nelore. Revista Brasileira de Zootecnia, v.32, p.1141-1146, 2003.

SILVEIRA, D. D.; DE VARGAS, L.; ROSO, V. M., CAMPOS, G. S.; SOUZA, F. R. P.; BOLIGON, A. A. Genetic study of visual scores and hip height at different ages in Nelore cattle. Animal production science, 57(4), 614-621, 2017.

SOUZA, L. D. A.; MALHADO, C. H. M.; BRACCINI NETO, J.; MARTINS FILHO, R.; CARNEIRO, P. L. S. Genotype-environment interactions on the weight of Tabapua cattle in the northeast of Brazil. Revista Caatinga, v. 29 n. 1, p. 206-215, 2016.

SOUZA, J. C.; FIALHO, F. R. L., REZENDE, M. P. G., MACHADO, C. H. C., ALENCAR, M. P.; DE SOUZA, C. F.; FERRAZ FILHO, P. B.; FERRAZ, A. L. J. Genotype-environment interaction, genetic trends, and performance dissimilarity of Nellore herds raised in three different environmental gradients. Semina: Ciências Agrárias, 39(1), 349-362, 2018.

SPIEGELHALTER, D. J.; BEST, N. G.; CARLIN, B. P.; VAN DER LINDE, A. Bayesian mensures of model complexity and fit. Journal of the Royal Statistical Society Series BStatistical Methodology, London, v. 64, n. 4, p. 583-639, 2002.

SU, G.; MADSEN, P.; LUND, M. S.; SORENSEN, D.; KORSGAARD, I. R.; JENSEN, J. Bayesian analysis of the linear reaction norm model with unknown covariates. Journal of Animal Science, Champaign, v. 84, p. 1651-1657, 2006.

SUMÁRIO DE TOUROS E MATRIZES NELORE 2019, Nova Odessa: Instituto de Zootecnia, 2019, 28 p.

STRANDBERG, E. Genotype by environment interaction in Nordic Dairy Cattle studied by use of reaction norms, Slovenia. In: Porceedings Interbull meeting, Bled Slovenia: p.41-45, 2000.

YOKOO, M.J.; ALBUQUERQUE, L.G.; LÔBO, R.B.; SAINZ, R.D.; CARNEIRO JÚNIOR, J.M.; BEZERRA, L.A.F.; ARAUJO, F.R. da C. Estimativas de parâmetros genéticos para altura do posterior, peso e circunferência escrotal em bovinos da raça Nelore. Revista Brasileira de Zootecnia, v.36, p.1761-1768, 2007.

TONSOR, S. J.; ELNACCASH, T. W.; SCHEINER, S. M. Developmental instability is genetically correlated with phenotypic plasticity, constraining heritability, and fitness. Evolution, v. 67, p. 2923-2935, 2013.

VALENTE, B.D. Estruturas de covariância de peso em função da idade de animais Nelore das regiões Sudesde e Centro-Oeste. Dissertação (Mestrado) - Universidade Federal de Minas Gerais, Belo Horizonte, 2007.

VIA, S.; LANDE, R. Genotype-environment interaction and the evolution of phenotypic plasticity. Evolution, v.39, p.505-522, 1985. 
WOLTERECK, R. Weitere experimentelle Untershungen uber Artveranderung speziel uber das Wesen quatitativer Artunterschiede bei Daphniden. Further Experimantal Investigations about Species Change, Especially about the Essense of Quantitative Differences in Daphnia. Verhandlungen der deutschen zoologischen Gesellschaft, v. 19, p.110-173, 1909. 


\section{APÊNDICE}

Tabela 5. Componentes de covariância para peso a desmama padronizado (P210), peso a seleção (PS), altura da garupa (ALT), perímetro escrotal (PE) e dias para o primeiro parto (DPP) para cada linha estimados pelo modelo de norma de reação (MNR).

\begin{tabular}{|c|c|c|c|c|c|}
\hline \multirow{2}{*}{$\begin{array}{l}\text { Componente } \\
\text { Variância do }\end{array}$} & & \multirow[t]{2}{*}{ Média } & \multirow[t]{2}{*}{ DP } & \multicolumn{2}{|c|}{ IPP95\% } \\
\hline & \multicolumn{3}{|c|}{ Variância do intercepto } & & \\
\hline P210 & $\mathrm{NeC}$ & 100,90 & 42,52 & 17,57 & 184,24 \\
\hline \multirow[t]{2}{*}{ Direto } & $\mathrm{NeS}$ & 239,67 & 43,30 & 154,80 & 324,54 \\
\hline & $\mathrm{NeT}$ & 422,74 & 54,76 & 315,41 & 530,08 \\
\hline \multirow[t]{3}{*}{ Materno } & $\mathrm{NeC}$ & 274,78 & 69,79 & 137,99 & 411,57 \\
\hline & $\mathrm{NeS}$ & 335,69 & 72,42 & 193,75 & 477,63 \\
\hline & $\mathrm{NeT}$ & 260,70 & 68,28 & 126,88 & 394,53 \\
\hline \multirow[t]{3}{*}{ PS } & $\mathrm{NeC}$ & 808,16 & 140,10 & 533,55 & $1.082,80$ \\
\hline & $\mathrm{NeS}$ & 1061,00 & 82,36 & 899,55 & $1.222,40$ \\
\hline & $\mathrm{NeT}$ & 1342,80 & 89,70 & $1.166,90$ & $1.518,60$ \\
\hline \multirow[t]{3}{*}{ ALT } & $\mathrm{NeC}$ & 17,23 & 2,59 & 12,15 & 22,31 \\
\hline & $\mathrm{NeS}$ & 29,85 & 4,71 & 20,62 & 39,08 \\
\hline & $\mathrm{NeT}$ & 21,22 & 1,62 & 18,05 & 24,38 \\
\hline \multirow[t]{3}{*}{ PE } & $\mathrm{NeC}$ & 4,07 & 1,17 & 1,77 & 6,37 \\
\hline & $\mathrm{NeS}$ & 4,19 & 0,77 & 2,69 & 5,70 \\
\hline & $\mathrm{NeT}$ & 6,33 & 0,76 & 4,84 & 7,82 \\
\hline \multirow[t]{3}{*}{ DPP } & $\mathrm{NeC}$ & 645,52 & 332,88 & 12,67 & $1.278,40$ \\
\hline & $\mathrm{NeS}$ & 221,84 & 121,31 & $-15,93$ & 459,61 \\
\hline & $\mathrm{NeT}$ & 356,60 & 175,47 & 12,67 & 700,52 \\
\hline \multicolumn{6}{|c|}{ Variância da inclinação } \\
\hline P210 & $\mathrm{NeC}$ & 40,05 & 21,00 & $-1,10$ & 81,20 \\
\hline \multirow[t]{2}{*}{ Direto } & $\mathrm{NeS}$ & 16,67 & 9,12 & $-1,20$ & 34,54 \\
\hline & $\mathrm{NeT}$ & 44,47 & 18,05 & 9,08 & 79,85 \\
\hline \multirow[t]{3}{*}{ Materno } & $\mathrm{NeC}$ & 49,17 & 19,16 & 11,61 & 86,73 \\
\hline & $\mathrm{NeS}$ & 23,38 & 9,65 & 4,46 & 42,30 \\
\hline & $\mathrm{NeT}$ & 20,77 & 8,72 & 3,68 & 37,85 \\
\hline \multirow[t]{3}{*}{ PS } & $\mathrm{NeC}$ & 105,33 & 43,21 & 20,64 & 190,03 \\
\hline & $\mathrm{NeS}$ & 47,76 & 22,39 & 3,87 & 91,65 \\
\hline & $\mathrm{NeT}$ & 262,67 & 52,91 & 158,96 & 366,38 \\
\hline \multirow[t]{3}{*}{ ALT } & $\mathrm{NeC}$ & 0,51 & 0,37 & $-0,22$ & 1,24 \\
\hline & $\mathrm{NeS}$ & 4,64 & 2,68 & $-0,61$ & 9,90 \\
\hline & $\mathrm{NeT}$ & 2,18 & 0,49 & 1,22 & 3,14 \\
\hline \multirow[t]{3}{*}{ PE } & $\mathrm{NeC}$ & 0,76 & 0,41 & $-0,05$ & 1,56 \\
\hline & $\mathrm{NeS}$ & 0,27 & 0,19 & $-0,11$ & 0,65 \\
\hline & $\mathrm{NeT}$ & 0,96 & 0,35 & 0,28 & 1,65 \\
\hline \multirow[t]{3}{*}{ DPP } & $\mathrm{NeC}$ & 282,88 & 194,31 & $-97,97$ & 663,74 \\
\hline & $\mathrm{NeS}$ & 79,60 & 54,92 & $-28,04$ & 187,24 \\
\hline & $\mathrm{NeT}$ & 140,35 & 69,18 & 4,76 & 275,94 \\
\hline
\end{tabular}




\begin{tabular}{|c|c|c|c|c|c|}
\hline \multicolumn{6}{|c|}{ Covariância entre intercepto e inclinação } \\
\hline $\mathrm{P} 210$ & $\mathrm{NeC}$ & $-38,78$ & 20,72 & $-79,38$ & 1,82 \\
\hline \multirow[t]{2}{*}{ Direto } & $\mathrm{NeS}$ & 17,98 & 14,27 & $-9,98$ & 45,95 \\
\hline & $\mathrm{NeT}$ & $-3,79$ & 19,59 & $-42,19$ & 37,61 \\
\hline \multirow[t]{3}{*}{ Materno } & $\mathrm{NeC}$ & $-34,60$ & 25,53 & $-84,64$ & 15,44 \\
\hline & $\mathrm{NeS}$ & $-18,22$ & 19,50 & $-56,44$ & 20,01 \\
\hline & $\mathrm{NeT}$ & 7,40 & 18,87 & $-29,58$ & 44,40 \\
\hline \multirow[t]{3}{*}{ PS } & $\mathrm{NeC}$ & 209,00 & 38,26 & 134,01 & 284,00 \\
\hline & $\mathrm{NeS}$ & 172,70 & 29,48 & 114,92 & 230,49 \\
\hline & $\mathrm{NeT}$ & 18,54 & 38,14 & $-56,21$ & 93,28 \\
\hline \multirow[t]{3}{*}{ ALT } & $\mathrm{NeC}$ & 0,70 & 0,54 & $-0,36$ & 1,77 \\
\hline & $\mathrm{NeS}$ & 7,26 & 3,22 & 0,94 & 13,58 \\
\hline & $\mathrm{NeT}$ & $-1,30$ & 0,45 & $-2,18$ & $-0,41$ \\
\hline \multirow[t]{3}{*}{ PE } & $\mathrm{NeC}$ & 0,05 & 0,31 & $-0,56$ & 0,66 \\
\hline & $\mathrm{NeS}$ & 0,33 & 0,26 & $-0,18$ & 0,84 \\
\hline & $\mathrm{NeT}$ & $-0,35$ & 0,28 & $-0,90$ & 0,20 \\
\hline \multirow[t]{3}{*}{ DPP } & $\mathrm{NeC}$ & $-179,90$ & 170,64 & $-514,35$ & 154,55 \\
\hline & $\mathrm{NeS}$ & $-50,88$ & 67,31 & $-182,81$ & 81,05 \\
\hline & $\mathrm{NeT}$ & $-188,79$ & 84,44 & $-354,29$ & $-23,29$ \\
\hline \multicolumn{6}{|c|}{ Variância de ambiente permanente materno } \\
\hline \multirow[t]{3}{*}{$\mathrm{P} 210$} & $\mathrm{NeC}$ & 53,46 & 20,65 & 12,98 & 93,94 \\
\hline & $\mathrm{NeS}$ & 125,51 & 23,87 & 78,72 & 172,30 \\
\hline & $\mathrm{NeT}$ & 125,63 & 22,76 & 81,01 & 170,25 \\
\hline \multicolumn{6}{|c|}{ Variância residual } \\
\hline \multirow[t]{3}{*}{ P210 } & $\mathrm{NeC}$ & 177,07 & 13,52 & 150,57 & 203,57 \\
\hline & $\mathrm{NeS}$ & 233,31 & 13,87 & 206,12 & 206,50 \\
\hline & $\mathrm{NeT}$ & 237,55 & 15,98 & 206,24 & 268,86 \\
\hline \multirow[t]{3}{*}{ PS } & $\mathrm{NeC}$ & 296,02 & 37,71 & 222,10 & 369,94 \\
\hline & $\mathrm{NeS}$ & 505,33 & 25,21 & 455,92 & 554,74 \\
\hline & $\mathrm{NeT}$ & 582,79 & 30,41 & 523,18 & 642,39 \\
\hline \multirow[t]{3}{*}{ ALT } & $\mathrm{NeC}$ & 5,75 & 0,72 & 4,34 & 7,16 \\
\hline & $\mathrm{NeS}$ & 8,35 & 0,55 & 7,27 & 9,43 \\
\hline & $\mathrm{NeT}$ & 6,93 & 0,50 & 5,94 & 7,92 \\
\hline \multirow[t]{3}{*}{ PE } & $\mathrm{NeC}$ & 1,60 & 0,39 & 0,83 & 2,36 \\
\hline & $\mathrm{NeS}$ & 2,18 & 0,27 & 1,65 & 2,71 \\
\hline & $\mathrm{NeT}$ & 2,41 & 0,26 & 1,89 & 2,92 \\
\hline \multirow[t]{3}{*}{ DPP } & $\mathrm{NeC}$ & 731,51 & 125,88 & 484,78 & 978,25 \\
\hline & $\mathrm{NeS}$ & 841,21 & 64,37 & 715,06 & 967,39 \\
\hline & $\mathrm{NeT}$ & 841,40 & 79,85 & 684,89 & 997,91 \\
\hline
\end{tabular}




\section{MANUSCRITO}

O manuscrito intitulado "Different selection practices affect the environmental sensitivity of beef cattle" foi submetido a revista Journal of Animal Science, com fator de impacto 2,092 e classificação A1 de periódicos do quadriênio 2013-2016 (vigente) para a área de avaliação de "Zootecnia/recursos pesqueiros", na data de 31 de julho de 2020. 


\section{Different selection practices affect the environmental sensitivity of beef cattle}

\begin{tabular}{|c|c|}
\hline Journal: & Journal of Animal Science \\
\hline Manuscript ID & JAS-2020-4818 \\
\hline Manuscript Type: & Animal Genetics and Genomics \\
\hline $\begin{array}{r}\text { Date Submitted by the } \\
\text { Author: }\end{array}$ & $31-J u l-2020$ \\
\hline Complete List of Authors: & $\begin{array}{l}\text { de Paula Freitas, Anielly; Universidade de São Paulo, Genetic } \\
\text { Santana Júnior, Mário Luiz; Instituto de Zootecnia, Centro de Pesquisa } \\
\text { avançado em bovinos de corte } \\
\text { Schenkel, Flavio; University of Guelph, Animal \& Poultry Science } \\
\text { Zerlotti Mercadante, Maria ; Institute of Animal Science, Sao Paulo } \\
\text { Agribusiness Technology Agency } \\
\text { Cyrillo, Joslaine Noely; Instituto de Zootecnia, Centro APTA Bovinos de } \\
\text { Corte } \\
\text { Paro Paz, Claudia Cristina; Instituto de Zootecnia, Centro de Pesquisa } \\
\text { avançado em bovinos de corte }\end{array}$ \\
\hline Key Words: & Bayesian inference, reaction norm model, environmental sensitivity \\
\hline
\end{tabular}

\section{SCHOLARONE" Manuscripts}




\section{Different selection practices affect the environmental sensitivity of beef cattle}

2

Anielly de Paula Freitas, ${ }^{* 1,2}$ Mário Luiz Santana Júnior, $†$ Flavio Schramm Schenkel,\# Maria Eugênia Zerlotti Mercadante, $\uparrow$ Joslaine Noely dos Santos Goncalves Cyrillo, $\uparrow$ and Claudia

$$
\text { Cristina Paro de Paz*, } \uparrow
$$

6

*Department of Genetics, Ribeirão Preto Medical School, University of São Paulo, Av.

Bandeirantes, 3900, Ribeirão Preto, SP, 14049-900, Brazil.

†Advanced Beef Cattle Research Center, Animal Science Institute/APTA/SAA, Rodovia

Carlos Tonani, Km 94, Sertãozinho, São Paulo, 14174-000, Brazil.

11 \#Centre for Genetic Improvement of Livestock, Department of Animal Biosciences, University of Guelph, 50 Stone Road East, N1G 2W1 Guelph, ON, Canada.

${ }^{1}$ The authors would like to acknowledge the São Paulo Research Foundation (FAPESP, Brazil, grant number \#2016/17517-4 and \#2019/01814-8) and Coordenação de Aperfeiçoamento de Pessoal de Nível Superior - Brasil (CAPES) for the fellowship.

${ }^{2}$ Corresponding author: E-mail: aniellypf@hotmail.com 
17 Abstract: The objective of this study was to evaluate the effects of different selection practices on the environmental sensitivity of reproductive and growth traits in males and females of three Nellore cattle lines [control $(\mathrm{NeC})$, selection $(\mathrm{NeS})$, and traditional $(\mathrm{NeT})$ lines] with different selection goals. Moreover, genetic trends for the intercept and slope were estimated for each line, and the possible reclassification of sires was examined. A total of 8,757 records of selection weight (SW), 3,331 records of scrotal circumference (SC), and 2,311 records of days to first calving (DFC) from Nellore cattle born between 1981 and 2017 at the Advanced Beef Cattle Research Center of the Animal Science Institute, Sertãozinho, SP, Brazil, were analyzed in this study. (Co)variance components and genetic parameters of all traits were estimated using a reaction norm model using Gibbs sampler. The environmental descriptor adopted were the solutions of contemporary groups (CG). Mean heritability of the studied traits ranged from 0.39 to 0.75 for $\mathrm{SW}$ in both males and females, from 0.46 to 0.68 for $\mathrm{SC}$, and from 0.06 to 0.57 for DFC, along the environmental descriptor, in all cattle lines. The genetic correlation coefficients between the intercept and slope ranged from 0.03 to 0.81 for $\mathrm{SW}$, from -0.14 to 0.39 for $\mathrm{SC}$, and from -0.87 to -0.42 for DFC in all cattle lines. Genetic trends for the slope and proportion of plastic genotypes indicated that the $\mathrm{NeS}$ line was more responsive to environmental changes, whereas the $\mathrm{NeC}$ and $\mathrm{NeT}$ lines tended to respond more modestly. Reclassification of sires was observed for all traits, specifically in the $\mathrm{NeC}$ and $\mathrm{NeT}$ lines, because of the weak correlation between the opposite extreme environments. In the NeS line, reclassification of sires was observed for DFC alone. Our results indicate that the effects of genotype by environment interaction are important and should be considered in genetic evaluations of Nellore cattle. Moreover, different selection practices affected the environmental sensitivity of Nellore selection lines tested in this study.

41 Key words: Bayesian inference, reaction norm model, environmental sensitivity 


\section{List of Abbreviations}

43 CG: Contemporary group

44 DFC: Days at first calving

$45 \mathrm{G} \times \mathrm{E}$ : Genotype by environment interaction

46 NeC: Control

47 NeS: Selection

48 NeT: Traditional

49 RFI: Residual feed intake

50 RNM: Reaction norm model

51 SC: Scrotal circumference

52 SW: Selection weight

\section{Introduction}

Phenotypic modifications induced by the environment are more common in quantitative traits of living organisms inhabiting heterogeneous environments (Squilassi et al., 2003). The actions of functional genes may be conditioned by a set of environmental factors, which can alter the genetic and phenotypic characteristics as well as the genetic merit of animals in response to the environment they inhabit, ultimately changing the estimates of

60 genetic parameters and ranking of animals for breeding (Corrêa et al., 2009; Cardoso and

61 Tempelman, 2012; Mota et al., 2016). Therefore, it is important to elucidate the contribution

62 of the genotype by environment interaction $(\mathrm{G} \times \mathrm{E})$ in genetic evaluations for increasing the efficiency of beef cattle selection programs, offering enhanced security in the purchase most appropriate genetic material for each production environment. When any organism produces a phenotypic response that varies as a continuous

66 function of its environment, this relationship is called a reaction norm (Woltereck, 1909). 
67 Reaction norm models (RNMs) can be developed for an infinite number of environments.

Moreover, several genetic values can be assigned for the same animal, and the phenotypic expression of a genotype along the environmental gradient can be assessed (De Jong, 1995). Previous studies have reported high efficiency of RNMs for assessing the influence of $\mathrm{G} \times \mathrm{E}$ (Kolmodin and Bijma, 2004; Cardoso et al., 2011; Ambrosini et al., 2016). RNMs are effective since animal response to selection can be predicted more accurately due to more reliable estimation of variance components as well as of direct and correlated responses at all time points along a trajectory, which is particularly useful when the phenotypes vary steadily along the environmental gradient.

In a study evaluating the effects of $\mathrm{G} \times \mathrm{E}$, along with the estimation of parameters and genetic trends of growth traits in Nellore cattle, Souza et al. (2018) reported that breeding values increased over time and confirmed the occurrence of $\mathrm{G} \times \mathrm{E}$, emphasizing that sires with a greater genetic value in a particular region may not be the best in other regions. Similarly, Ambrosini et al. (2016) reported genetic variation in the sensitivity of animals to different environments, highlighting the importance of selecting animals with genotypes that are more suitable for production in a given environment.

Although several studies have reported the effects of $\mathrm{G} \times \mathrm{E}$ on growth and reproductive traits, genetic evaluations under breeding programs for beef cattle are performed under general assumptions of no $\mathrm{G} \times \mathrm{E}$ and constant residual and genetic variances. However, effects of this interaction are evident, and improper modeling of these effects may lead to biased predictions of genetic values and consequently reduce genetic progress (Ribeiro et al., 2009; Lima Silva et al., 2019), ultimately resulting in economic losses to the producer.

There have been few studies on the effects of selection on animals' responses to the environment. Aguilar et al. (2010) compared 100 most and 100 least heat-tolerant bulls and concluded that the former ones transmitted heat-tolerance to their daughters, which showed 
lower productive but higher reproductive performance. According to Carabaño et al. (2019), heat stress is a complex phenomenon triggering several response mechanisms in dairy cattle, and it negatively affects farm profitability because of antagonism between productivity and heat tolerance.

Nonetheless, studies with beef cattle are scarce in the literature, therefore, the aims of this study were to evaluate the effects of different selection practices on the environmental sensitivity of reproductive and growth traits of males and females in Nellore cattle lines using an RNM as well as to estimate genetic trends related to general production capacity (intercept of the reaction norm) and specific ability to respond to environmental variations (slope of the reaction standard) in each line.

Materials and methods

Ethics

Animal care and use committee approval was not required for this study because information was obtained from an existing database of the Advanced Beef Cattle Research

107 Center of the Animal Science Institute, Sertãozinho, SP, Brazil.

Data description

A total of 8,757 records of selection weight (SW) from males and females born between

1111981 and 2017, 3,331 records of scrotal circumference (SC) collected at 378 days of age from

112 males born between 1990 and 2017, and 2,311 records of days to first calving (DFC) from

113 females born between 1981 and 2015 were analyzed.

114 The beef cattle selection program at this center began in 1976 with the objective of

115 increasing the postweaning weight of Nellore cattle based on individual performance, thus

116 offering an adequate data structure to assess the effect of selection practices on the animals' 
117 environmental sensitivity. In 1980, the Nellore population was divided into three selection

118 lines. The control $(\mathrm{NeC})$ line is a closed line in which sires from the same center were used and

119 the animals were selected for average postweaning weight. The selection (NeS) line is another

120 closed line, while the traditional (NeT) line is an open line in which sires from other populations

121 both within and outside the same center were used, especially during early years of the breeding program (Mercadante et al., 2003). In NeS and NeT lines, the animals were selected for the highest differentials to increase postweaning weight. In 2012, the NeT line was also selected for residual feed intake (RFI) (Sumário, 2019).

\section{Trait definitions}

In the weight gain test initially performed at the Advanced Beef Cattle Research Center, the animals were weighed after fasting for food and water, and the weights were adjusted to values at 210 days of age based on average daily gain from birth to weaning. After weaning, the males were confined in paddocks measuring 3,600 $\mathrm{m}^{2}$, with food provided ad libitum twice a day. Feed included corn silage, hay, soybean meal, ground corn, and mineral salts with urea. During confinement, all males were subjected to a performance test in which they were weighed three times. The males were confined for 168 days; the first 56 days were considered the acclimatization period and were not accounted for in the analysis. After this period, weights adjusted for values at 378 days of age were obtained, by adding the weaning weight to weight

136 gain during the confinement period. After weaning, all females were sent to a pasture and 137 weighed three to four times for a period of 340 days. After this period, the weight adjusted for value at 550 days of age was obtained, by adding weaning weight to weight gain during the 340-day period. The selection criteria used were weight adjusted to 378 days of age for males and weight adjusted to 550 days of age for females. In this study, these weights were considered

141 the same trait (SW). In this study, only males were confined shortly after weaning but females 
were sent to a pasture; therefore, SW of females was adjusted later. In addition to SW, SC $(\mathrm{cm})$ of males was measured at approximately 378 days of age, at the end of the performance test.

the breeding season, considering the difference between the dates of beginning of breeding season and calving. During quality control, data on abortions, calving outside the breeding season, and artificial insemination were excluded. Records from heifers that failed to calve were included, and a projected value was assigned to each mating record. The highest DFC record within each contemporary group (CG) by year and population of birth was identified, and 21 days were added to this record to generate the projected value for females that failed to calve (Johnston and Bunter, 1996).

\section{Environmental descriptor}

Preliminary analysis of variance was performed using generalized linear modeling with

SAS (SAS Institute Inc., Cary, NC, USA) to select non-genetic effects, such as birth year, selection line, birth month class, sex, sex-selection line interactions, and the sire effect for DFC alone, for inclusion in the model. To establish an environmental descriptor, selection line, sex, and birth year for SW and selection line and birth year for SC were considered fixed effects in the definition of CGs for each trait. However, $\mathrm{CG}$ solutions corresponding to the $\mathrm{NeC}$ line alone were used, as they would more reliably describe the environmental conditions regardless

161 of genetic trends since the beginning of the selection program. The CG for DFC included only birth year as the main effect, with records from animals of all selection lines, because the $\mathrm{NeC}$ line had no records for all studied years. CG solutions were obtained by fitting a standard animal model to the data of all studied animals, and CGs represented the environmental conditions the animals were subjected to over the years of selection (Mattar et al., 2011;

166 Cardoso and Tempelman, 2012; Santana et al., 2015). 
Data quality control

For quality control, CGs with fewer than 10 animals; with progeny of a single sire; with animals suffering from health problems; and without records of age, female age at calving, or weight at entry into the breeding season (for DFC) were excluded. Due limited data for DFC, CGs with over four observations were maintained. included as the fixed effect in the model. The model also included the following covariables: age of animal at measurement as a linear effect for all traits, age of dam at calving as linear and quadratic effects for SW and SC, and weight at entry into the breeding season for DFC. Table quality control.

Data analysis

For data analysis, an RNM with homogeneous residuals was developed, in which the breeding value was expressed along the environmental descriptor (Falconer, 1990), and described as follows:

$$
\mathrm{y}_{i j}=\text { fixed }_{\mathrm{i}}+\varphi_{f} \phi_{f}\left(\mathrm{CG}_{j}\right)+a_{j} \phi_{f}\left(\mathrm{CG}_{j}\right)+e_{i j}
$$

where $\mathrm{y}_{i j}$ is the phenotype of animal $i$ in environment $j$; fixed $\mathrm{i}_{\mathrm{i}}$ indicates the fixed effects (sex for SW, birth month class for SW and SC, and sire for DFC) and covariates [age of animal at measurement (linear) for all traits, age of dam at calving (linear and quadratic) for SW and SC, and weight at entry into the breeding season for DFC]; $\varphi_{f}$ is the fixed regression coefficient of 
$\Phi_{f} ; \Phi_{f}$ is the second-order Legendre polynomial for CG solutions in environment $j$ (i.e., the environmental descriptor $\mathrm{CG}_{j}$ obtained from the standard animal model; nested within sex for $\mathrm{SW}) ; a_{\mathrm{i}}$ is the random regression coefficient of the additive genetic effect of $\mathrm{CG} j$ on animal $i$; and $e_{i j}$ is the random residual associated with each animal $i$ along the environmental descriptor 196 CGj.

The additive genetic variances for a given environment $\mathrm{X}$ in the RNM were obtained using the following equation:

$$
\sigma_{a}^{2} \mid \mathrm{X}=\sigma_{a}^{2}+\mathrm{X}^{2} \sigma_{b}^{2}+2 \mathrm{X} \sigma_{a, b}
$$

where $\sigma_{\mathrm{a}}^{2}$ is the additive genetic variance of intercept of the reaction norm; $\sigma_{\mathrm{b}}^{2}$ is the additive genetic variance of slope of the reaction norm; and $\sigma_{\mathrm{a}, \mathrm{b}}$ is the covariance between the intercept and slope.

(Co)variance components for the selected traits were estimated by GIBBS2F90 (Misztal et al., 2002) with Bayesian inference using Gibbs sampler and a single-trait animal model. The number of cycles was determined based on the trait and selection line studied. Analyses comprised single chains of $2,500,000$ samples, with a burn-in period of 100,000 iterations and a thinning interval of 480 iterations, with the exception of DFC in the NeT line for which single chains of 3,500,000 samples, with a burn-in period of 100,000 iterations and a thinning interval of 680 iterations, were used. Thus, the variance components for the regression coefficients and genetic parameters were estimated from the remaining 5,000 samples. Inferences for all (co)variance components and genetic parameters were based on mean,

213 standard deviation, and 95\% posterior probability. The posteriori estimates were obtained using

214 POSTGIBBSF90 (Misztal et al., 2002). Owing to the complexity of models and small number 215 of records available, several tests with different number of chains and cycles were performed 216 using the BOA package in R (R Core Team, R Foundation for Statistical Computing, Vienna, 
217 Austria, 2007) until convergence occurred for all parameters according to the Geweke criteria

218 (Geweke, 1992) and weak autocorrelation between the samples was attained.

219

220

\section{Genetic trends and environmental sensitivity}

After estimating breeding values, genetic trends based on the average of estimates of the intercept (general production level) and slope (environmental sensitivity) of reaction norms for all traits according to birth year were established. A simple linear regression model was applied to these data in order to assess the significance of genetic trends. Finally, the possible effects of type of selection practiced over the years on the general genetic merit and environmental sensitivity of cattle were evaluated.

Phenotypic plasticity

An individuals' phenotypic plasticity was classified according to the standard deviation of slopes $\left(\sigma_{\mathrm{b}}\right)$ as an absolute value of $b_{j}:\left|\mathrm{b}_{\mathrm{j}}\right|<\sigma_{\mathrm{b}}$ indicates robust genotypes; $\sigma_{\mathrm{b}} \leq\left|\mathrm{b}_{\mathrm{j}}\right|<2 \sigma_{\mathrm{b}}$ indicates plastic genotypes; and $\left|b_{j}\right| \geq 2 \sigma_{b}$ indicates extremely plastic genotypes (Mattar et al., 2011). The ratio of variances of the slope and intercept was also calculated to infer about genetic variability associated with the environmental sensitivity of the reaction norm.

\section{Reclassification of animals}

To identify possible changes in ranking, the top $25 \%$ sires of all selection lines with at

237 least 5 progenies each were selected. The numbers of sires of the $\mathrm{NeC}, \mathrm{NeS}$, and $\mathrm{NeT}$ lines, respectively, per trait were 82,135 , and 164 for SW; 56, 94, and 117 for SC; and 51, 94, and

240 of sires under different environments (favorable, intermediate, or unfavorable) for each 241 selection line. 
243 favorable environments, respectively, were 180, 206, and $250 \mathrm{~kg}$ for males and 115, 149, and

$244180 \mathrm{~kg}$ for females for SW; $-1.59,0.54$, and $2.57 \mathrm{~cm}$ for SC; and 484, 518, and 560 days for

245 DFC. These reflect the expected quality of environments the animals were subjected to over 246 the selection years.

Results

The posterior mean heritability of SW for males was higher than that for females of the $\mathrm{NeC}$ and $\mathrm{NeS}$ lines $(\mathrm{NeC}: 0.56$ to 0.75 for males and 0.39 to 0.56 for females; $\mathrm{NeS}: 0.51$ to 0.62 for males and 0.37 to 0.51 for females) but practically equal to that of the NeT line $(0.53$ to 0.65 for males and 0.53 to 0.64 for females). The estimates of heritability increased with improving environmental quality, except for females of the NeT line that showed decreasing heritability along the environmental descriptor (Fig. 1). These results indicate that response to selection may vary with environment and sex.

The posterior mean heritability of SC in opposite extreme environments was comparable between the $\mathrm{NeC}$ and $\mathrm{NeT}$ lines, but estimates for the $\mathrm{NeS}$ line were slightly different. In the NeS line, the heritability estimates slightly increased with improving environmental quality; therefore, response to selection may vary with environment (Fig. 1). Mean heritability estimates along the environmental descriptor ranged from 0.26 to 0.57 for the $\mathrm{NeC}$ line, from 0.10 to 0.26 for the $\mathrm{NeS}$ line, and from 0.06 to 0.44 for the NeT line. environmental quality for all lines, with the NeS line showing the smallest increase (Fig. 1). Mean heritability estimates along the environmental descriptor ranged from 0.55 to 0.66 for the $\mathrm{NeC}$ line, from 0.46 to 0.58 for $\mathrm{NeS}$ line, and from 0.56 to 0.68 for the $\mathrm{NeT}$ line. 
$267(0.14)$ and $0.81(0.13)$ for the $\mathrm{NeC}$ and $\mathrm{NeS}$ lines, respectively, and null $(0.03 \pm 0.06)$ for the

268 NeT line. This null correlation between the interception and slope of reaction norms of SW in 269 the NeT line indicates possible reclassification of animals under different environments; in this 270 context, the selection of SW would result in little or no environmental sensitivity of animals.

271 For SC, the genetic correlation coefficients between the intercept and slope of reaction norms were $0.02(0.22), 0.39(0.33)$, and $-0.14(0.12)$ for the $\mathrm{NeC}, \mathrm{NeS}$, and $\mathrm{NeT}$ lines, respectively, which are considered low or even null due to the high standard deviation. These results also imply the possible reclassification of animals under different environments, indicating that the best animals in a particular environment would not necessarily be the best in other environments. Genetic correlation coefficients between the intercept and slope of reaction norms for DFC were $-0.49(0.44),-0.42(0.54)$, and $-0.87(0.17)$ for the $\mathrm{NeC}, \mathrm{NeS}$, and $\mathrm{NeT}$ lines, respectively. Similar to those of other traits, correlations of DFC for the $\mathrm{NeC}$ and $\mathrm{NeS}$ lines were considered null due to the high standard deviation, indicating possible reclassification of animals in different environments. for all lines $(0.95$ for males and 0.80 for females of the $\mathrm{NeC}$ line; 0.98 for males and 0.95 for females of the NeS line; and 0.78 for males and 0.81 for females of the NeT line). Genetic correlation coefficients for SW between intermediate and extreme environments were also high for both males and females of all three lines, ranging from 0.92 to 1 under favorable

286 environments and from 0.93 to 0.99 under unfavorable environments (Fig. 2). Genetic correlation coefficients for SC in opposite extreme environments were moderate for all lines (NeC, 0.28; NeS, 0.69; and NeT, 0.38) (Fig. 2). Genetic correlation coefficients for SC between intermediate and extreme environments were also high (favorable: $\mathrm{NeC}, 0.81 ; \mathrm{NeS}, 0.93$; and

NeT, 0.91; unfavorable: $\mathrm{NeC}, 0.79$; NeS, 0.90 , and NeT, 0.85). Contrary to those for other 
291 traits, genetic correlation coefficients for DFC in opposite extreme environments were low for 292 all lines $(\mathrm{NeC},-0.15$; NeS, -0.04; and $\mathrm{NeT},-0.15)$ (Fig. 2). For all lines, genetic correlation 293 coefficients for DFC between intermediate and favorable environments were high, ranging 294 from 0.84 to 0.96 , while those between intermediate and unfavorable environments were low, 295 ranging from 0.12 to 0.50 . These results suggest an important effect of $\mathrm{G} \times \mathrm{E}$ on $\mathrm{DFC}$ in different environments. males and $0.09(0.06)$ for females of the $\mathrm{NeC}$ line; $2.60(0.13)$ for males and $2.81(0.14)$ for females of the NeS line; and $3.23(0.18)$ for males and $3.52(0.23) \mathrm{kg}_{\text {year }}{ }^{-1}$ for females of the

300 NeT line (Fig. 3). Genetic trend for the NeC line was non-significant (P > 0.05). The NeS and

301 NeT lines tended to show higher productive performance for this trait, particularly the NeT line, which was expected since both lines were selected for the highest postweaning weight differentials. Regression coefficients of intercept of the reaction norm for SC were $0.01(0.01)$, $0.06(0.01)$, and $0.08(0.01) \mathrm{cm}$ year $^{-1}$ for the $\mathrm{NeC}, \mathrm{NeS}$, and NeT lines, respectively (Fig. 3), Genetic trend for the $\mathrm{NeC}$ line was non-significant $(\mathrm{P}>0.05)$, while the $\mathrm{NeS}$ and $\mathrm{NeT}$ lines tended to show higher productive performance for this trait. Regression coefficients of intercept of the reaction norm for DFC, were decreasing and with values of $-0.56(0.06) ;-0.19(0.02)$, and $-0.12(0.01)$ days year-1 for the $\mathrm{NeC}, \mathrm{NeS}$, and $\mathrm{NeT}$ lines, respectively (Fig. 4). Indicating higher reproductive performance of heifers, particularly of the $\mathrm{NeC}$ line. Regression coefficients of slope of the reaction norm for SW were $-0.003(0.01)$ for males and $0.004(0.02)$ for females of the $\mathrm{NeC}$ line; $0.39(0.02)$ for males and $0.42(0.02)$ for

312 females of the NeS line; and $-0.14(0.06)$ for males and $-0.13(0.07) \mathrm{kg}$ year $^{-1}$ for females of

313 the NeT line (Fig. 4). Genetic trends for both sexes of the $\mathrm{NeC}$ line as well as for females of 314 the NeT line were non-significant $(\mathrm{P}>0.05)$. Genetic trends for both sexes of the NeS line 315 alone moved toward greater sensitivity, indicating that these animals are becoming more 
316 responsive to environmental changes. Regression coefficients of slope of the reaction norm for

317 SC were $-0.004\left(0.001,0.01(0.001)\right.$, and $-0.01(0.003) \mathrm{cm} \cdot y^{-}{ }^{-1}$ for the $\mathrm{NeC}, \mathrm{NeS}$, and NeT

318 lines, respectively (Fig. 4). Again, genetic trends for the NeS line alone moved toward a greater

319 sensitivity, indicating a greater ability to respond to environmental changes. Regression

320 coefficients of slope of the reaction norm for DFC were $0.17(0.02), 0.06(0.01)$, and $0.06(0.01)$

321 daysyear $^{-1}$ for the $\mathrm{NeC}, \mathrm{NeS}$, and $\mathrm{NeT}$ lines, respectively (Fig. 4), indicating that all three lines,

322 albeit slowly, are moving toward greater sensitivity. Specifically, the $\mathrm{NeC}$ line presented the greatest increasing genetic trend for this trait.

The observed frequencies of robust, plastic, and extremely plastic genotypes of SE, SC,

and DFC are presented in Figure 5. The results for SW indicated that key differences in environmental sensitivity associated with this trait could be verified, especially in the NeS line, which was more sensitive to environmental changes. The percentages of plastic and extremely plastic genotypes were $30.98 \%$ for males and $30.83 \%$ for females of the $\mathrm{NeC}$ line; $54.80 \%$ for males and $56.31 \%$ for females of the NeS line; and $38.91 \%$ for males and $35.51 \%$ for females of the NeT line. The ratios of variances between the slope and intercept of reaction norm for SW were $0.13,0.04$, and 0.20 for the $\mathrm{NeC}, \mathrm{NeS}$, and $\mathrm{NeT}$ lines, respectively, indicating that the NeS line showed the lowest genetic variability associated with environmental sensitivity proportionally to the intercept, as opposed to the NeT line, which showed the greatest variability associated with environmental sensitivity.

The results for SC followed the trends for SW, indicating that key differences in environmental sensitivity associated with this trait could be verified, particularly for the $\mathrm{NeS}$ line, which showed more plastic genotypes than robust ones, corroborating the positive genetic trend for environmental sensitivity. The percentages of plastic and extremely plastic genotypes were $34.28 \%, 51.26 \%$, and $32.23 \%$ for the $\mathrm{NeC}$, $\mathrm{NeS}$, and $\mathrm{NeT}$ lines, respectively. The ratios

340 of variance between the slope and intercept of reaction norm for SC were $0.19,0.06$, and 0.15 
341 for the $\mathrm{NeC}, \mathrm{NeS}$, and $\mathrm{NeT}$ lines, respectively, indicating that the $\mathrm{NeS}$ line showed the lowest

342 genetic variability associated with environmental sensitivity proportionally to the intercept.

343 However, unlike that for $\mathrm{SW}$, the $\mathrm{NeC}$ line showed the greatest genetic variability associated

344 with environmental sensitivity for SC.

345 The ratios of variance between the slope and intercept of reaction norm for DFC were

$3460.44,0.36$, and 0.39 for the $\mathrm{NeC}, \mathrm{NeS}$, and $\mathrm{NeT}$ lines, respectively, indicating greater genetic

347 variability associated with environmental sensitivity for DFC. Moreover, the percentage of

348 robust genotypes of this trait were high in all lines $(58.76 \%, 67.39 \%$, and $67.38 \%$ for the $\mathrm{NeC}$,

$349 \mathrm{NeS}$, and NeT lines, respectively). However, genetic trends-based regression coefficients of

350 slope of reaction norm for this trait indicated a high percentage of robust genotypes, indicating

351 an increasing trend of environmental sensitivity in these animals.

352 Spearman correlation analysis revealed potential changes in the classification of top

$35325 \%$ sires each selection line in each environment (Table 2). For SW, the Spearman correlation

354 coefficients between favorable and intermediate environments were moderate for the $\mathrm{NeC}$ and

355 NeT lines and high for the NeS line, whereas correlation coefficients between the favorable

356 and unfavorable environments were low for the $\mathrm{NeC}$ and $\mathrm{NeT}$ lines and high for the $\mathrm{NeS}$ line;

357 genetic trend for the $\mathrm{NeC}$ line was non-significant. For SC, Spearman correlation coefficients

358 between favorable and intermediate environments were high for all lines, with the NeT line

359 showing the lowest values among the three lines. Spearman correlation coefficients between

360 favorable and unfavorable environments were moderate for the $\mathrm{NeC}$ and $\mathrm{NeT}$ lines and high

361 for the NeS line. And, for DFC, Spearman correlation coefficients between favorable and 362 intermediate environments were low for the $\mathrm{NeC}$ and $\mathrm{NeT}$ lines and negative for the $\mathrm{NeT}$ line;

363 however, genetic trends for all lines were non-significant. The correlation coefficient for the

364 NeS line was moderate, but below 0.80. Spearman correlation coefficients between favorable 
and unfavorable environments were low for all lines, and genetic trends for the $\mathrm{NeC}$ and $\mathrm{NeT}$ lines were non-significant.

\section{Discussion}

In this study, the posterior mean heritability of $\mathrm{SW}$ in the $\mathrm{NeC}$ and $\mathrm{NeS}$ lines was higher in the most favorable environments, which is consistent with trends reported by Araújo Neto et al. (2018) (heritability estimates, 0.28 to 0.55 ). In contrast, the NeT line showed a slight decrease in heritability, indicating that genetic parameters may vary depending on environment in this case, unfavorable environment.

Chiaia et al. (2015) reported heritability estimates for SC ranging between 0.51 and 0.67 , similar to the estimates obtained in this study; however, they reported that heritability increased as the environment became less restricted, which occurred only in the NeS line in the present study. For the other two lines, heritability estimates were similar under opposite extreme environments and lower in intermediate environments, corroborating the results of Santana et al. (2013). Therefore, $\mathrm{SC}$ of the $\mathrm{NeC}$ and $\mathrm{NeT}$ lines showed a satisfactory response to selection in both unfavorable and favorable environments.

The heritability estimates for DFC showed an increasing trend in all lines, with the highest values obtained in favorable environments. This trend indicates a possible greater response to selection in favorable environments, which would allow for the selection of more precocious heifers for breeding in these environments. Consistent with these trends, Chiaia et al. (2015) and Lemos et al. (2015) observed that the heritability of reproductive traits of Nellore females increased as the environments became less restricted. $\mathrm{NeC}$ and $\mathrm{NeS}$ lines indicated that a higher general productive performance of these lines is genetically associated with increased SW due to improvements in the environment. Although 
390 this trend is interesting, as it would facilitate the selection of best animals, it may be detrimental 391 in unfavorable environments, as animals may show poor performance. These trends 392 corroborate the findings reported by Santana et al. (2013). In the NeT line, null correlation 393 indicated possible reclassification of animals in different environments, corroborating the

394 findings of Ribeiro et al. (2017) and Araújo Neto et al. (2018). Regarding reproduction-related 395 traits of the $\mathrm{NeC}$ and $\mathrm{NeS}$ lines, while the correlations between intercept and slope of reaction 396 norms were positive for SC, these were negative for DFC. However, due to high standard 397 deviation, both traits showed trends indicating possible reclassification of animals in different 398 environments. In the NeT line, the correlations were negative for both traits. While the 399 correlations for SC were practically null, those for DFC were high, indicating possible 400 reclassification of breeding values in different environments; these results are consistent with the reports of Santana et al. (2013).

According to Robertson (1959), genetic correlation between the same traits in different environments below 0.80 demonstrate an important effect of $\mathrm{G} \times \mathrm{E}$ and indicate possible reclassification of breeding values. Genetic correlations of SW in opposite extreme environments were high for all lines, except for males in the NeT line, indicating that selection in any environment may be relevant for breeding programs aimed at selecting this trait under extreme environments, this facilitates the selection process in different environments. The expression of this trait is essentially the same between environments, as evidenced by Santana et al. (2013).

All genetic correlation coefficients of SC in opposite extreme environments were below

4110.80 , demonstrating an important effect of $\mathrm{G} \times \mathrm{E}$ and indicating possible reclassification of

412 animals in these environments. Genetic correlations of SC in intermediate and opposite extreme 413 environments were high in the $\mathrm{NeS}$ and NeT lines, corroborating the trends reported by Santana 414 et al. (2015). 
417 negative genetic correlations of age at first calving (-0.27) in opposite environments, demonstrating an important effect of $\mathrm{G} \times \mathrm{E}$ in these environments.

Genetic trends observed for regression coefficients of intercept of reaction norms for

SW and SC were non-significant in the $\mathrm{NeC}$ line, but significant and positive in the $\mathrm{NeS}$ and

NeT lines, indicating genetic gain over the years in both lines selected for the highest $\mathrm{SC}$ in the NeS and NeT lines.

All lines showed genetic gain for DFC, albeit with negative trends, indicating that heifers tended to impregnate earlier during the breeding season, showing precocity, over the years; however, the less downward trend was observed in the $\mathrm{NeC}$ line. This may be explained by the possible negative effects of selection for highest differentials to increase postweaning weight on DFC. In other words, selection to increase postweaning weight likely impaired the reproductive performance of heifers of the $\mathrm{NeS}$ and $\mathrm{NeT}$ lines, at least compared with that of heifers of the $\mathrm{NeC}$ line (Fig. 3).

Genetic trends for the regression coefficients of slope of reaction norm for SW in the

$\mathrm{NeC}$ line were non-significant; however, the $\mathrm{NeS}$ and NeT lines followed opposite trends. For animals of the NeS line, genetic trends for this trait indicated that this line is moving toward greater sensitivity, that is, becoming more responsive to environmental changes. Moreover, animals of this line showed a significant genetic gain, as demonstrated by regression coefficients of intercept of reaction norm for this trait, which corroborates the trends reported by Santana et al. (2015). For animals of the NeT line indicated a decrease in the animals' 
440 gain for SW, as demonstrated by higher coefficient of intercept of reaction norm for this trait 441 in the NeT line than in the NeS line. were negative in the $\mathrm{NeC}$ and $\mathrm{NeT}$ lines and positive in the $\mathrm{NeS}$ line. As stated earlier, these opposite trends between the selected lines may be explained by the selection of the highest differentials to increase postweaning weight in $\mathrm{NeS}$ and $\mathrm{NeT}$ lines. Animals of the $\mathrm{NeC}$ and

NeT lines showed a decreased tendency to respond to environmental changes, corroborating the findings of Santana et al. (2015) reported a negative genetic trend of environmental sensitivity for SC in study with Nellore cattle.

Genetic trends observed for the regression coefficients of slope of reaction norm for DFC showed positive regression coefficients for all lines, indicating that the animals of these three lines, particularly of the $\mathrm{NeC}$ line, are moving toward greater sensitivity. Mota et al. (2020) also observed high environmental sensitivity associated with DFC, indicating possible reclassification of heifers under restricted environments. in response to changing environmental conditions (Bradshaw, 1965). However, the effects of different selection practices on environmental sensitivity of animals remain poorly understood. In a study by Tonsor et al. (2013), a reduction in heritability may be due to plasticity resulting in a lower response to selection. In the present study, the heritability estimates of SW and SC in the $\mathrm{NeS}$ line were lower than estimates in the $\mathrm{NeT}$ and $\mathrm{NeC}$ lines. In the $\mathrm{NeS}$ line, the animals

460 are selected exclusively for highest differentials to increase postweaning weight, resulting in 461 greater selection pressure for weight, which decreases genetic variability this trait. In addition to, as consequence of the high genetic correlation that exists between weight and SC, we also have the correlated response for SC (Pires et al., 2016). The NeT line is selected for highest 
differentials to increase postweaning weight as well as for RFI, which decreased the selection pressure on weight in this line.

Phenotypic robustness and plasticity are closely related to $\mathrm{G} \times \mathrm{E}$, and the presence of diverse reaction norms across different genotypes is indicative of occurrence of $\mathrm{G} \times \mathrm{E}$ (De Jong and Bijma, 2002; Souza et al. 2016), as evidenced in this study. We observed significant genetic trends associated with environmental sensitivity for all traits, specifically in the NeS line.

For SW and SC, animals of the $\mathrm{NeC}$ and $\mathrm{NeT}$ lines were considered more robust, with null or negative genetic trends, indicating that animals of these lines tend to respond more modestly to environmental changes; however, performance of the NeT line was evidently better than that of the $\mathrm{NeC}$ line and even better than that of the $\mathrm{NeS}$ line. Animals of the NeS line, on the other hand, were more sensitive to environmental changes, as evidenced by the higher frequency of plastic and extremely plastic genotypes $(>50 \%)$ and the positive trend of coefficients of slope of the reaction norms for all traits in this line.

DFC was the most plastic trait, and all lines were considered plastic for this trait, with a greater genetic variability (De Jong and Bijma, 2002). Despite the higher percentage of robust genotypes of this trait, all animals, particularly of the $\mathrm{NeC}$ line, tended to exhibit greater plasticity or sensitivity environmental. Based on the upward trends of coefficients of slope of reaction norm for this trait and according to the results reported by Falconer (1990), variation in the slope of reaction norm for a trait is directly associated with $\mathrm{G} \times \mathrm{E}$, thus reflecting the environmental sensitivity of animals.

According to Strandberg et al. (2000), an ideal breeding system would be the one in which genotypes show high performance with a slope close to zero, that is, more robust animals with a better performance in different environments. This could be the case for animals of the NeT line, which showed an overall higher performance than animals of the NeS line; however, 
these animals showed a greater percentage of robust phenotypes, with downward or null trends of coefficients of slope of reaction norm for some traits.

Among the top $25 \%$ sires within a selection line, the correlation coefficients for traits were mostly below 0.80 in the $\mathrm{NeC}$ line, except for $\mathrm{SC}$, which showed higher correlation coefficients $(>0.80)$ between favorable and intermediate environments. These results indicate 493 possible reclassification of animals of this line for all traits, confirming the importance of including $\mathrm{G} \times \mathrm{E}$ in genetic evaluations of these traits. According to Ambrosini et al. (2016) and Corrêa et al. (2010), even moderate correlations can lead to reclassification of animals. Unlike those of the other lines, sires of the NeS line showed higher correlation coefficients than the reference value for SW and SC but lower correlation coefficients than the reference value for $\mathrm{DFC}$, indicating possible reclassification of sires for DFC. Possible reclassifications for all traits were observed for sires of the NeT line. Similarly, Santos et al. (2008) have reported weak correlations of traits between opposite environments. sensitivity. Genetic correlations between the traits of interest for selection, such as reproductive traits, can produce either positive or negative side effects. Negative side effects of SW on DFC the same does not seem to have occurred with on SC were observed, perhaps because SC is not as plastic as reported by Santana et al. (2013). Nonetheless, the intriguing differences between the plastic NeS line and the robust $\mathrm{NeT}$ line may be due to many factors. For instance, the NeS

507 line has been subjected to a greater selection pressure as it is selected only for the highest 508 postweaning weight differentials, while the line NeT is selected for RFI as well. In addition, the NeT line was the only one to receive sires from both within and outside the center.

511 environmental sensitivity of Nellore cattle lines tested in this study. The $\mathrm{NeC}$ line, but not the

$512 \mathrm{NeS}$ and NeT lines, showed approximately null genetic trends for regression coefficients of 
513 slope of reaction norms of selected traits. While the NeS line showed greater environmental sensitivity, the NeT line was more robust and less responsive to environmental changes. However, all lines showed a trend toward greater environmental sensitivity for DFC. Our results also suggest that selection for increased postweaning weight gain may affect the animals' environmental sensitivity, including their genetic parameters and ranking, in addition to a likely side effect on reproductive traits estimates along the environmental descriptor, weak genetic correlations of traits between opposite extreme environments, and possible reclassification of top $25 \%$ sires under different environments, particularly for the $\mathrm{NeC}$ and $\mathrm{NeT}$ lines and for DFC. genetic evaluations. The environmental sensitivity is an important trait that should be included in the selection indices for growth and reproductive traits of Nellore cattle.

\section{Declaration of interest}

The authors declare no conflicts of interest.

\section{Literature cited}

531 Aguilar, I., Misztal, I., Tsuruta, S. 2010. Genetic trends of milk yield under heat stress for US

532 Holsteins. J. Dairy Sci. 93(4):1754-1758. doi: 10.3168/jds.2009-2756

533 Ambrosini, D. P., Malhado, C. H. M., Martins filho, R., Carneiro, P. L. S. 2016. Interação genótipo x ambiente via modelos de normas de reação para características de crescimento em bovinos Nelore. Pesq. Agropec. Bras. Brasília. 51(2):177-186. doi: 10.1590/S0100- 
537 Araújo Neto, F. R., Pegolo, N. T., Aspilcueta-Borquis, R. R., Pessoa, M. C., Bonifácio, A., 538 Lobo, R. B., De Oliveira, H. N. 2018. Study of the effect of genotype-environment interaction 539 on age at first calving and production traits in Nellore cattle using multi-trait reaction norms 540 and Bayesian inference. Anim. Sci. J. 89(7):939-945. doi: https://doi.org/10.1111/asj.12994

541 Bradshaw, A. D. 1965. Evolutionary significance of phenotypic plasticity in plants. Adv. genet.

542 New York. 13(21):115-155.

543 Carabaño, M. J., Ramón, M., Menéndez-Buxadera, A., Molina, A., Díaz, C. 2019. Selecting 544 for heat tolerance. Anim. Front. 9(1):62-68. doi: 10.1093/af/vfy033

545 Cardoso, L. L., Braccini neto, J., Cardoso, F. F., Cobuci, J. A., Biassus, I. O., Barcellos, J. O. 546 J. 2011. Hierarchical Bayesian models for genotype environment estimates in post-weaning 547 gain of Hereford bovine via reaction norms. R. Bras. Zootec. 40:294-300. doi: https://doi.org/10.1590/S1516-35982011000200009

549 Cardoso, F. F., Tempelman, R. J. 2012. Linear reaction norm models for genetic merit 550 prediction of Angus cattle under genotype by environment interaction. J. Anim. Sci, 551 Champaign. 90(7):2130-2141. doi: 10.2527/jas.2011-4333

552 Chiaia, H. L. J., De LEmos, M. V. A., Venturini, G. C., Aboujaoude, C., Berton, M. P., Feitosa, 553 F. B., Carvalheiro, R., Albuquerque, L. G., Oliveira, H. N., Baldi, F. 2015. Genotype x 554 environment interaction for age at first calving, scrotal circumference, and yearling weight in 555 Nellore cattle using reaction norms in multi-trait random regression models. J. Anim. 556 Sci, Champaign. 93(4):1503-1510. doi:10.2527/jas2014-8217

557 Corrêa M. B. B., Dionello N. J. L., Cardoso F. F. 2009. Caracterização da interação genótipo558 ambiente e comparação entre modelos para ajuste do ganho pós-desmama de bovinos Devon 559 via normas de reação. R. Bras. Zootec, Viçosa. 38:1468-1477. doi: 560 https://doi.org/10.1590/S1516-35982009000800010 
561 Corrêa, M.B.B., Dionello, N.J.L., Cardoso, F.F. 2010. Genetic evaluation of Devon Cattle

562 using a reaction norms model. R. Bras. Zootec. 39:128-133. doi:

563 https://doi.org/10.1590/S1516-35982010000100017

564 De Jong, G. 1995. Phenotypic plasticity as a product of selection in a variable environment.

565 Am. Nat. Chicago. 145(4):493-512, 1995. https://doi.org/10.1086/285752

566 De Jong, G., Bijma, P. 2002. Selection and phenotypic plasticity in evolutionary biology and

567 animal breeding. Livest. Prod. Sci. Shannon. 78(3):195-214. doi:

568 https://doi.org/10.1016/S0301-6226(02)00096-9

569 Falconer, D. S. 1990. Selection in different environments: effects on environmental sensitivity

570 (reaction norm) and on mean performance. Genet. Res. Cambridge. 56:57-70. doi:

571 https://doi.org/10.1017/S0016672300028883

572 Geweke, J. 1992. Evaluating the accuracy of sampling-based approaches to the calculation of

573 posterior moments. Bernardo, J.M., Berger, J.O., Dawid, A.P., Smith, A.F.M., editors. 4,

574 Bayesian statistics. New York, USA: Oxford University Press. p.625-631.

575 Johnston, D. J., K. L. Bunter. 1996. Days to calving in Angus cattle: Genetic and environmental

576 effects, and covariances with other traits. Livest. Prod. Sci. 45:13-22. doi:

577 https://doi.org/10.1016/0301-6226(95)00088-7

578 Kolmodin, R., Strandberg, E., Madsen, P., Jensen, J., Jorjani, H. 2002. Genotype by 579 environment interaction in Nordic dairy Cattle studied using reaction norms. ACTA Agr

580 SCAND A-AN. Stockholm. 52(1):11-24. doi: 10.1080/09064700252806380

581 Kolmodin, R., Bijma, P. 2004. Response to mass selection when the genotype by environment 582 interaction is modelled as a linear reaction norm. Genet. Sel. Evol. London. 36(4):1-20. doi: 10.1051/gse:2004010

584 Lemos, M. V. A., Chiaia, H. L. J., Berton, M. P., Feitosa, F. L. B., Aboujaoude, C., Venturini,

585 G. C., Oliveira, H. N., Albuquerque, L. G., Baldi, F. 2015. Reaction norms for the study of 
genotype-environment interaction for growth and indicator traits of sexual precocity in Nellore cattle. Genet. Mol. Res. 14(Suppl. 2):7151-7162. doi: http://dx.doi.org/10.4238/2015.June.29.9 Lima Silva, T., Carneiro, P. L. S., Ambrosini, D. P., Lôbo, R. B., Martins Filho, R., Malhado, C. H. M. 2019. Genotype-environment interaction in the genetic variability analysis of 590 reproductive traits in Nellore cattle. Livest. Sci. 230:103825. doi: $\underline{\text { https://doi.org/10.1016/j.livsci.2019.103825 }}$

Mattar, M., Silva, L. O. C., Alencar, M. M., Cardoso, F. F. 2011. Genotype $\times$ environment interaction for long-yearling weight in Canchim cattle quantified by reaction norm analysis. J. Anim. Sci, Champaign. 89:2349-2355. doi:10.2527/jas.2010-3770 2003. Direct and correlated responses to selection for yearling weight on reproductive performance of Nelore cows. J. Anim. Sci. 81:376-84. doi: https://doi.org/10.2527/2003.812376x

Misztal, I., Tsuruta, S., Strabel, T., Auvray, B., Druet, T., Lee, D. H. 2002. BLUPF90 and 600 related programs. In: INRA, editor. 7th World Congress on Genetics Applied to Livestock 601 Production. Montpellier, France. p.4.

602 Mota, R. R., Tempelman, R. J., Lopes, P. S., Aguilar, I., Silva, F. F., Cardoso, F. F. 2016.

603 Genotype by environment interaction for tick resistance of Hereford and Braford beef cattle 604 using reaction norm models. Genet. Sel. Evol. London. 48:3. doi: 10.1186/s12711-015-0178$605 \quad 5$

606 Mota, L. F., Lopes, F. B., Júnior, G. A. F., Rosa, G. J., Magalhães, A. F., Carvalheiro, R., 607 Albuquerque, L. G. 2020. Genome-wide scan highlights the role of candidate genes on 608 phenotypic plasticity for age at first calving in Nellore heifers. Sci. Rep. 10(1):1-13. doi: 609 https://doi.org/10.1038/s41598-020-63516-4 
610 Pires, B. C., Tholon, P., Buzanskas, M. E., Sbardella, A. P., Rosa, J. O., Campos Da Silva, L.

611 O., Torres Júnior, R. A. A., Munari, D. P., Mello De Alencar, M. 2016. Genetic analyses on

612 bodyweight, reproductive, and carcass traits in composite beef cattle. Anim. Prod. Sci. 613 57(3):415-421. doi: http://dx.doi.org/10.1071/AN15458

614 Raidan, F. S. S., Passafaro, T. L., Fragomeni, B. O., Josahkian, L. A., Pereira, I. G., Toral, F.

615 L. B. 2015. Genotype $\mathrm{x}$ environment interaction in individual performance and progeny tests 616 in beef cattle. J. Anim. Sci, Champaign. 93(3):920-933. doi:10.2527/jas2014-7983

617 Ribeiro, S., Eler, J. P., Balieiro, J. C. C., Ferraz, J. B. S., Pedrosa, V. B., Mattos, E. C. 2009. 618 Influência da interação genótipo x ambiente sobre o peso à desmama em bovinos da raça 619 Nelore. Arq. Bras. Med. Vet. Zootec. Belo Horizonte. 61(3):668-675. doi: 620 http://dx.doi.org/10.1590/S0102-09352009000300021

621 Ribeiro, S., Eler, J. P., Pedrosa, V. B., Rosa, G. J. D. M., Ferraz, J. B. S., Balieiro, J. C. C. 622 2015. Genotype x environment interaction for weaning weight in Nellore cattle using reaction norm analysis. Livest. Sci. Amsterdam. 176:40-46.

624 Ribeiro, S., Eler, J. P., Pedrosa, V. B., Rosa, G. J. D. M., Ferraz, J. B. S., Balieiro, J. C. C. 625 2017. Genotype by environment interaction for yearling weight in Nellore cattle applying 626 reaction norms models. Anim. Prod. Sci. 58(11):1996-2002. doi: 627 http://dx.doi.org/10.1016/j.livsci.2015.03.032

628 Robertson. A. 1959. The sampling variance of the genetic correlation coefficient. Biometrics 629 15:469-485. doi: 10.2307/2527750

630 Santana, M. L., Eler, J. P., Cardoso, F. F., Albuquerque, L. G., Ferraz, J. B. S. 2013. Phenotypic 631 plasticity of composite beef cattle performance using reaction norms model with unknown 632 covariate. Animal. 7(2)202-210. doi:10.1017/S1751731112001711

633 Santana, M. L., Eler, J. P., Bignardi, A. B., Menéndez-Buxadera, A., Cardoso, F. F., Ferraz, J. 634 B. S. 2015. Multi-trait linear reaction norm model to describe the pattern of phenotypic 
635 expression of some economic traits in beef cattle across a range of environments. J. Appl. 636 Genet. Heidelberg, .56(2):219-229. doi: 10.1007/s13353-014-0242-9

637 Santos, G. G., Corrêa, G. S. S., Valente, B. D., Silva, M. A., Corrêa, A. B., Felipe, V. P. S., 638 Wenceslau, R. R. 2008. Sensibilidade dos valores genéticos de codornas de corte em 639 crescimento às modificações de níveis de proteína das dietas. Arq. Bras. Med. Vet. Zootec. 640 60:1188-1196. doi: https://doi.org/10.1590/S0102-09352008000500022

641 Silva, J.A. de V., Van Melis, M.H., Eler, J.P., Ferraz, J.B.S. 2003. Estimação de parâmetros 642 genéticos para probabilidade de prenhez aos 14 meses e altura na garupa em bovinos da raça Nelore. R. Bras. Zootec. 32:1141-1146. doi: https://doi.org/10.1590/S151635982003000500014

645

Souza, L. A., Malhado, C. H. M., Braccini Neto, J., Martins Filho, R., Carneiro, P. L. S. 2016. Genotype-environment interactions on the weight of Tabapua cattle in the northeast of Brazil. Rev. Caatinga. 29(1):206-215. doi: https://doi.org/10.1590/1983-21252016v29n124rc Souza, J. C., Fialho, F. R. L., Rezende, M. P. G., Machado, C. H. C., Alencar, M. P., De Souza, C. F., Ferraz Filho, P. B., Ferraz, A. L. J. 2018. Genotype-environment interaction, genetic trends, and performance dissimilarity of Nellore herds raised in three different environmental gradients. Semina: Ciênc. Agrár. 39(1), 349-362. doi: 10.5433/1679-0359.2018v39n1p349 técnico (INFOTECA-E), Aracaju, SE, dezembro, 2003, 47p. Disponível em:

654 https://www.infoteca.cnptia.embrapa.br/bitstream/doc/897925/1/LivroGXE.pdf. Access in: 655 jun 2020.

656 Sumário .2019. Sumário de touros e matrizes nelore de touros e matrizes Nelore. Instituto de Zootecnia. Nova Odessa, SP. p.1-28.

658 Strandberg, E. 2000. Genotype by environment interaction in Nordic Dairy Cattle studied by 659 use of reaction norms, Slovenia. In: Porceedings Interbull meeting, Bled Slovenia: p.41-45. 
660 Tonsor, S. J., Elnaccash, T. W., Scheiner, S. M. 2013. Developmental instability is genetically 661 correlated with phenotypic plasticity, constraining heritability, and fitness. Evolution.

662

663

664

665

666

667

668

669

670

671

672

673

674

675

676

677

678

679

680

681

682

683

684 67:2923-2935. doi:10.1111/evo.12175

Woltereck, R. 1909. Weitere experimentelle Untershungen uber Artveranderung speziel uber das Wesen quatitativer Artunterschiede bei Daphniden. Further Experimantal Investigations about Species Change, Especially about the Essense of Quantitative Differences in Daphnia. Verh. Dtsch. Zool. Ges. 19:110-173, 1909.

\section{Figure legends}

Figure 1. Heritability estimates of selection weight (SW, $\mathrm{kg}$ ) in males and females, scrotal circumference $(\mathrm{SC}, \mathrm{cm}$ ), and days at first calving (DFC, days) along the environmental descriptor for in three Nellore cattle lines $(\mathrm{NeC}$, control; NeS, selection; and $\mathrm{NeT}$, traditional line).

Figure 2. Genetic correlations between selection weight (SW, $\mathrm{kg}$ ) of males and females, scrotal circumference (SC, cm), and days at first calving (DFC, days) along the environmental descriptor in three Nellore cattle lines ( $\mathrm{NeC}$, control; NeS, selection; and NeT, traditional).

Figure 3. Genetic trends for regression coefficients related to the intercept of reaction norms for selection weight (SW), scrotal circumference (SC), and days at first calving (DFC) in three Nellore cattle lines ( $\mathrm{NeC}$, control; $\mathrm{NeS}$, selection; and $\mathrm{NeT}$, traditional), $\mathrm{NeC} \_\mathrm{M}$, males of the control line; $\mathrm{NeC} \_\mathrm{F}$, females of the control line; NeS_M, males of the selection line; NeS_F, females of the selection line; NeT_M, males of the traditional line; NeT_F, females of the traditional line.

Figure 4. Genetic trends for regression coefficients related to the slope of reaction norms for selection weight (SW), scrotal circumference (SC), and days at first calving (DFC) in three Nellore cattle lines ( $\mathrm{NeC}$, control; $\mathrm{NeS}$, selection; and NeT, traditional); NeC_M, males of the 
685 control line; NeC_F, females of the control line; NeS_M, males of the selection line; NeS_F, 686 females of the selection line; NeT_M, males of the traditional line; NeT_F, females of the 687 traditional line.

688 Figure 5. Observed frequencies of robust, plastic, and extremely plastic genotypes for selection 689 weight (SW), scrotal circumference (SC), and for days at first calving (DFC) in three Nellore 690 cattle lines $(\mathrm{NeC}$, control; $\mathrm{NeS}$, selection; and NeT traditional); NeC_M, males of the control 691 line; NeC_F, females of the control line; NeS_M, males of the selection line; NeS_F, females 692 of the selection line; NeT_M, males of the traditional line; NeT_F, females of the traditional 693 line.

694 
695 Table 1. Descriptive data of the control $(\mathrm{NeC})$, selection $(\mathrm{NeS})$, and traditional $(\mathrm{NeT})$ lines of 696 Nellore cattle

\begin{tabular}{|c|c|c|c|}
\hline Variable & $\mathrm{NeC}$ & NeS & NeT \\
\hline \multicolumn{4}{|l|}{ Selection weight, kg } \\
\hline Animals in the pedigree & 1,964 & 3,756 & 4,975 \\
\hline Sires & 86 & 138 & 180 \\
\hline Dams & 437 & 899 & 1150 \\
\hline Animals with measurements & 1,592 & 3,146 & 4,019 \\
\hline Males & 820 & 1,562 & 1,979 \\
\hline Females & 772 & 1,584 & 2,040 \\
\hline Contemporary groups & 74 & 74 & 74 \\
\hline Mean of the trait (standard deviation) & $\begin{array}{l}264.7 \\
(33.2) \\
\end{array}$ & $\begin{array}{l}310.8 \\
(48,7) \\
\end{array}$ & $\begin{array}{l}314.6 \\
(51.2) \\
\end{array}$ \\
\hline \multicolumn{4}{|l|}{ Scrotal circumference, $\mathrm{cm}$} \\
\hline Animals in the pedigree & 1,204 & 2,468 & 3,159 \\
\hline Sires & 66 & 114 & 146 \\
\hline Dams & 276 & 566 & 692 \\
\hline Males with measurements & 601 & 1,188 & 1,542 \\
\hline Contemporary groups & 28 & 28 & 28 \\
\hline Mean of the trait (standard deviation) & $21.9(2.4)$ & $22.9(2.5)$ & $23,6(2.9)$ \\
\hline \multicolumn{4}{|l|}{ Days to first calving, days } \\
\hline Animals in the pedigree & 893 & 1469 & 1860 \\
\hline Sires & 73 & 125 & 141 \\
\hline Dams & 242 & 516 & 548 \\
\hline Heifers with measurements & 450 & 926 & 935 \\
\hline Contemporary groups & 35 & 35 & 35 \\
\hline Mean age for entry into the breeding season (standard & 774.9 & 769.8 & 771.6 \\
\hline deviation) & $(23.2)$ & $(24.9)$ & $(24.9)$ \\
\hline & 340.9 & 349.4 & 346.1 \\
\hline Mean of the trait (standard deviation) & $(35.6)$ & $(36.3)$ & $(35.7)$ \\
\hline
\end{tabular}


698 Table 2. Spearman correlations of the top 25\% sires according to breeding values of selection 699 weight (SW), scrotal circumference (SC), and days at first calving (DFC) in control (NeC), 700 selection $(\mathrm{NeS})$, and traditional $(\mathrm{NeT})$ lines of Nellore cattle obtained using the reaction 701 norm model under different environments (favorable, intermediate, and unfavorable)

\begin{tabular}{lcccccc}
\hline \multicolumn{2}{c}{ NeC } & \multicolumn{2}{c}{ NeS } & \multicolumn{2}{c}{ NeT } \\
\hline SW & \multicolumn{7}{c}{ Unfavorable } & Intermediate & Unfavorable & Intermediate & Unfavorable & Intermediate \\
Favorable & $0.18^{\mathrm{NS}}$ & $0.67^{* *}$ & $0.81^{* *}$ & $0.95^{* *}$ & $0.07^{\mathrm{NS}}$ & $0.41^{* *}$ \\
\hline SC & \multicolumn{7}{c}{} & & \\
\hline & Unfavorable & Intermediate & Unfavorable & Intermediate & Unfavorable & Intermediate \\
Favorable & $0.56^{*}$ & $0.83^{* *}$ & $0.87^{* *}$ & $0.96^{* *}$ & $0.46^{*}$ & $0.78^{* *}$ \\
\hline DFC & \multicolumn{7}{c}{} & & \\
\hline & Unfavorable & Intermediate & Unfavorable & Intermediate & Unfavorable & Intermediate \\
Favorable & $0.28^{\mathrm{NS}}$ & $0.28^{\mathrm{NS}}$ & $0.55^{* *}$ & $0.67^{* *}$ & $-0.37^{\mathrm{NS}}$ & $-0.36^{\mathrm{NS}}$ \\
\hline
\end{tabular}

${ }^{*} \mathrm{P}<0.05,{ }^{* *} \mathrm{P}<0.01,{ }^{\mathrm{NS}}$ non-significant. 

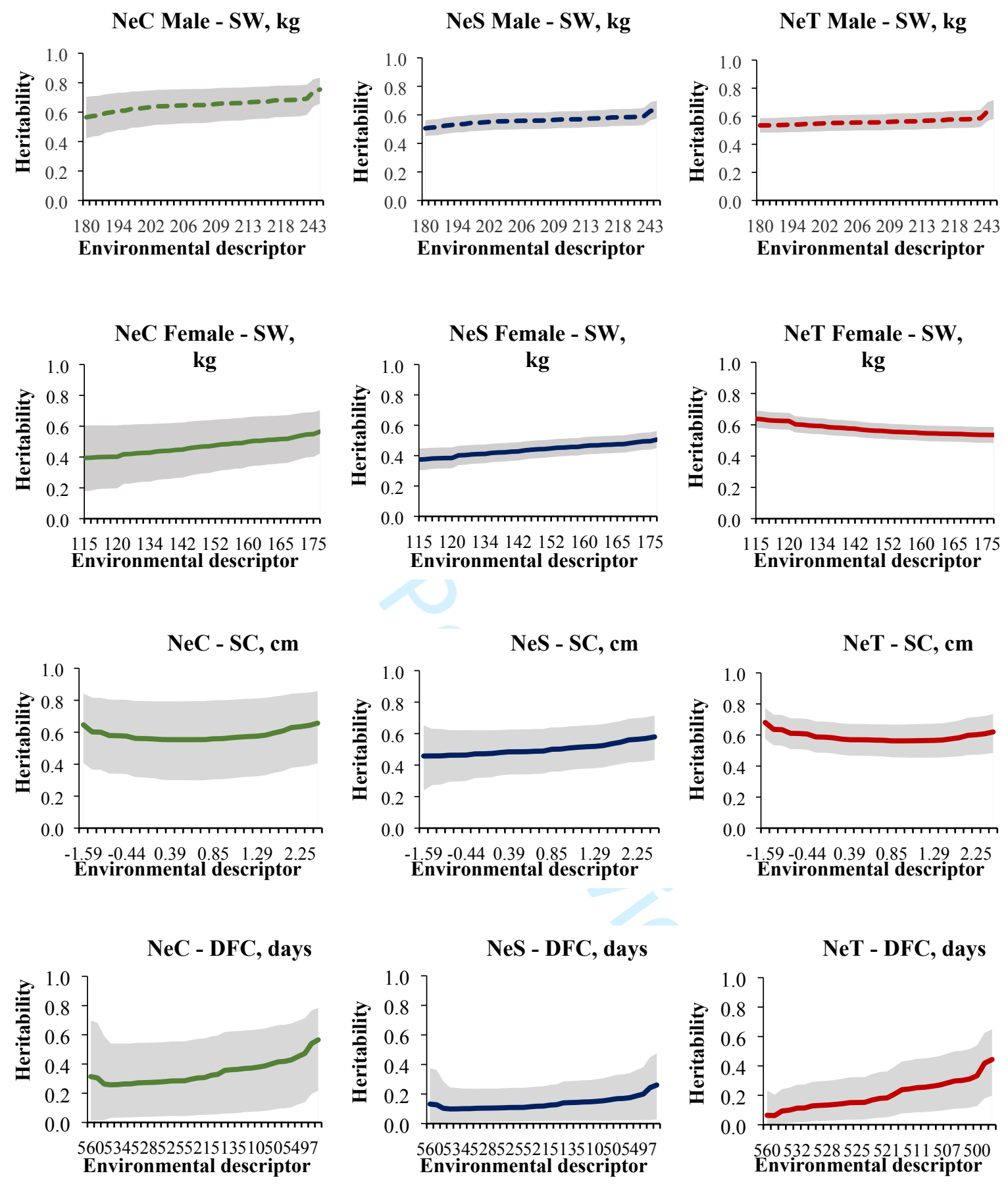

709 Figure 1. Heritability estimates of selection weight (SW, $\mathrm{kg}$ ) in males and females, scrotal 710 circumference ( $\mathrm{SC}, \mathrm{cm}$ ), and days at first calving (DFC, days) along the environmental 711 descriptor for in three Nellore cattle lines $(\mathrm{NeC}$, control; NeS, selection; and $\mathrm{NeT}$, traditional 712 line). 


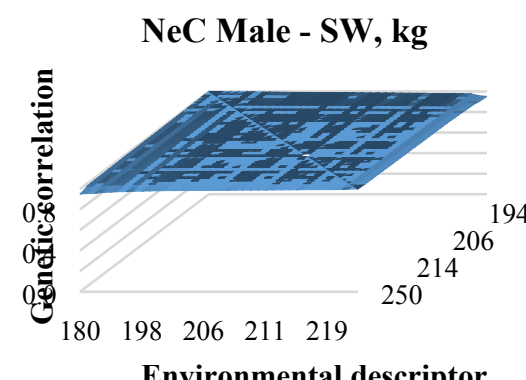

Environmental descriptor

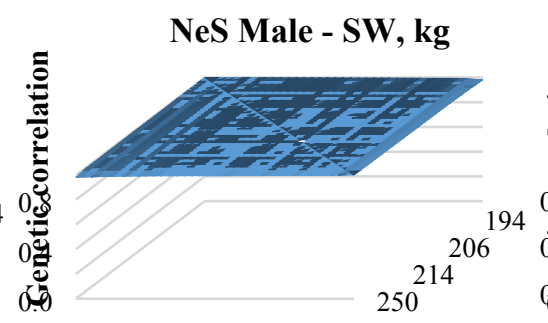

$\begin{array}{lllll}180 & 198 & 206 & 211 & 219\end{array}$

Environmental descriptor

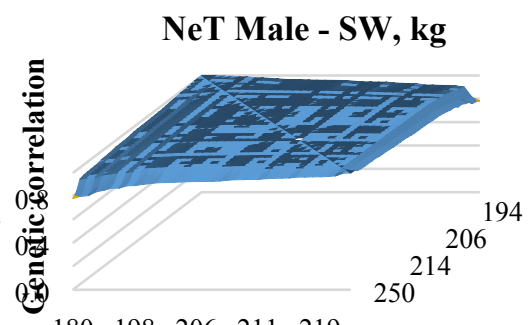

$\begin{array}{lllll}180 & 198 & 206 & 211 & 219\end{array}$

Environmental descriptor

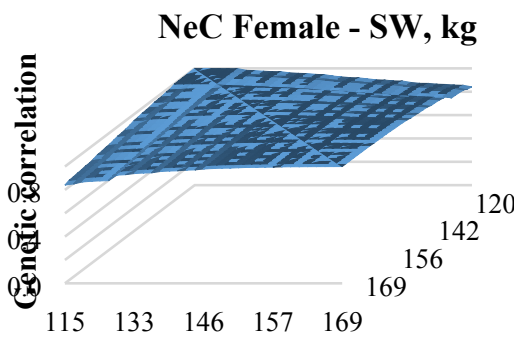

Environmental descriptor

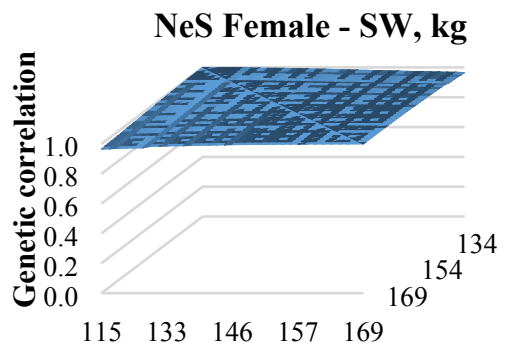

Environmental descriptor

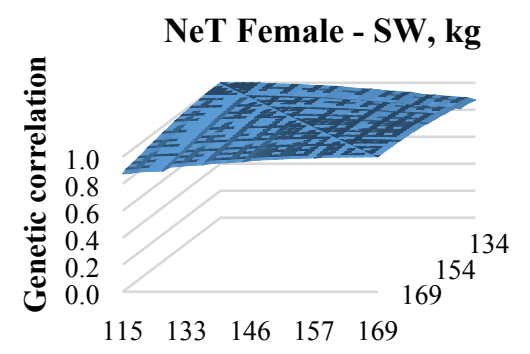

Environmental descriptor

716

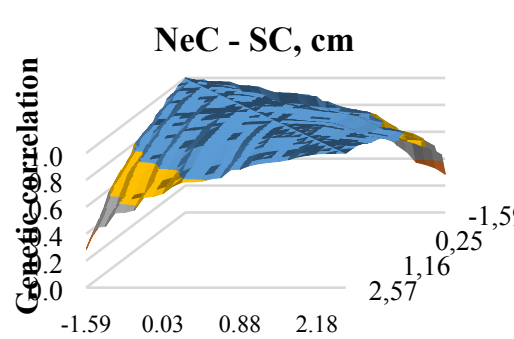

Environmental descriptor

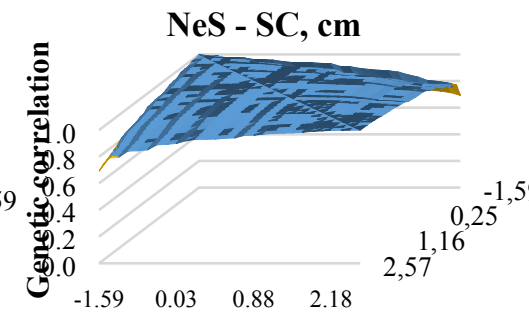

Environmental descriptor

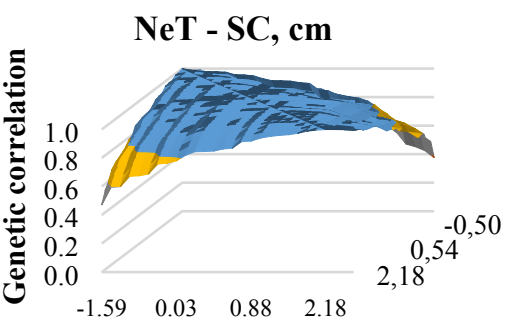

Environmental descriptor

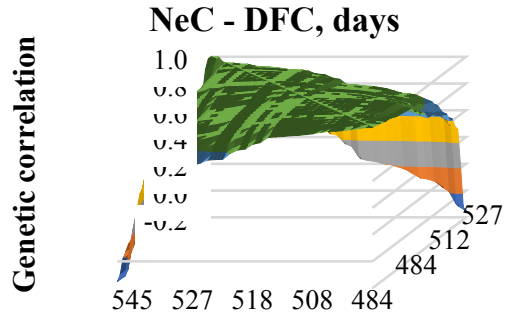

Environmental descriptor

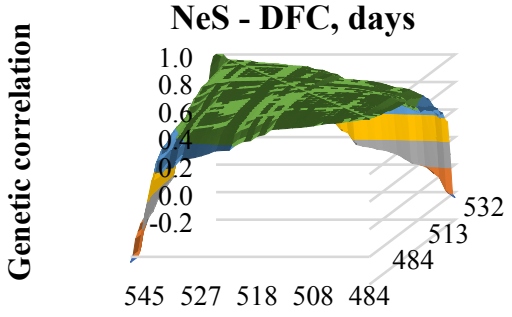

Environmental descriptor
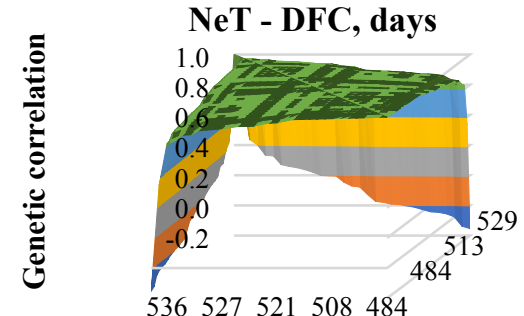

Environmental descriptor

720 Figure 2. Genetic correlations between selection weight (SW, kg) of males and females, scrotal 721 circumference (SC, cm), and days at first calving (DFC, days) along the environmental descriptor in three Nellore cattle lines ( $\mathrm{NeC}$, control; $\mathrm{NeS}$, selection; and $\mathrm{NeT}$, traditional). 
Figure 3
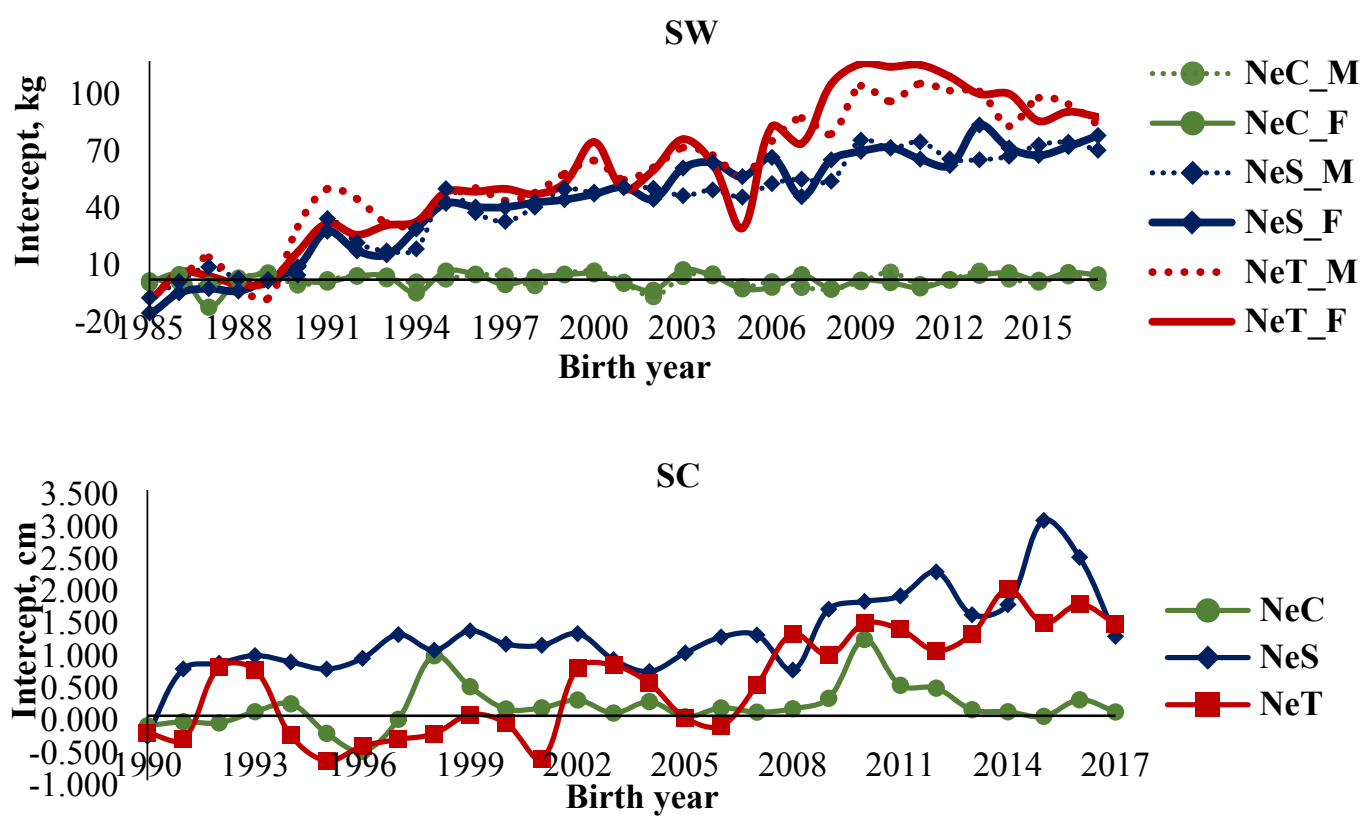

\section{DFC}

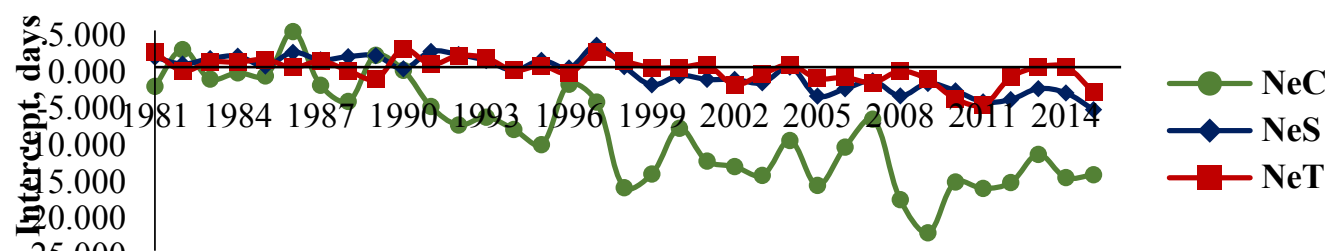

$-25.000$

Birth year

728 Figure 3. Genetic trends for regression coefficients related to the intercept of reaction norms for selection weight (SW), scrotal circumference (SC), and days at first calving (DFC) in three Nellore cattle lines ( $\mathrm{NeC}$, control; $\mathrm{NeS}$, selection; and $\mathrm{NeT}$, traditional), $\mathrm{NeC} \_\mathrm{M}$, males of the control line; $\mathrm{NeC}$ F, females of the control line; $\mathrm{NeS}$ _M, males of the selection line; NeS_F, females of the selection line; $\mathrm{NeT}_{-} \mathrm{M}$, males of the traditional line; NeT_F, females of the traditional line. 
735 Figure 4

736

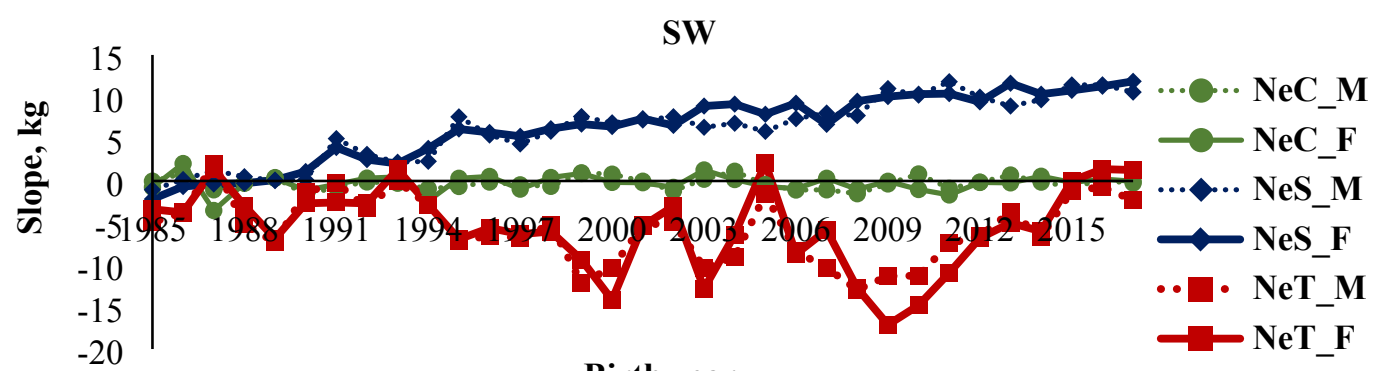

Birth year

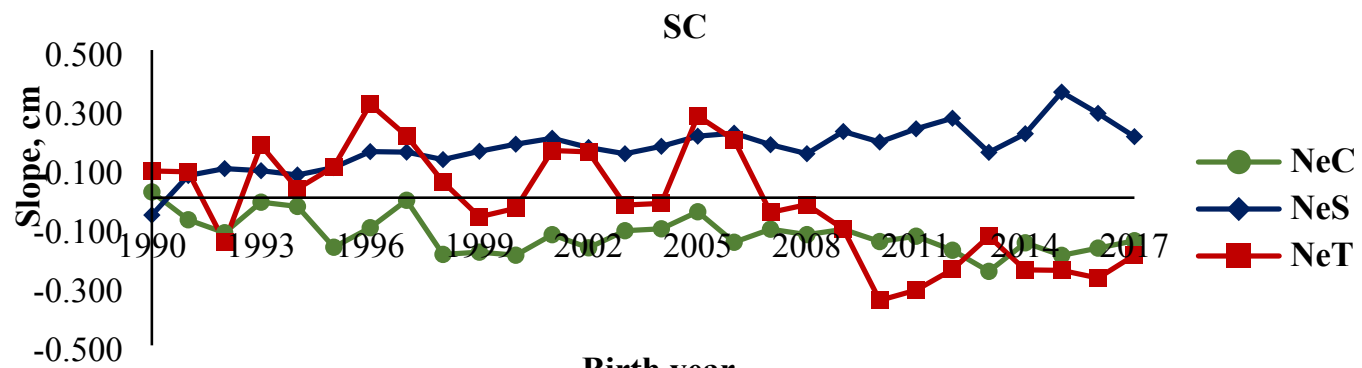

737

Birth year

DFC

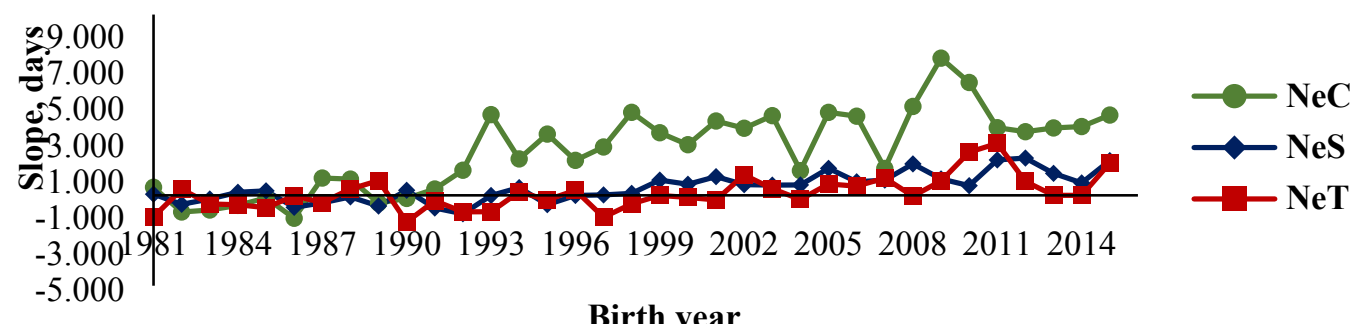

Figure 4. Genetic trends for regression coefficients related to the slope of reaction norms for selection weight (SW), scrotal circumference (SC), and days at first calving (DFC) in three Nellore cattle lines (NeC, control; $\mathrm{NeS}$, selection; and $\mathrm{NeT}$, traditional); $\mathrm{NeC} \_\mathrm{M}$, males of the control line; $\mathrm{NeC}_{-} \mathrm{F}$, females of the control line; NeS_M, males of the selection line; NeS_F, females of the selection line; NeT_M, males of the traditional line; NeT_F, females of the traditional line. 
$745 \quad$ Figure 5
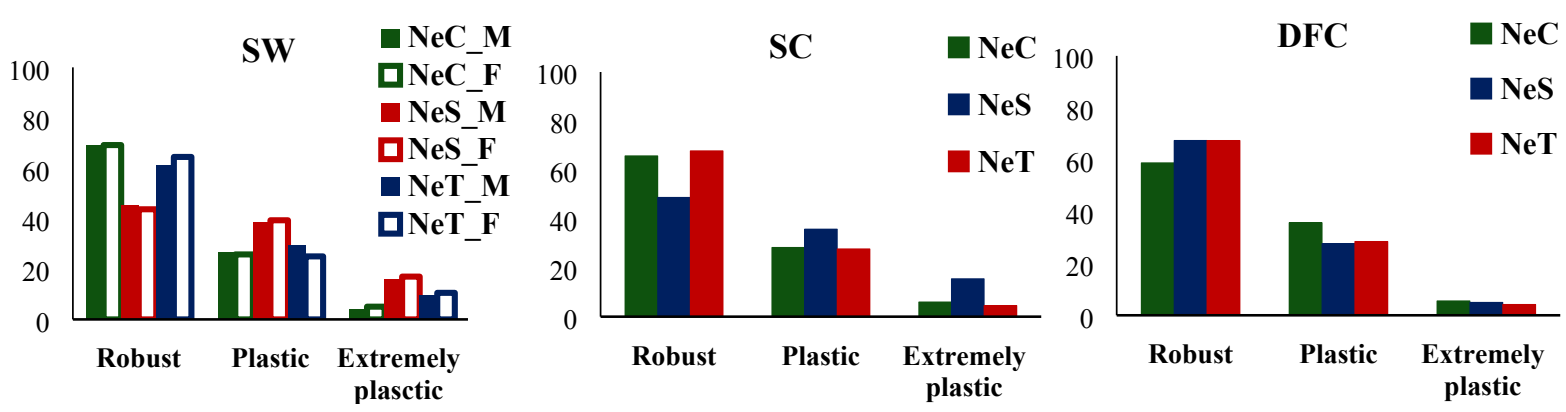

747 Figure 5. Observed frequencies of robust, plastic, and extremely plastic genotypes for selection 748 weight (SW), scrotal circumference (SC), and for days at first calving (DFC) in three Nellore 749 cattle lines $(\mathrm{NeC}$, control; $\mathrm{NeS}$, selection; and $\mathrm{NeT}$ traditional); $\mathrm{NeC}$ M, males of the control 750 line; NeC_F, females of the control line; NeS_M, males of the selection line; NeS_F, females 751 of the selection line; NeT_M, males of the traditional line; NeT_F, females of the traditional 752 line. 
Universidade de São Paulo

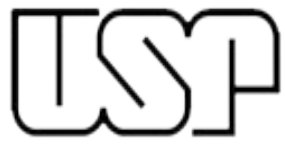

Faculdade de Medicina de Ribeirão Preto

Programa de Pós-Graduação em Genética

Av. Bandeirantes, 3900 - Monte Alegre - CEP 14049-900, Ribeirão Preto - SP, Brasil

\section{July 31, 2020}

Editor-in-chief: Sally Johnson

Journal of Animal Science

Dear Dr. Sally Johnson,

Please find attached the manuscript entitled "Different selection practices affect the environmental sensitivity of beef cattle" by Anielly de Paula Freitas, Mário Luiz Santana Júnior, Flavio Schramm Schenkel, Maria Eugênia Zerlotti Mercadante, Joslaine Noely dos Santos Goncalves Cyrillo and Claudia Cristina Paro de Paz, which we are submitting for consideration for publication in Journal of Animal Science.

In our manuscript, we evaluated the effects of different selection practices on the environmental sensitivity of reproductive and growth traits of males and females in beef cattle lines using a reaction norm model. There are few reports in the literature on how selection can affect the animals' response to the environment, especially in beef cattle and studies that have an adequate data structure to evaluate the effects of selection practices for more than 30 years on sensitivity environmental, counting on two selection lines selected for the highest differentials to increase postweaning weight and one control line selected for average postweaning weight are even rarer. Thus, we believe that this study may be of interest to its readers to update the scientific literature on this subject.

Thank you for attention, Anielly de Paula Freitas 


\section{Supplementary material}

Table 3. Covariance component for select weight (SW), scrotal circumference (SC) and days to first calving (DFC) for each selection line given by reaction norm model.

\begin{tabular}{|c|c|c|c|c|c|}
\hline \multirow{2}{*}{\multicolumn{2}{|c|}{$\begin{array}{l}\text { Component } \\
\text { Variance of intercept } \\
\end{array}$}} & \multirow{2}{*}{ Mean } & \multirow[t]{2}{*}{ SD } & \multicolumn{2}{|c|}{ PPI95\% } \\
\hline & & & & & \\
\hline \multirow[t]{3}{*}{ SW } & $\mathrm{NeC}$ & 808.16 & 140.10 & 533.55 & $1,082.80$ \\
\hline & $\mathrm{NeS}$ & 1061.00 & 82.36 & 899.55 & $1,222.40$ \\
\hline & $\mathrm{NeT}$ & 1342.80 & 89.70 & $1,166.90$ & $1,518.60$ \\
\hline \multirow[t]{3}{*}{$\mathrm{SC}$} & $\mathrm{NeC}$ & 4.07 & 1.17 & 1.77 & 6.37 \\
\hline & $\mathrm{NeS}$ & 4.19 & 0.77 & 2.69 & 5.70 \\
\hline & $\mathrm{NeT}$ & 6.33 & 0.76 & 4.84 & 7.82 \\
\hline \multirow[t]{3}{*}{ FDC } & $\mathrm{NeC}$ & 645.52 & 332.88 & 12.67 & $1,278.40$ \\
\hline & $\mathrm{NeS}$ & 221.84 & 121.31 & $-15,93$ & 459.61 \\
\hline & $\mathrm{NeT}$ & 356.60 & 175.47 & 12.673 & 700.52 \\
\hline \multicolumn{6}{|c|}{ Variance of slope } \\
\hline \multirow[t]{3}{*}{ SW } & $\mathrm{NeC}$ & 105.33 & 43.21 & 20.64 & 190.03 \\
\hline & $\mathrm{NeS}$ & 47.76 & 22.39 & 3.87 & 91.65 \\
\hline & $\mathrm{NeT}$ & 262.67 & 52.91 & 158.96 & 366.38 \\
\hline \multirow[t]{3}{*}{$\mathrm{SC}$} & $\mathrm{NeC}$ & 0.76 & 0.41 & $-0,05$ & 1.56 \\
\hline & $\mathrm{NeS}$ & 0.27 & 0.19 & $-0,11$ & 0,65 \\
\hline & $\mathrm{NeT}$ & 0.96 & 0.35 & 0.28 & 1.65 \\
\hline \multirow[t]{3}{*}{ FDC } & $\mathrm{NeC}$ & 282.88 & 194.31 & $-97,97$ & 663.74 \\
\hline & $\mathrm{NeS}$ & 79.60 & 54.92 & $-28,04$ & 187.24 \\
\hline & $\mathrm{NeT}$ & 140.35 & 69.18 & 4.76 & 275.94 \\
\hline \multicolumn{6}{|c|}{ Covariance between intercept and slope } \\
\hline \multirow[t]{3}{*}{ SW } & $\mathrm{NeC}$ & 209.00 & 38.26 & 134.01 & 284.00 \\
\hline & $\mathrm{NeS}$ & 172.70 & 29.48 & 114.92 & 230.49 \\
\hline & $\mathrm{NeT}$ & 18.54 & 38.14 & $-56,21$ & 93.28 \\
\hline \multirow[t]{3}{*}{$\mathrm{SC}$} & $\mathrm{NeC}$ & 0.05 & 0.31 & $-0,56$ & 0.66 \\
\hline & $\mathrm{NeS}$ & 0.33 & 0.26 & $-0,18$ & 0,84 \\
\hline & $\mathrm{NeT}$ & $-0,35$ & 0,28 & $-0,90$ & 0,20 \\
\hline \multirow[t]{3}{*}{ FDC } & $\mathrm{NeC}$ & $-179,9$ & 170.64 & $-514,35$ & 154.55 \\
\hline & $\mathrm{NeS}$ & $-50,88$ & 67.31 & $-182,81$ & 81,05 \\
\hline & $\mathrm{NeT}$ & $-188,79$ & 84.44 & $-354,29$ & $-23,29$ \\
\hline \multicolumn{6}{|c|}{ Residual variance } \\
\hline \multirow[t]{3}{*}{ SW } & $\mathrm{NeC}$ & 296.02 & 37.71 & 222.10 & 369.94 \\
\hline & $\mathrm{NeS}$ & 505.33 & 25.21 & 455.92 & 554.74 \\
\hline & $\mathrm{NeT}$ & 582.79 & 30.41 & 523.18 & 642.39 \\
\hline \multirow[t]{3}{*}{$\mathrm{SC}$} & $\mathrm{NeC}$ & 1.60 & 0.39 & 0.83 & 2.36 \\
\hline & $\mathrm{NeS}$ & 2.18 & 0.27 & 1.65 & 2.71 \\
\hline & $\mathrm{NeT}$ & 2.41 & 0.26 & 1.89 & 2.92 \\
\hline \multirow[t]{3}{*}{ FDC } & $\mathrm{NeC}$ & 731.51 & 125.88 & 484.78 & 978.25 \\
\hline & $\mathrm{NeS}$ & 841.21 & 64.37 & 715.06 & 967.39 \\
\hline & $\mathrm{NeT}$ & 841.40 & 79.85 & 684.89 & 997.91 \\
\hline
\end{tabular}


$5 \mathrm{SD}=$ standard deviation; $\mathrm{PPI}=$ posterior probability interval. $\mathrm{NeC}$, control; $\mathrm{NeS}$, selection; and 6 NeT, traditional 